\title{
A chemical-genetic map of the pathways controlling drug potency in Mycobacterium tuberculosis
}

Shuqi Li ${ }^{1 *}$, Nicholas C. Poulton ${ }^{1 *}$, Jesseon S. Chang ${ }^{1}$, Zachary A. Azadian ${ }^{1}$, Michael A. DeJesus ${ }^{1}$, Nadine Ruecker ${ }^{2}$, Matthew D. Zimmerman ${ }^{3}$, Kathryn Eckartt ${ }^{1}$, Barbara Bosch ${ }^{1}$, Curtis Engelhart ${ }^{2}$, Daniel Sullivan², Martin Gengenbacher ${ }^{3,4}$, Véronique A. Dartois ${ }^{3,4}$, Dirk Schnappinger ${ }^{2}$, Jeremy M. Rock ${ }^{1}$

1: Laboratory of Host-Pathogen Biology, The Rockefeller University, New York, New York, United States of America

2: Department of Microbiology and Immunology, Weill Cornell Medicine, New York, New York, United States of America

3: Center for Discovery and Innovation, Hackensack Meridian Health, Nutley, New Jersey, USA

4: Hackensack Meridian School of Medicine, Hackensack Meridian Health, Nutley, New Jersey, USA

*: co-first authors

Address correspondence to: rock@rockefeller.edu 
Mycobacterium tuberculosis (Mtb) infection is notoriously difficult to treat. Treatment efficacy is limited by Mtb's intrinsic drug resistance, as well as its ability to evolve acquired resistance to all antituberculars in clinical use. A deeper understanding of the bacterial pathways that govern drug efficacy could facilitate the development of more effective therapies to overcome resistance, identify new mechanisms of acquired resistance, and reveal overlooked therapeutic opportunities. To define these pathways, we developed a CRISPR interference chemical-genetics platform to titrate the expression of Mtb genes and quantify bacterial fitness in the presence of different drugs. Mining this dataset, we discovered diverse and novel mechanisms of intrinsic drug resistance, unveiling hundreds of potential targets for synergistic drug combinations. Combining chemical-genetics with comparative genomics of Mtb clinical isolates, we further identified numerous new potential mechanisms of acquired drug resistance, one of which is associated with the emergence of a multidrug-resistant tuberculosis (TB) outbreak in South America. Lastly, we make the unexpected discovery of an "acquired drug sensitivity." We found that the intrinsic resistance factor whiB7 was inactivated in an entire Mtb sublineage endemic to Southeast Asia, presenting an opportunity to potentially repurpose the macrolide antibiotic clarithromycin to treat TB. This chemical-genetic map provides a rich resource to understand drug efficacy in Mtb and guide future TB drug development and treatment.

\section{INTRODUCTION}

Infections caused by the bacterial pathogen Mycobacterium tuberculosis (Mtb) are notoriously difficult to treat. Current standard of care requires a multidrug regimen lasting for several months, which limits patient compliance and contributes to the development of drug-resistant Mtb (WHO, 2021). While the reasons necessitating prolonged chemotherapy are multifactorial, including variable drug penetration into Mtbcontaining granulomas (Dartois, 2014) and the presence of phenotypically drug-tolerant bacterial subpopulations (Balaban et al., 2019), the intrinsic resistance of the infecting bacterium and its ability to evolve acquired resistance to all antituberculars in clinical use limits treatment efficacy (Colangeli et al., 2018; Xu et al., 2017).

Mtb is intrinsically resistant to many antibacterials. While relatively underexplored, intrinsic resistance is typically ascribed to the low permeability of the Mtb cell envelope and the numerous efflux pumps encoded in the Mtb genome (Batt et al., 2020; Jarlier and Nikaido, 1994; da Silva et al., 2011). All acquired drug resistance in Mtb occurs via mutation, and in recent decades many resistance mutations have been mapped and characterized (Walker et al., 2015). These mutations most commonly occur in the drug target or drug activator, reducing the affinity of the drug-target interaction or reducing conversion of the drug to the bioactive molecule (Banerjee et al., 1994; Walker et al., 2015; Zhang et al., 1992). Yet, our knowledge of acquired drug resistance in Mtb remains incomplete, particularly for mutations outside of the drug target or activator and which typically confer low to intermediate, but clinically relevant, levels of drug resistance (Carter, 2021; Colangeli et al., 2018; Hicks et al., 2020; Walker et al., 2015). A deeper understanding of both intrinsic and acquired drug resistance in Mtb could facilitate the development of therapies to overcome resistance mechanisms, improve the diagnosis of drug-resistant TB, and reveal overlooked therapeutic opportunities (Blondiaux et al., 2017; Hugonnet et al., 2009).

To provide a genome-wide overview of the bacterial pathways that control drug potency, we developed a CRISPR interference (CRISPRi) (Bosch et al., 2021; Choudhary et al., 2015; Qi et al., 2013; Rock et al., 2017) chemical-genetics platform to titrate the expression of nearly all Mtb genes (essential and nonessential) and quantify bacterial fitness in the presence of different drugs. This approach identified hundreds of Mtb genes whose inhibition altered fitness in the presence of partially inhibitory drug concentrations, including genes encoding the direct drug target and non-target hit genes. Mining this dataset, we discovered diverse mechanisms of intrinsic drug resistance that can be targeted to potentiate therapy. Overlaying the chemical-genetic results with comparative genomics of Mtb clinical isolates, we identified new, clinically relevant mechanisms of acquired drug resistance. Lastly, we make the unexpected discovery of "acquired drug sensitivities," whereby loss-of-function mutations in intrinsic drug resistance genes render some Mtb clinical strains hypersusceptible to clarithromycin, a macrolide antibiotic not typically used to treat 
bioRxiv preprint doi: https://doi.org/10.1101/2021.11.27.469863; this version posted November $27,2021$. The copyright holder for this preprint (which was not certified by peer review) is the author/funder, who has granted bioRxiv a license to display the preprint in perpetuity. It is made available under aCC-BY-ND 4.0 International license.

tuberculosis (TB). This chemical-genetic map provides a rich resource to understand drug potency in Mtb and guide future TB drug development and treatment.

\section{RESULTS}

To define genes that alter drug potency in Mtb, we performed 90 CRISPRi screens across nine drugs in the Mtb reference strain, H37Rv. These screens used a genome-scale CRISPRi library containing 96,700 sgRNAs (Bosch et al., 2021) to enable titratable knockdown for nearly all Mtb genes, including both protein coding genes and non-coding RNAs (Figure 1A). Titrated gene knockdown was achieved by targeting noncanonical Sth1 dCas9 protospacer adjacent motifs (PAMs) (Rock et al., 2017) and modulating the extent of complementarity between the sgRNA and DNA target (Bosch et al., 2021). Knockdown tuning enabled hypomorphic silencing of in vitro essential genes, thereby allowing assessment of chemical-genetic interactions for both in vitro essential and non-essential genes to provide a global overview of gene-drug interactions in Mtb.

Anhydrotetracycline (ATC) was added 1,5, or 10 days prior to drug exposure to transcriptionally activate CRISPRi and deplete target gene products (Figure 1A). Drugs were chosen to represent the majority of clinically relevant Mtb targets (Table 1), including three of the four first-line agents (pyrazinamide was not included because it is not active under standard culture conditions), four second-line agents, and two drugs not traditionally used to treat TB. Drugs were screened at concentrations spanning the predicted minimum inhibitory concentration (MIC) (Supplemental Figure 1A-I). Triplicate CRISPRi library cultures were outgrown in the presence or absence of drug. After outgrowth, we harvested genomic DNA from cultures treated with three descending doses of partially inhibitory drug concentrations ("High", "Med", and "Low"; Supplemental Figure 1A-I) and analyzed sgRNA abundance by deep sequencing. Growth phenotypes were well correlated among triplicate screens (average Pearson correlation between replicate screens: $r>$ 0.99). Hits were identified by MAGeCK (Li et al., 2014) as those genes whose CRISPRi inhibition reduced or increased relative fitness in the presence of a given drug (false discovery rate (FDR) $<0.01$, log2 foldchange $|\mathrm{L} 2 \mathrm{FC}|>1$ ). Analysis of the number of unique hit genes across different drugs showed that the 1 and 5-day target pre-depletion datasets recovered the majority ( $>95 \%)$ of unique hits (Supplemental Figure 2A-I; Supplemental Data 1). Thus, hit genes were further defined as the union of 1 and 5-day target pre-depletion screens. These criteria identified 1,373 genes whose knockdown led to sensitization and 775 genes whose knockdown led to resistance to at least one drug (Supplemental Data 1), representing at least one chemical-genetic interaction for $38.5 \%(n=1,587 / 4,125)$ of all annotated genes in the Mtb genome. Most hit genes had a single chemical-genetic interaction, but some had as many as seven (Supplemental Figure 2J, Supplemental Data 1).

The chemical-genetic screens recovered expected hit genes. For example, the genes encoding the targets of rifampicin (rpoB) (Campbell et al., 2001) (Figure 1B), isoniazid (inhA) (Banerjee et al., 1994) (Figure 1C), and bedaquiline (ATP synthase) (Andries et al., 2005) (Figure 1D) were among the most sensitized hits in each respective screen. Genes encoding the targets of known synergistic drug combinations were also recovered, for example ethambutol $(e m b A B)+$ rifampicin and SQ109 $(m m p L 3)+$ rifampicin (Figure 1B) (Cokol et al., 2017). Lastly, genes whose inactivation is known to confer acquired drug resistance were also observed, including glycerol kinase glpK (Figure 1B-D) (Bellerose et al., 2019; Safi et al., 2019), catalase-peroxidase katG (Figure 1C) (Vilchèze and Jacobs JR., 2014), and the transcriptional repressor rv0678 (Figure 1D) (Andries et al., 2014). Consistent with the robust recovery of expected hits, benchmarking our CRISPRi approach against published transposon sequencing (TnSeq) chemical-genetic results revealed a high degree of overlap (63.3-87.7\% TnSeq hit recovery; Supplemental Data 2) (Xu et al., 2017), although TnSeq is necessarily restricted to interrogation of in vitro non-essential genes, at least as currently implemented in Mtb.

The number of hit genes varied widely across drugs (Figure 1E,F; Supplemental Data 1; Supplemental Figure 2A-I;), from hundreds for rifampicin, vancomycin, and ethambutol to tens for streptomycin. Interestingly, in vitro essential genes were enriched relative to non-essential genes for chemical-genetic interactions (Figure 1E,F; Supplemental Figure 3A), even when taking into account the bias towards sgRNAs targeting in vitro essential genes in the CRISPRi library. This enrichment demonstrates the 
bioRxiv preprint doi: https://doi.org/10.1101/2021.11.27.469863; this version posted November $27,2021$. The copyright holder for this preprint (which was not certified by peer review) is the author/funder, who has granted bioRxiv a license to display the preprint in perpetuity. It is made available under aCC-BY-ND 4.0 International license.

111 increased information content available when assaying essential genes by chemical-genetics and highlights

112 the power of titratable CRISPRi to assay gene classes typically intractable with more traditional approaches

113 like TnSeq. Hierarchical clustering of hit genes revealed unique chemical-genetic signatures for each drug

114 (Supplemental Figure 3B) that were then mined for biological insight.

115

116

117

118

119

120

121

122

123

124

125

126

127

128

129

130

131

132

133

134

135

136

137

138

139

140

141

142

143

144

145

146

147

148

149

150

151

\section{Table 1: Drugs Profiled and their Target Processes}

\begin{tabular}{|c|c|c|c|}
\hline Drug & Abbreviation & Class & Target Process \\
\hline Bedaquiline & BDQ & Diarylquinoline & ATP synthesis \\
\hline Clarithromycin & CLR & Macrolide & Translation \\
\hline Ethambutol & EMB & Ethylenediamine & Arabinogalactan biosynthesis \\
\hline Isoniazid & INH & Pyridine & Mycolic acid biosynthesis \\
\hline Levofloxacin & LVX & Fluoroquinolone & DNA replication \\
\hline Linezolid & LZD & Oxazolidinone & Translation \\
\hline Rifampicin & RIF & Rifamycin & Transcription \\
\hline Streptomycin & STR & Aminoglycoside & Translation \\
\hline Vancomycin & VAN & Glycopeptide & Peptidoglycan biosynthesis \\
\hline
\end{tabular}

Despite the fact that they target distinct cellular processes (Table 1), clustering analysis revealed correlated chemical-genetic signatures for rifampicin, vancomycin, and bedaquiline (Supplemental Figure 3B), suggesting shared mechanisms of intrinsic resistance or sensitivity. Enrichment analysis identified the essential mycolic acid-arabinogalactan-peptidoglycan (mAGP) complex to be a common sensitizing hit between rifampicin, vancomycin, and bedaquiline but not the ribosome targeting drugs clarithromycin, linezolid, or streptomycin (Supplemental Figure 3C). The mAGP is the primary constituent of the cell envelope and has long been known to serve as a permeability barrier that mediates intrinsic drug resistance in Mtb (Batt et al., 2020; Jarlier and Nikaido, 1994; da Silva et al., 2011). Interestingly, it was not obvious which chemical features for each drug were driving selective sensitization to mAGP disruption (Supplemental Figure 3D) (Davis et al., 2014). For example, despite having similar molecular weights, bedaquiline (555.5 daltons) displayed a strong mAGP signature whereas streptomycin (581.6 daltons) did not; despite similar polar surface areas, rifampicin $\left(220 \AA^{2}\right)$ displays a strong mAGP signature but clarithromycin $\left(183 \AA^{2}\right)$ does not.

To ensure the validity of the screen results, we quantified drug susceptibility with individual hypomorphic CRISPRi strains targeting mAGP-biosynthetic genes, demonstrating 2- to 43-fold reductions in $\mathrm{IC}_{50}$ for rifampicin, vancomycin, and bedaquiline but little to no change in $\mathrm{IC}_{50}$ for linezolid (Supplemental Figure 4A-D). To validate these results chemically, we chose to focus on the $\beta$-ketoacyl-ACP synthase KasA. KasA is an essential component of the FAS-II pathway responsible for elongation of meromycolic acids and is an actively pursued drug target (Abrahams et al., 2016; Kumar et al., 2018). Consistent with our genetic results, checkerboard assays demonstrated synergy between the KasA inhibitor GSK3011724A (GSK'724A) and rifampicin, vancomycin, and bedaquiline but not linezolid (Supplemental Figure 4E,F). Because drug interactions can be influenced by the growth environment (Lenaerts et al., 2015), we also confirmed the synergy between GSK'724A and rifampicin in a macrophage infection model (Supplemental Figure 4G). Consistent with the hypothesis that synergy between GSK'724A and this mechanistically diverse group of antibiotics could be explained, at least in part, by inhibition of mycolic acid biosynthesis resulting in improved drug uptake, Mtb cultures pre-treated with a sub-MIC dose of GSK'724A showed increased uptake of ethidium bromide and a fluorescent vancomycin conjugate (Supplemental Figure $\mathbf{4 H , I}$. These results validate the screen and confirm the role of the mAGP complex as a selective mechanism of intrinsic resistance relevant for some antitubercular agents but not others (Larrouy-Maumus et al., 2016). 
bioRxiv preprint doi: https://doi.org/10.1101/2021.11.27.469863; this version posted November 27, 2021. The copyright holder for this preprint (which was not certified by peer review) is the author/funder, who has granted bioRxiv a license to display the preprint in perpetuity. It is made available under aCC-BY-ND 4.0 International license.

A

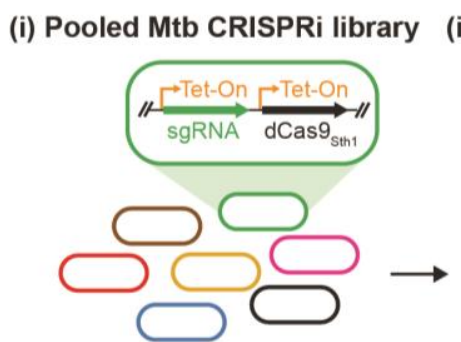

Titratable CRISPRi library targeting $98 \%$ of all Mtb genes $\begin{array}{ll}\text { (ii) } \begin{array}{c}\text { Target } \\ \text { pre-depletion }\end{array} & \text { (iii) Outgrowth with } \\ \text { drug selection }\end{array}$

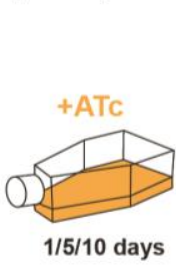

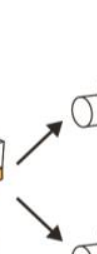

Control

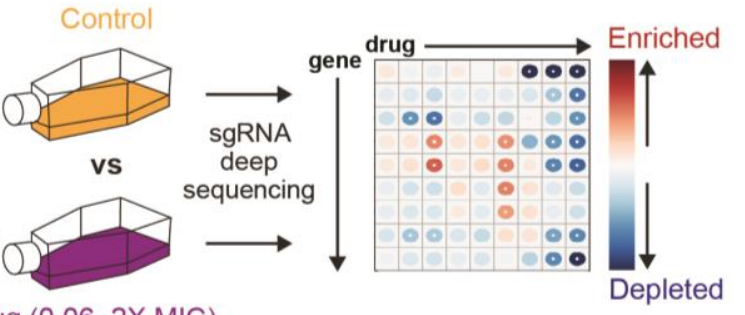

Drug (0.06-2X MIC)

(iv) Hit calling \& data mining
B

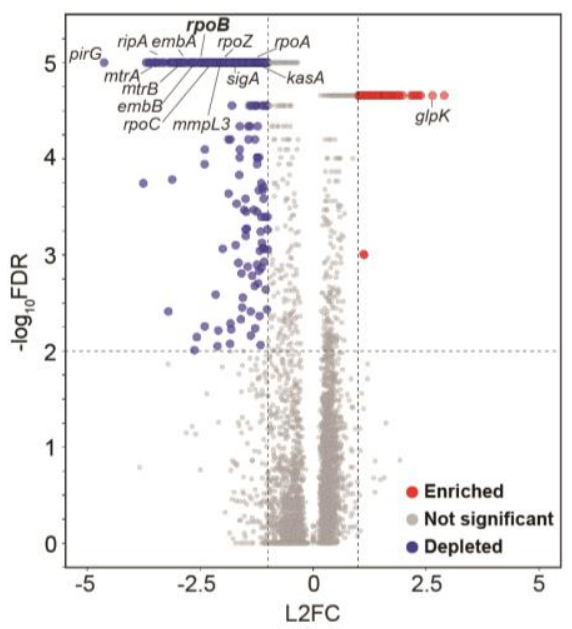

C

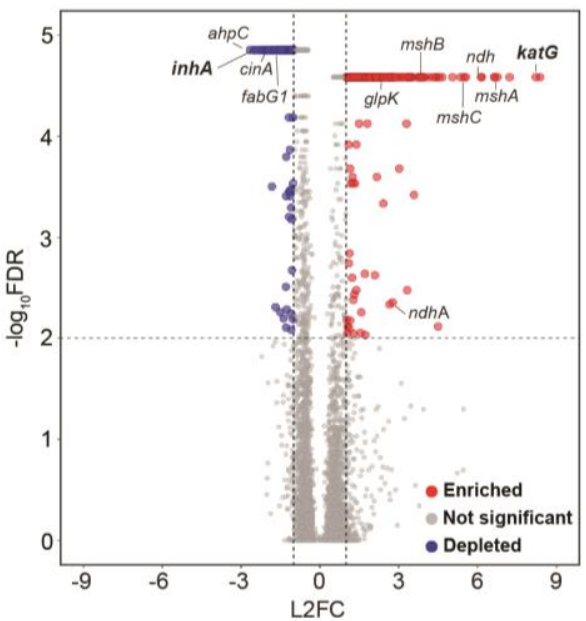

D

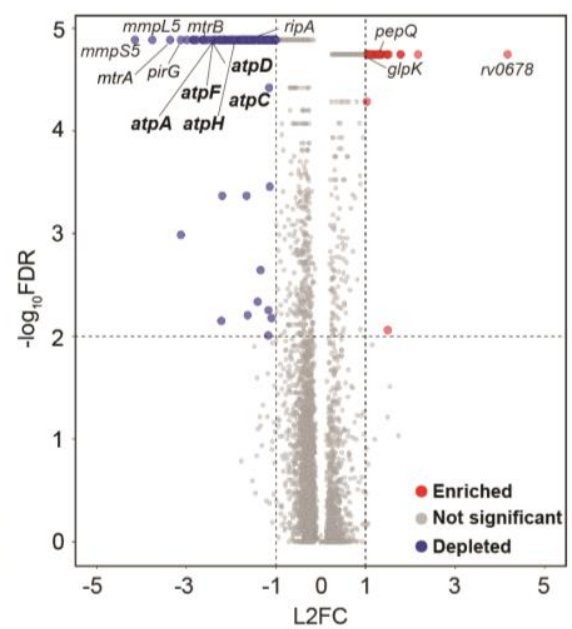

E

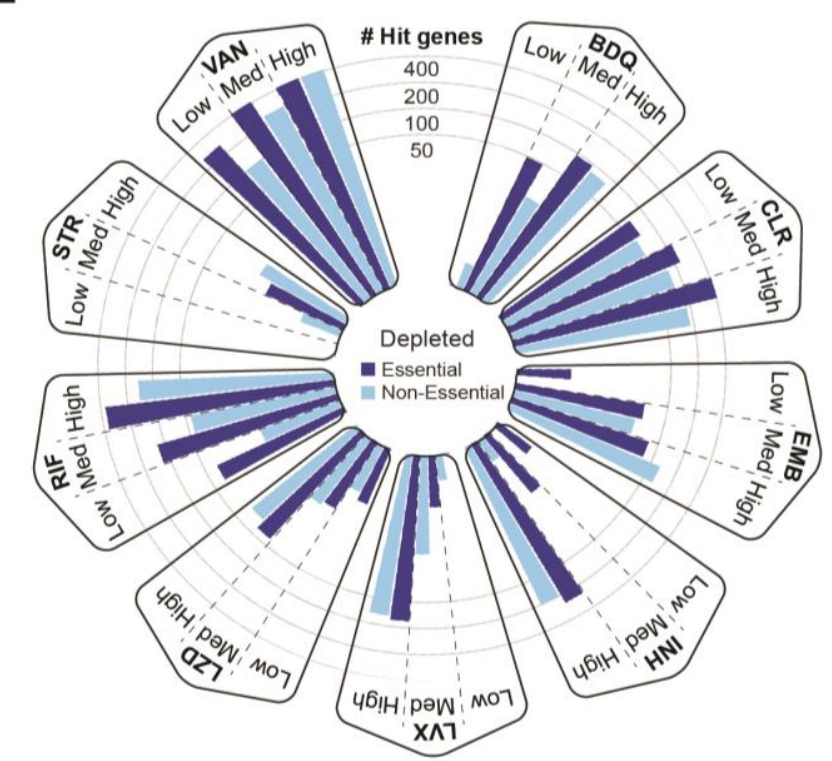

F

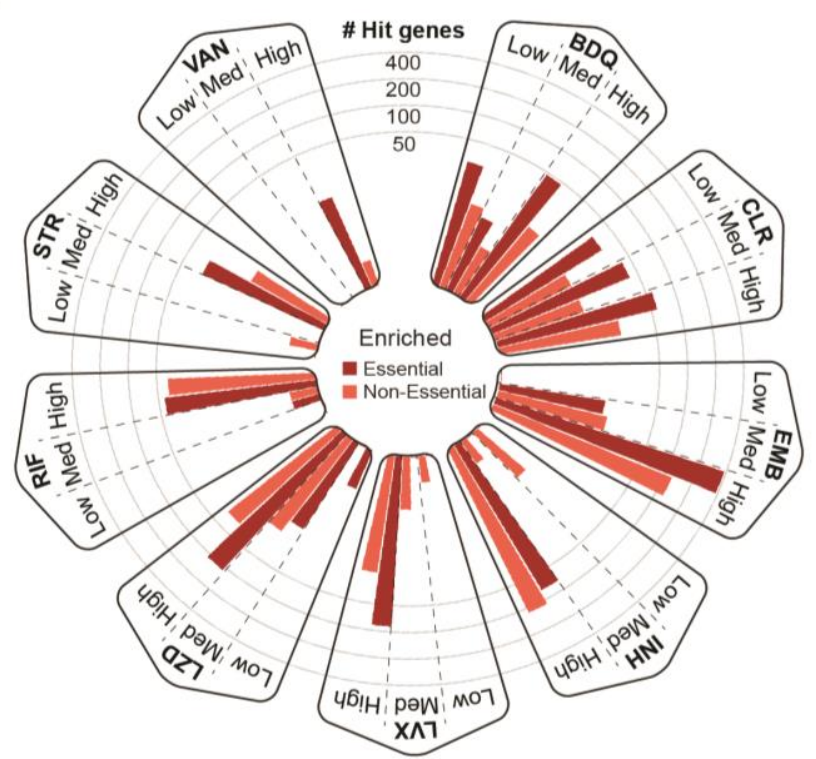

Figure 1: Chemical-genetic profiling identifies hundreds of genes that alter drug efficacy in $M$. tuberculosis

(A) Experimental design to quantify chemical-genetic interactions in Mtb. (i) The pooled Mtb CRISPRi library contains 96,700 sgRNAs targeting 4,052/4,125 of all Mtb genes. In vitro essential genes were targeted for titratable knockdown by varying the targeted PAM and sgRNA targeting sequence length; non-essential genes were targeted only with the strongest available sgRNAs (Bosch et al., 2021). (ii) The CRISPRi inducer anhydrotetracycline (ATC) was added for 1, 5, or 10 days prior to drug exposure to pre-deplete target gene products. (iii) Triplicate cultures were outgrown +ATc in DMSO or drug at six concentrations spanning the predicted minimum inhibitory concentration (MIC). (iv) Following 


\section{The two-component system $m$ trAB and associated lipoprotein IpqB promote envelope integrity and are central mediators of intrinsic drug resistance in Mtb}

Two of the most sensitizing hit genes across multiple drugs were the response regulator $m$ tr $A$ and its cognate histidine kinase $m$ trB (Figure 1B,D; Figure 2A; Supplemental Data 1), which together encode the MtrAB two-component signaling system (Gorla et al., 2018; Zahrt and Deretic, 2000). The mtrAB operon also encodes a putative lipoprotein IpqB (Figure 2B). LpqB is proposed to interact with MtrB to promote MtrA phosphorylation and activation (Nguyen et al., 2010). The similarities between the chemical-genetic signatures of $m$ tr $A B-I p q B$ and mAGP biosynthetic genes (Figure 2A; Supplemental Figure 4B) are consistent with a critical role for this two-component system in regulating mAGP integrity. Given the predicted essentiality of $m t r A$, $m t r B$, and IpqB (Dejesus et al., 2017; Zahrt and Deretic, 2000) and the magnitude by which inhibition of these genes sensitized Mtb to various antibiotics, we next sought to better define the mechanism by which $m \operatorname{tr} A B-l p q B$ promotes intrinsic drug resistance.

Consistent with the predicted essentiality, strong CRISPRi-silencing of $m \operatorname{tr} A, m \operatorname{tr} B$, and lpqB prevented Mtb growth (Figure 2B). Complementation of CRISPRi knockdown with CRISPRi-resistant $m \operatorname{tr} A, m \operatorname{tr} B$, or IpqB alleles reversed this growth defect (Figure 2B), demonstrating specificity for the observed phenotypes. Whereas inhibition of $m t r B$ was bacteriostatic both in axenic culture and macrophages, inhibition of $m t r A$ was bacteriostatic in axenic culture but bactericidal in resting and IFN-y activated macrophages (Figure 2C, Supplemental Figure 5A,B). Consistent with the chemical-genetic screen results, knockdown of $m t r A$, $m t r B$, and $I p q B$ strongly sensitized $M t b\left(10-100\right.$ fold decreases in $\left.I_{50}\right)$ to rifampicin, vancomycin, and bedaquiline, but not other drugs (Figure 2D, Supplemental Figure 5C). Also consistent with the screen, the magnitude of drug sensitization was not identical across all three genes, being more similar between $m t r A$ and $m t r B$ than IpqB (Figure 2D). As with inhibition of KasA (Supplemental Figure $\mathbf{4 H}$,I), silencing of $m \operatorname{tr} A, m t r B$, and to a lesser extent $l p q B$ led to increased permeability to ethidium bromide and a fluorescent vancomycin conjugate (Figure 2E). Together, these results suggest that the increase in drug susceptibility in $m t r A B-I p q B$ knockdown strains is at least in part mediated by increased envelope permeability and are consistent with an essential role for $m \operatorname{tr} A B-I p q B$ in regulating mAGP integrity.

To better understand the mechanism(s) by which the response regulator $m$ trA mediates multi-drug intrinsic resistance, we next defined its regulon. RNA-sequencing (RNA-seq) following mtrA silencing identified 41 significantly down-regulated and 11 significantly upregulated genes ( $p_{\text {adi }}<0.05,|\mathrm{~L} 2 \mathrm{FC}|>1$ ) (Figure 2F, Supplemental Data 3). Consistent with a direct regulatory role, MtrA was found to bind the promoters of 25 of the significantly down-regulated and two of the significantly upregulated genes in a previously published ChIP-seq study (Supplemental Figure 5D, Supplemental Data 3) (Gorla et al., 2018). Upregulated genes not found to be bound by MtrA included the envelope stress response genes iniB and iniA (Alland et al., 2000), and thus at least some of the upregulated genes following $m$ trA silencing may reflect secondary consequences of envelope stress. A consensus MtrA recognition site derived from promoters of genes differentially regulated upon mtrA inhibition and found to interact with MtrA by ChIP-seq was broadly similar to previously published MtrA binding-motifs (Gorla et al., 2018; Peterson et al., 2021)(Supplemental Figure $5 \mathrm{E})$. We next confirmed that $m t r A$ and $m t r B$ knockdown led to a downregulation of putative MtrA regulon genes by RT-qPCR (Supplemental Figure 5F), validating the RNA-seq results. Surprisingly, in contrast to 
217 the results observed with $m \operatorname{tr} A B$ knockdown, silencing $I p q B$ led to an upregulation of MtrA regulon genes

218 (Supplemental Figure $5 \mathrm{G}$ ). In contrast to proposed role of $\mathrm{LpqB}$ as a positive regulator of this pathway 219 (Nguyen et al., 2010), these data instead suggest that LpqB may be a negative regulator of MtrA signaling.

220 To distinguish whether MtrA activation in the absence of LpqB requires MtrB, or whether loss of LpqB activates MtrA independent of MtrB, we next tested MtrA regulon expression upon simultaneous silencing of $m t r B$ and $I p q B$. Consistent with the former model, MtrA activation required MtrB in the absence of LpqB (Figure 2G). These results, as well as the overlapping but distinct chemical-genetic interactions observed for $m \operatorname{tr} A B$ and IpqB (Figure 2A), are consistent with a model whereby the extracytoplasmic lipoprotein LpqB functions as a negative regulator of MtrB to restrain MtrA activation.

While the functions of most of the candidate MtrA regulon genes are unknown, a number of these genes encode peptidoglycan remodeling enzymes, including the endopeptidases $\operatorname{rip} A$, rip $B$, rip $D$, the amidase ami1, and the transglycosylase rpfC (Supplemental Data 3) (Gorla et al., 2018; Peterson et al., 2021; Sharma et al., 2015). These gene products are important for proper peptidoglycan remodeling during growth and division. Intriguingly, a number of the MtrA regulon genes were also identified as sensitizing hits in the chemical-genetic screen, phenocopying the chemical-genetic effects of $m$ trA silencing (Figure 2A). Transcript levels of neither $m t r A B$ nor its regulon were altered in response to antibacterial challenge (Supplemental Figure $5 \mathrm{H}$ ), indicating that unlike some two-component signaling systems in Staphylococci (Rajagopal et al., 2016; Yin et al., 2006), MtrAB is unlikely to be a stress-responsive signaling system. Instead, these results highlight the central role of the MtrAB signal transduction pathway in coordinating proper peptidoglycan remodeling during bacterial growth and division (Figure $2 \mathrm{H}$ ). These results further suggest that both inhibition (MtrAB inhibitors) or activation (LpqB inhibitors) of this pathway has the potential to prevent Mtb growth and dramatically reduce intrinsic drug resistance, highlighting the potential utility of small molecule inhibitors of this pathway.
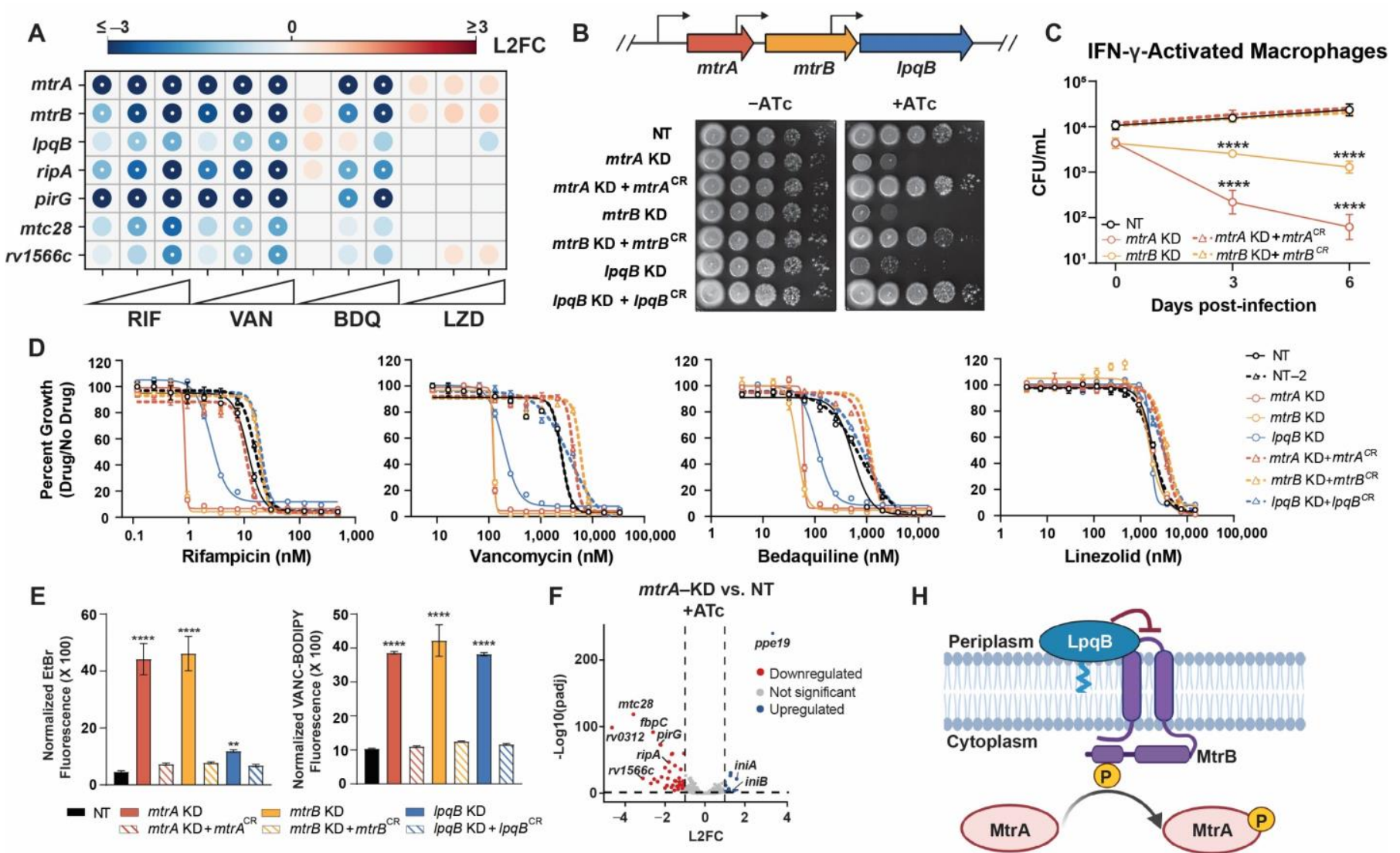

G

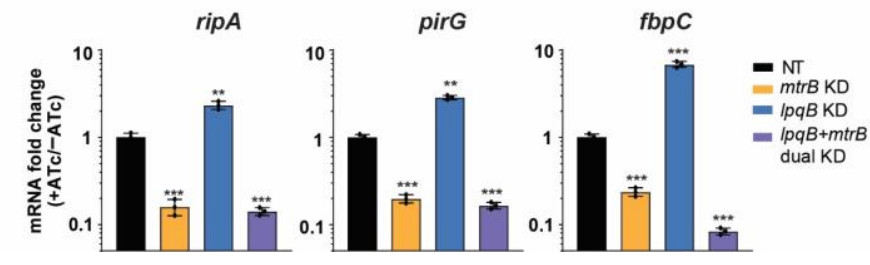

H

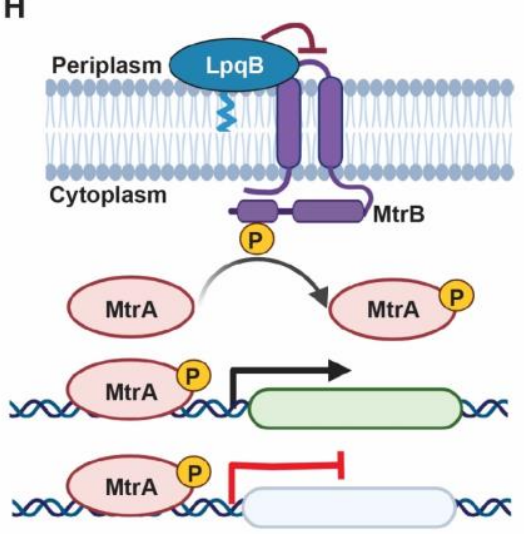

Cell division, cell wall remodelling... 
Figure 2: MtrAB-LpqB promote envelope integrity and are central mediators of intrinsic drug resistance

(A) Feature-expression heatmap of select chemical-genetic hit genes for the indicated drugs from the 5day CRISPRi library pre-depletion screen. The color of each circle represents the gene-level L2FC. A white dot represents an FDR $<0.01$ and a $|\mathrm{L} 2 \mathrm{FC}|>1$.

(B) Growth of the indicated CRISPRi strains. NT = non-targeting; KD = knockdown; CR = CRISPRiresistant. Transcriptional start sites (Shell et al., 2015) are indicated with black arrows.

(C) Growth of the indicated CRISPRi strains in IFN-y-activated murine bone marrow derived macrophages. Bacterial strains were exposed to ATc for 24 hours prior to macrophage infection. 3 and 6 days after infection, bacteria were harvested and quantified by colony-forming units (CFU). Data represent mean \pm SEM for technical triplicates. Significance was determined by two-way ANOVA and adjusted for multiple comparisons. ${ }^{* * *}, p<0.0001$.

(D) MIC values for the indicated drugs were measured against the indicated strains. Data represent mean \pm SEM for technical triplicates and are representative of at least two independent experiments.

(E) Ethidium bromide and Vancomycin-BODIPY uptake of the indicated strains. Data represent mean \pm SEM for three replicates and are representative of at least two independent experiments. Results from an unpaired t-test are shown: ${ }^{* * *}, \mathrm{p}<0.0001$.

(F) $m$ trA and NT CRISPRi strains were grown for two days with ATc, after which RNA was harvested and sequenced. L2FC and $-\log 10\left(p_{a d j}\right)$ for each gene are plotted. Dashed lines mark significant hits $\left(p_{a d j}<\right.$ 0.05 and $|\mathrm{L} 2 \mathrm{FC}|>1)$.

(G) Quantification of indicated gene mRNA levels by qRT-PCR. Strains were grown in the presence or absence of ATc for $\sim 3$ generations prior to harvesting RNA. Error bars are SEM of three technical replicates. Results from an unpaired t-test are shown: ${ }^{* *}, p<0.01 ;{ }^{* * *}, p<0.001$.

(H) Schematic of the proposed MtrAB-LpqB signaling system. The histidine kinase MtrB activates the response regulator MtrA to control expression of genes important for proper cell division and cell wall remodeling. The lipoprotein $L p q B$ interacts with MtrB and may negatively regulate MtrB-dependent activation of MtrA.

\section{A diverse set of pathways contribute to intrinsic resistance and susceptibility to ribosome-targeting antibiotics}

Unlike rifampicin, vancomycin, and bedaquiline, inhibition of mAGP biosynthesis did not sensitize Mtb to the three ribosome-targeting drugs streptomycin, clarithromycin, and linezolid (Supplemental Figure 3C,D; Supplemental Data 1). Thus, inhibition of mAGP biosynthesis is unlikely to be a relevant mechanism to potentiate the activity of these drugs. A prior publication reported that the cell-wall targeting drug ethambutol can synergize with clarithromycin (Bosne-David et al., 2000). In contrast to these results, neither our screen (Supplemental Data 1) nor checkerboard assays (Supplemental Figure 6A) validated a potentiating effect of ethambutol with clarithromycin, further validating the specificity of envelope-mediated intrinsic resistance for only a subset of antibiotics.

Streptomycin, the first successful antibiotic used to treat $T B$, is a natural product aminoglycoside which interacts with the 30S ribosomal subunit and induces mis-translation (Figure 3A) (Krause et al., 2016). Because streptomycin can be toxic it is currently reserved for the treatment of drug-resistant TB (Cohen et al., 2020). Clarithromycin is a semi-synthetic macrolide which targets the nascent polypeptide exit tunnel (NPET) and inhibits translation elongation in a sequence-specific manner (Kannan et al., 2014). Clarithromycin has minimal activity against Mtb both in vitro and in vivo (Luna-Herrera et al., 1995; TruffotPernot et al., 1995) and is used rarely as last resort, salvage therapy for multidrug-resistant TB (MDR-TB) (Seung et al., 2014). Linezolid is a synthetic oxazolidinone which targets the peptidyltransferase center (PTC) of the 50S ribosomal subunit, directly adjacent to the clarithromycin binding site, and also inhibits translation elongation in a sequence-specific manner (Marks et al., 2016). Linezolid is used as part of BPaL (Bedaquiline, Pretomanid, Linezolid), a new, potent combination therapy used to treat MDR-TB (Conradie et al., 2020). 
297 Streptomycin, clarithromycin, and linezolid had correlated but distinct chemical-genetic signatures (Figure

298 3B, Supplemental Figure 3B). Clustering of the ribosome targeting drugs appeared to be driven in large part 299 by the lack of an mAGP signature (Supplemental Figure 3B,C; Supplemental Data 1), rather than any 300 unique ribosome target signature, which may reflect the different mechanisms of action of the three ribosome 301 targeting drugs. The sole sensitizing hit gene observed uniquely among the three ribosome targeting drugs 302 was whiB7, a transcription factor that induces a stress response promoting intrinsic resistance to numerous 303 ribosome-targeting antibiotics (Morris et al., 2005). Grouping hit genes based on predicted function connected 304 the ribosome targeting antibiotics to both common and unique processes including: rRNA methylation, drug 305 efflux/import, ribosome rescue, ribosome regulation, proteasome activity, and numerous poorly characterized 306 genes (Figure 3B,C).

307

308

309

310

311

312

313

314

315

316

317

318

319

320

Consistent with prior publications, we found that rRNA methyltransferases can confer either intrinsic sensitivity or intrinsic resistance to ribosome-targeting drugs (Wilson, 2014). For example, silencing erm(37) resulted in strong depletion in clarithromycin treatment (Figure 3B), consistent with the role of Erm(37) in methylating the 23S rRNA to prevent macrolide binding (Madsen et al., 2005). Conversely, silencing the 16S rRNA methyltransferase gid resulted in strong enrichment in streptomycin treatment (Figure 3B), consistent with clinical observations whereby mutational inactivation of gid confers low-level acquired drug resistance to streptomycin (Wong et al., 2013). Interestingly, we found that knockdown of the predicted 23S rRNA methyltransferase tsn $R$ confers resistance to linezolid (Figure 3B). This is analogous to work in $S$. aureus, in which loss of the evolutionarily distinct $23 S$ methyltransferase $r / m N$ confers linezolid resistance both in vitro and in the clinic (LaMarre et al., 2011; Pi et al., 2019). To determine if loss-of-function (LOF) mutations in $t s n R$ could play a clinically relevant role in acquired linezolid resistance, we assembled a database of $>45,000$ whole genome sequences from Mtb clinical isolates (Supplemental Data 4). Given that linezolid has only recently been introduced to treat TB and is presently reserved to treat patients failing MDR-TB therapy, we expected linezolid-resistant TB to be rare. Consistent with this, we identified the most common linezolidresistance promoting mutation rp/C-Cys154Arg (Wasserman et al., 2019) only 122 times in our genome database. While putative LOF mutations in tsnR where even more rare (Supplemental Data 5), two MDR Mtb strains harbored both a $t s n R$ frameshift allele (Thr156fs) and an rp/C-Cys154Arg allele. The cooccurrence of these two mutations in two MDR Mtb strains is highly unlikely to have occurred by chance $\left(\chi^{2}\right.$ test with Yates' correction: $\mathrm{p}<0.0001)$. These data highlight that LOF tsnR mutations may serve as steppingstones to high-level resistance as linezolid is used more widely in the clinic.

Given the threat posed by linezolid resistance to future TB drug regimens and issues of linezolid toxicity, we next sought to determine if our findings could be exploited to identify synergistic drug-target combinations to overcome resistance and increase the therapeutic index for linezolid, analogous to pre-clinical efforts to boost ethionamide potency and tolerability (Blondiaux et al., 2017; Conradie et al., 2020). The essential transtranslation genes, smpB and ssr (Dejesus et al., 2017), were identified as strong linezolid sensitizing hits (Figure 3B,C). Trans-translation is a ribosome rescue pathway, thought to primarily rescue ribosomes stalled while translating non-stop mRNA transcripts (Alumasa et al., 2017). Due to its essentiality and potential importance for stress-tolerance, the trans-translation pathway has garnered attention as a mycobacterial drug target (Alumasa et al., 2017). Additionally, we identified the poorly characterized gene rv1473 as a strong and specific linezolid sensitizing hit (Figure 3B,C). rv1473 was previously reported to be a macrolide efflux pump (Duan et al., 2019). However, the lack of predicted transmembrane domains suggest $r v 1473$ is unlikely to be a membrane-embedded ABC transporter. Rather, homology suggests rv1473 encodes an antibiotic resistance (ARE) ABC-F protein that functions to rescue linezolid-stalled ribosomes (Supplemental Figure 6B) (Antonelli et al., 2018). ARE ABC-F proteins bind to the ribosome to promote dissociation of ribosometargeting antibiotics, thereby rescuing ribosomes from translation inhibition (Sharkey et al., 2016).

Our data suggest that inhibition of $r v 1473$ and trans-translation could make linezolid more potent, thereby lowering the dose of linezolid needed to inhibit bacterial growth. Confirming the screen predictions, individual CRISPRi knockdown of $r v 1473$ and $s m p B$ lowered the $\mathrm{IC}_{50}$ for linezolid by 2.3- and 5-fold respectively (Figure 3D; Supplemental Figure 6C) but did not alter sensitivity to other drugs. Inhibition of the Clp protease did not sensitize Mtb to linezolid (Supplemental Figure 6D,E), consistent with the critical role of trans-translation in rescuing linezolid-stalled ribosomes, not in Clp protease-mediated turnover of ssrA-tagged stalled translation products (Personne and Parish, 2014). Dual CRISPRi knockdown of both rv1473 and smpB 
lowered the linezolid $\mathrm{IC}_{50}$ by 12.2-fold (Figure 3D; Supplemental Figure 6C), consistent with rv1473 and trans-translation functioning in separate intrinsic resistance pathways. Interestingly, the increased linezolid sensitivity in the dual knockdown strain is similar to the magnitude of acquired resistance observed in linezolidresistant clinical strains (Beckert et al., 2012). Thus, we hypothesized that dual inhibition of $r v 1473$ and $s m p B$ could functionally reverse linezolid resistance. Consistent with this hypothesis, dual knockdown of $r v 1473$ and $s m p B$ in a linezolid-resistant strain (rp/C-Cys154Arg; Supplemental Figure 6F) restored linezolid sensitivity back to wild-type levels (Figure 3D; Supplemental Figure 6G), demonstrating that inhibition of intrinsic 360 resistance factors can potentiate linezolid and functionally reverse acquired drug resistance.

A

B

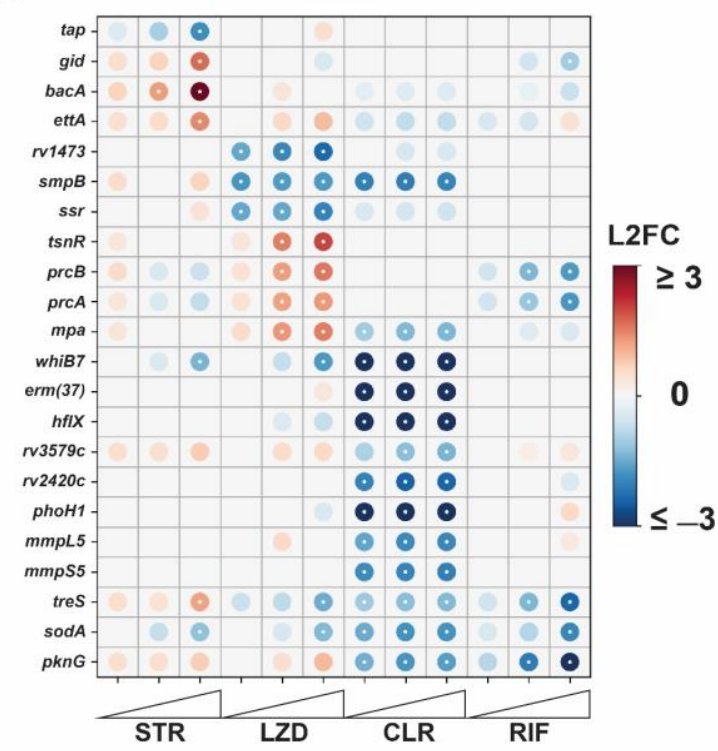

C

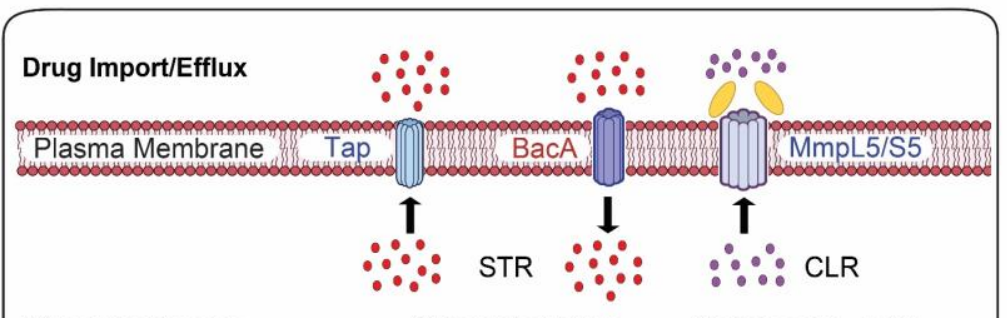

Ribosome Rescue

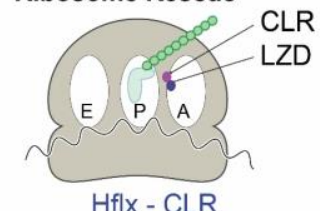

SmpB/Ssr - LZD, CLR Rv1473 - LZD

Ribosome Regulation
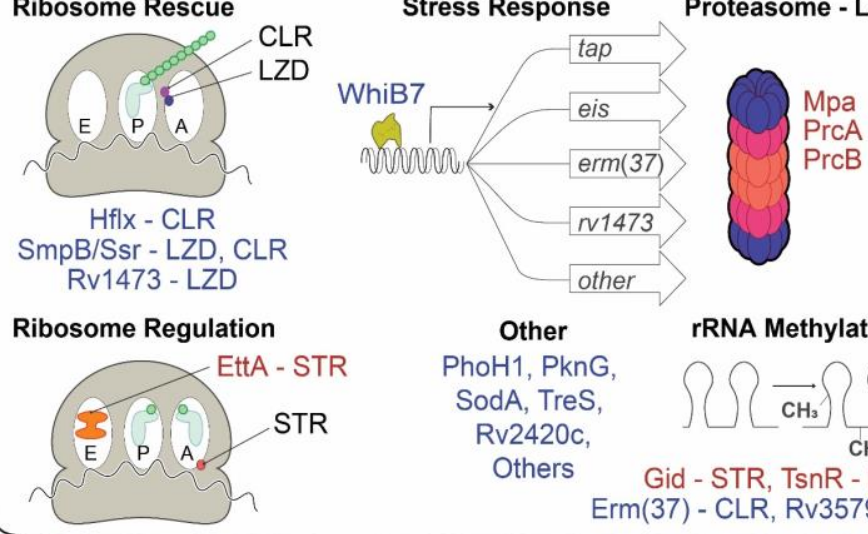

Other

PhoH1, PknG,

SodA, TreS,

Rv2420c,

Others

rRNA Methylation

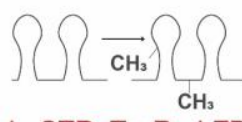

Gid - STR, TsnR - LZD Erm(37) - CLR, Rv3579c - CLR

D
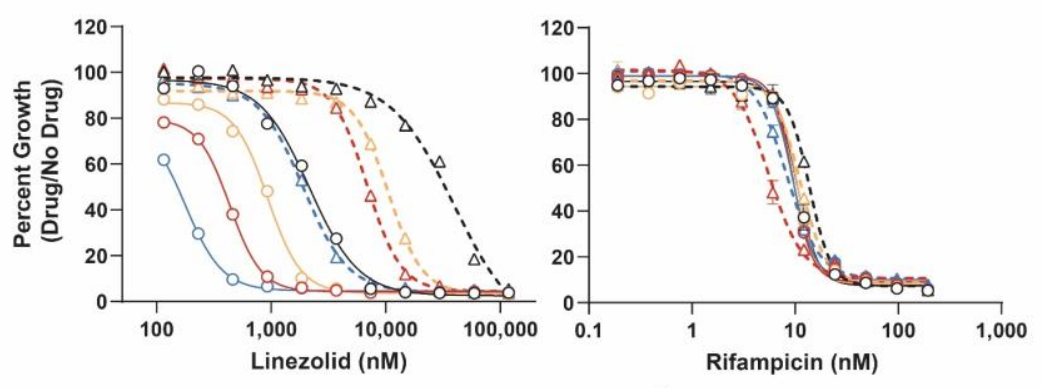

-o- WT - NT

WT - r1473 KD

$-\triangle \cdot L Z D^{R}-N T$

-O- WT - smpB KD

$-\Delta \cdot L^{\prime} D^{R}-r v 1473 \mathrm{KD}$

$-\Delta \cdot \quad L Z D^{R}-s m p B K D$

- $-W T-s m p B+r v 1473 \mathrm{KD}$

$-\Delta \cdot \quad \mathrm{LZD}^{\mathrm{R}}-s m p B+r v 1473 \mathrm{KD}$

Figure 3: A diverse set of pathways contribute to intrinsic resistance and susceptibility to three ribosome targeting antibiotics in $M$. tuberculosis

(A) Structure of LZD (blue), CLR (magenta), and STR (red) bound to the ribosome of Thermus thermophilus. PDB codes: LZD (3DLL), CLR (1J5A), STR (1FJG), and ribosome with tRNAs (4V5C).

(B) Feature-expression heatmap of select genes from the 5-day CRISPRi library pre-depletion screen. The color of each circle represents the gene-level L2FC; a white dot represents an FDR of $<0.01$ and a $|\mathrm{L} 2 \mathrm{FC}|>1$.

(C) Chemical-genetic hit genes from panel (B) are involved in a diverse set of cellular pathways. Genes whose CRISPRi inhibition results in decreased or increased relative fitness in the presence of the three ribosome-targeting drugs are listed in blue or red font, respectively. 
bioRxiv preprint doi: https://doi.org/10.1101/2021.11.27.469863; this version posted November $27,2021$. The copyright holder for this preprint (which was not certified by peer review) is the author/funder, who has granted bioRxiv a license to display the preprint in perpetuity. It is made available under aCC-BY-ND 4.0 International license.

(D) Single strain validation of LZD-associated hits. MIC values for LZD and RIF were measured for CRISPRi knockdown strains targeting smpB and rv1473 in H37Rv or rp/C-Cys154Arg linezolidresistant H37Rv $\left(L_{Z} D^{R}\right)$. Error bars represent the standard error of the mean (SEM) for technical triplicates. Data are representative of at least two independent experiments.

\section{bacA mutations observed in Mtb clinical isolates confer acquired resistance to aminoglycosides and capreomycin}

Acquired drug resistance is one of the greatest barriers to successful TB treatment. In recent decades, many acquired drug resistance mutations in Mtb have been mapped and characterized. However, our knowledge of the genetic basis of acquired drug resistance remains incomplete, particularly for mutations outside of the drug target or drug activator and which typically confer low to intermediate, but clinically relevant, levels of acquired drug resistance (Carter, 2021; Colangeli et al., 2018; Hicks et al., 2020; Walker et al., 2015). Given the ability of our chemical-genetic approach to identify hit genes associated with clinically relevant acquired drug resistance (Figure 1B-D, Figure 3B), we hypothesized that mining our chemical-genetic data may identify prevalent but previously unrecognized mechanisms of acquired drug resistance in Mtb.

We chose to focus our search for novel sources of acquired drug resistance to streptomycin. Streptomycin was introduced into the clinic in the late 1940s and remained an integral component of first-line TB therapy into the 1980s. It is now reserved to treat MDR-TB (Cohen et al., 2020). Unlike linezolid, which has only recently been used in the clinical management of TB, streptomycin has been used for almost eight decades. We hypothesized that this may have given rise to a diverse set of acquired resistance mutations which we could identify in our database of clinical Mtb genomes.

Aminoglycosides like streptomycin must traverse the Mtb envelope to access their ribosomal targets in the cytoplasm. The mechanism(s) by which aminoglycosides are taken up by mycobacteria are not well understood. Interestingly, and consistent with prior work (Domenech et al., 2009), the strongest hit gene leading to streptomycin resistance in our screen was $r v 1819 c$ (bacA; Figure 3B,C). Recently, structural and biochemical work demonstrated that bacA is an ABC importer of diverse hydrophilic solutes (Rempel et al., 2020). Thus, we hypothesized that bacA may serve as an importer of streptomycin into the Mtb cytosol and that LOF mutations in bacA may be an unrecognized source of streptomycin resistance in clinical Mtb strains.

Searching our clinical strain genome database, we observed numerous bacA non-synonymous single nucleotide polymorphisms (SNPs) and small insertion-deletions (indels) and chose six for experimental validation (see Materials and Methods for more detail on SNP selection criteria; Figure 4A; Supplemental Data 6). Each mutation was introduced into a bacA expressing plasmid and transformed into a bacA deletion Mtb strain. Consistent with bacA LOF, four of the six alleles displayed an elevated streptomycin MIC (Figure 4B). Interestingly, these strains also showed elevated MICs to the other aminoyglycosides amikacin and kanamycin and the tuberactinomycin capreomycin but not to other drugs (Figure 4B;

Supplemental Figure 7A). Moreover, overexpression of Mtb bacA in $M$. smegmatis sensitized $M$. smegmatis to streptomycin but not rifampicin or linezolid (Supplemental Figure 7B). While further studies are necessary to definitively demonstrate that bacA is an importer of aminoglycosides and tuberactinomycins, our data, in combination with prior studies (Domenech et al., 2009; Rempel et al., 2020), strongly suggest that BacA imports these hydrophilic drugs (Supplemental Figure 7C) into the Mtb cytosol. Importantly, since a bacA deletion strain is not entirely resistant to aminoglycosides and tuberactinomycins, other relevant import mechanisms must exit in Mtb. These results demonstrate that our chemical genetic screens paired with clinical strain genomics can identify novel acquired drug resistance mutations in Mtb. 
A

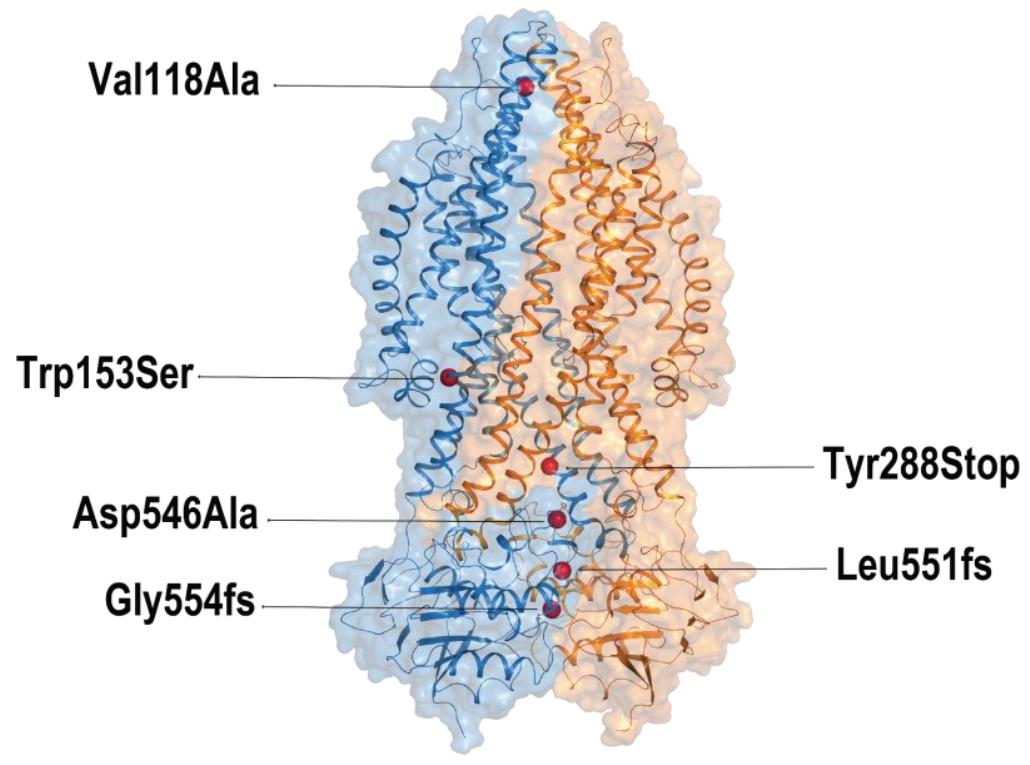

B
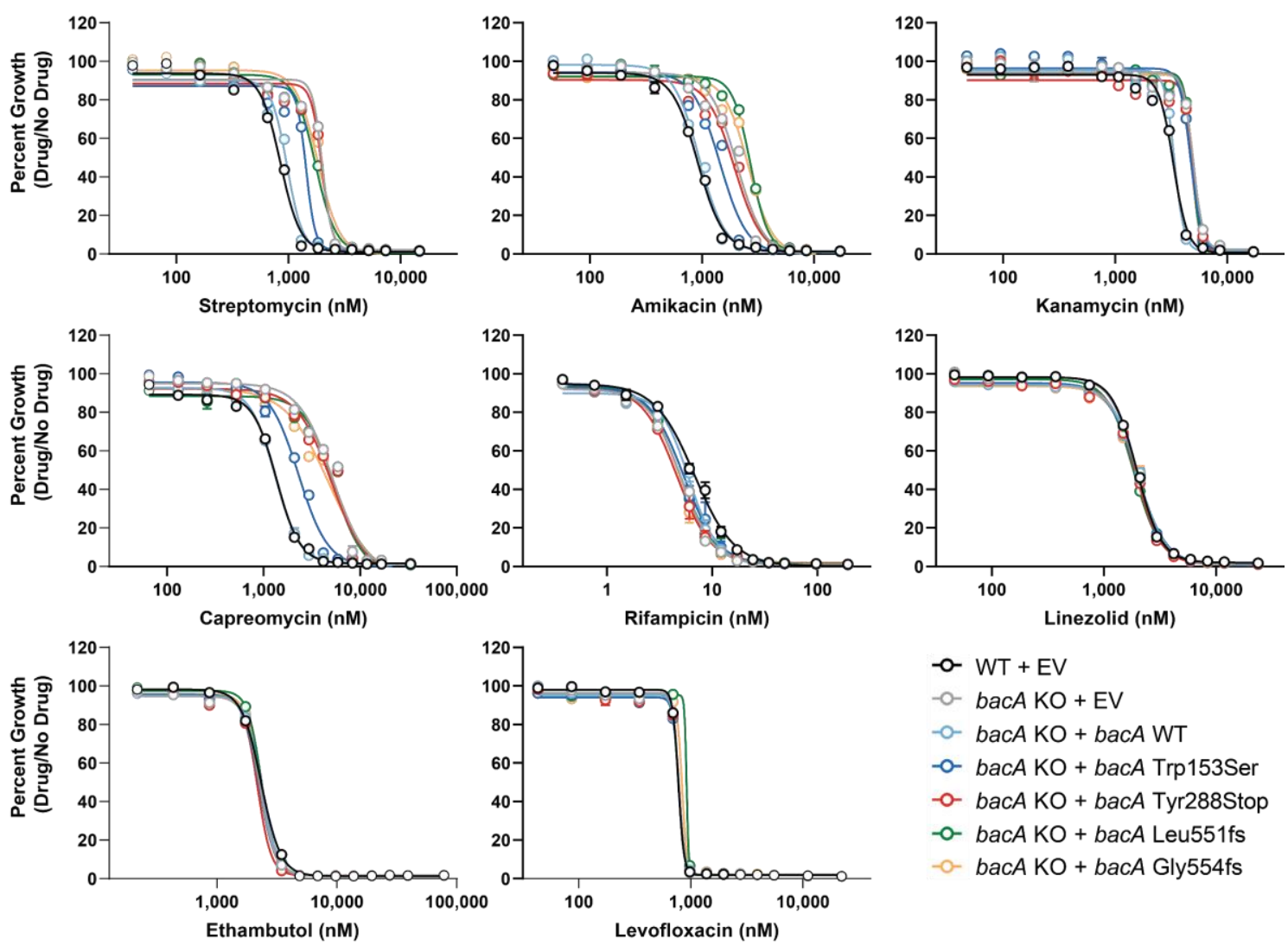

$-\infty \mathrm{WT}+\mathrm{EV}$

-

- - bacA KO + bacA WT

-o- bacA KO + bacA Trp153Ser

-o- bacA KO + bacA Tyr288Stop

-o bacA KO + bacA Leu551fs

-o- bacA KO + bacA Gly554fs

Figure 4: Loss-of-function mutations in bacA confer clinically relevant resistance to aminoglycosides and capreomycin

(A) Structure of bacA (PDB: 6TQF) (Rempel et al., 2020). Red spheres mark sites of experimentally tested clinical strain mutations in (C).

(B) Drug resistance phenotypes for strains harboring bacA mutations. MIC values for the indicated drugs were measured for the indicated strains. Data represent mean \pm SEM for technical triplicates. Results are representative data from at least two independent experiments. 
bioRxiv preprint doi: https://doi.org/10.1101/2021.11.27.469863; this version posted November $27,2021$. The copyright holder for this preprint (which was not certified by peer review) is the author/funder, who has granted bioRxiv a license to display the preprint in perpetuity. It is made available under aCC-BY-ND 4.0 International license.

436 Partial loss-of-function mutations in ettA confer clinically relevant, low-level, acquired multidrug 437 resistance

Another one of the strongest streptomycin resistance hits leading in our screen was $r 2477 c$, which also showed low-level resistance to other drugs (Figure 3B; Supplemental Data 1). rv2477c is an ortholog of the E. coli gene ettA ( 58\% amino acid identity), a ribosome-associated ABC-F protein that regulates the translation elongation cycle (Boël et al., 2014; Chen et al., 2013) (Figure 3C, Figure 5A). Due to its sequence similarity, we will refer to $r 2477 c$ as ettA. Biochemical studies demonstrated that ATP-bound EttA from E. coli stimulates formation of the first peptide bond of the initiating ribosome and then, concomitant with ATP hydrolysis, dissociates from the ribosome to allow translation elongation (Boël et al., 2014; Chen et al., 2013). Unlike ettA in E. coli, ettA is essential for the in vitro growth of Mtb (Bosch et al., 2021).

Using our clinical Mtb strain genome database, we identified four non-synonymous SNPs as being located within motifs predicted to be important for EttA function (Figure 5A) and/or showed evidence for enrichment in genotypically predicted drug resistant Mtb strains (Supplemental Data 7). Lastly, we also included an ettA Trp135Gly mutation that was identified in serial Mtb isolates from a patient in Thailand. This Trp135Gly mutation was observed directly preceding the transition from MDR-TB to extensively drug-resistant (XDR) TB (Faksri et al., 2016). Candidate SNPs (Figure 5A) were incorporated into a CRISPRi-resistant ettA allele and transformed into an H37Rv strain that allowed selective CRISPRi silencing of the endogenous, wildtype ettA allele. All SNPs tested were capable of complementing knockdown of the endogenous ettA allele (Figure 5B). Both the Gly41Glu and Trp135Gly variants displayed a modest growth defect (Figure 5B; Supplemental Figure $\mathbf{8 A}$ ), suggesting that these two SNPs are partial loss-of-function mutations. Consistent with a role for these ettA SNPs in conferring acquired drug resistance, four out of the five variants showed an increased MIC for streptomycin (Figure 5C). The Gly41Glu and Trp135Gly strains showed a $>5$-fold shift in $\mathrm{IC}_{50}$, similar in magnitude to gid mutants (Wong et al., 2011). Additionally, the Gly41Glu and Trp135Gly mutants showed low-level resistance to a mechanistically diverse panel of antibiotics including amikacin, ethambutol, rifampicin, and levofloxacin, but not other tested drugs (Figure 5C; Supplemental Figure 8C,D).

To determine the mechanism by which ettA SNPs may confer low-level, acquired multidrug resistance, we analyzed the M. smegmatis proteome after silencing the ettA homolog, ms4700. Two of the most upregulated proteins upon ms4700 knockdown were HfIX (Ms2736) and Eis (Ms3513) (Supplemental Figure 8E) (Bosch et al., 2021), encoded by two genes known to be part of the whiB7 regulon in Mtb (Morris et al., 2005). Thus, we hypothesized that partial loss of function ettA alleles may promote low-level, acquired multidrug resistance by stalling translation and constitutively upregulating the whiB 7 stress response- in essence, ettA mutations mimic the effects of translation stress caused by ribosome inhibitors to activate whiB7 (Schrader et al., 2021). Consistent with this hypothesis, whiB7 and known regulon genes (Morris et al., 2005) were constitutively upregulated in the ettA Gly41Glu Mtb mutant (Figure 5D). Furthermore, simultaneous knockdown of whiB 7 was able to reverse aminoglycoside resistance conferred by knockdown of ettA (Figure 5E). This effect was drug-specific, with knockdown of the efflux pump tap specifically reversing streptomycin resistance and knockdown of the acetyltransferase eis specifically reversing amikacin resistance (Liu et al., 2019; Zaunbrecher et al., 2009). Interestingly, knockdown of whiB7 did not reverse ethambutol or levofloxacin resistance, suggesting that the mechanism by which ettA mutations confer resistance to those drugs is independent of whiB7.

Further epidemiological analysis focused on ettA Gly41Glu,the most common ettA SNP in our database ( $n=291, \sim 0.7 \%$ of all Mtb strains). Phylogenetic analysis shows that this cluster of related strains is heavily enriched for additional acquired drug resistance mutations (Figure 5F, Supplemental Data 7). Molecular epidemiology shows that ettA Gly41Glu strains are found in Spain, Italy, the United States (Couvin et al., 2019), but are concentrated in Peru (Sheen et al., 2013) and indigenous communities of Colombia (Marín et al., 2021), where they are driving a MDR-TB outbreak (Figure 5F). 
bioRxiv preprint doi: https://doi.org/10.1101/2021.11.27.469863; this version posted November 27, 2021. The copyright holder for this preprint (which was not certified by peer review) is the author/funder, who has granted bioRxiv a license to display the preprint in perpetuity. It is made available under aCC-BY-ND 4.0 International license.

A

C

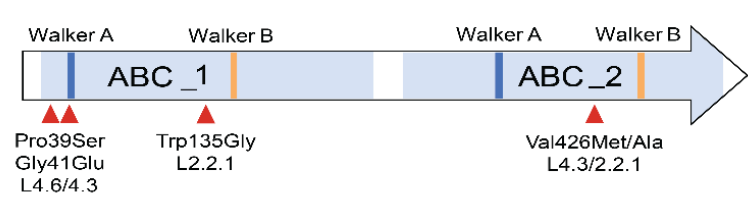

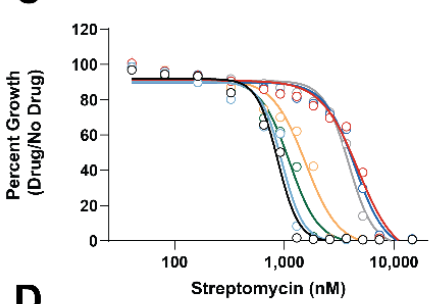

D

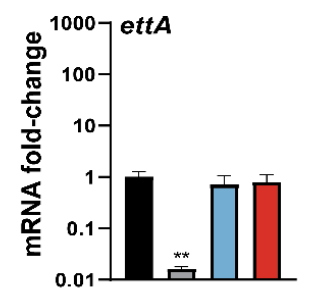

E
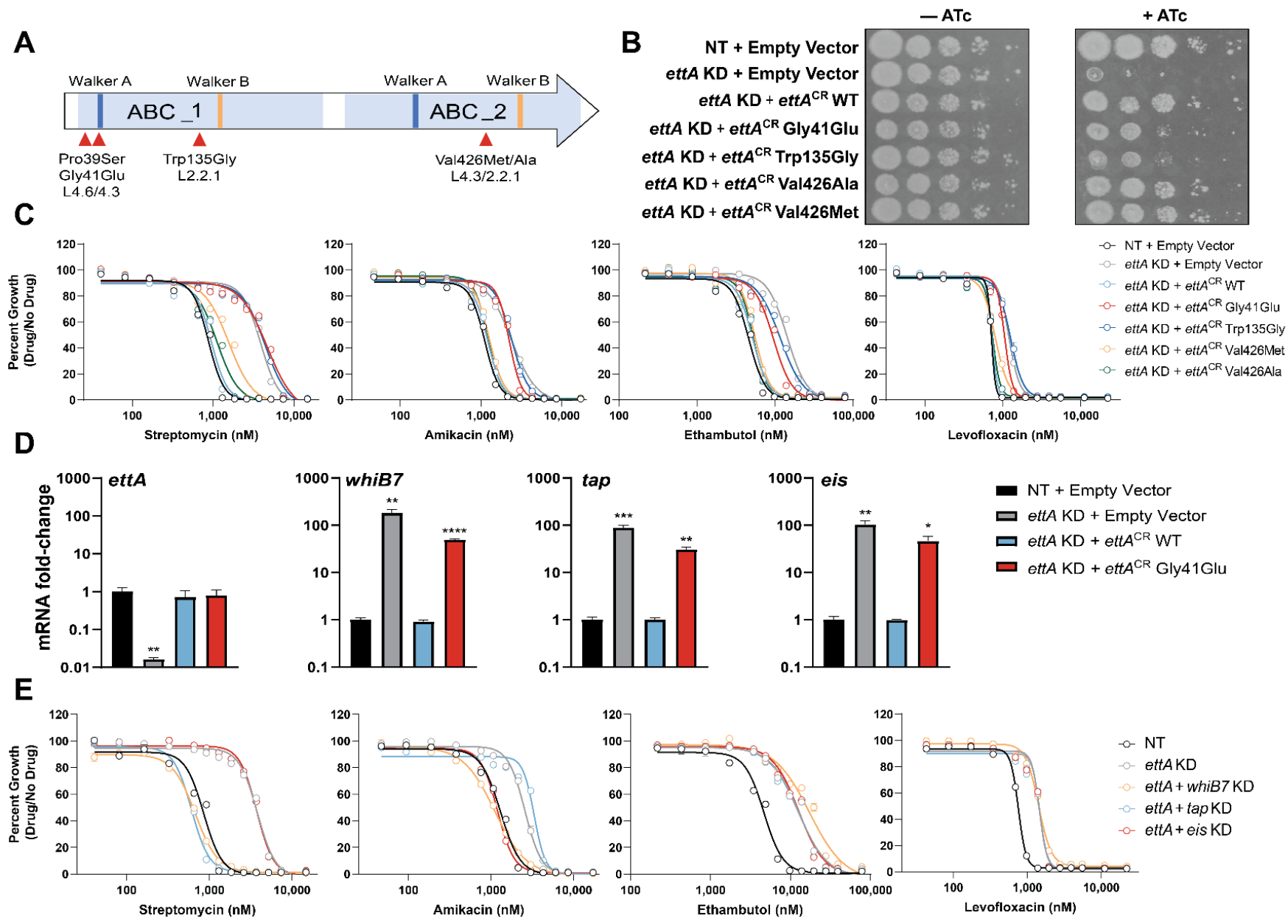

$\mathbf{F}$

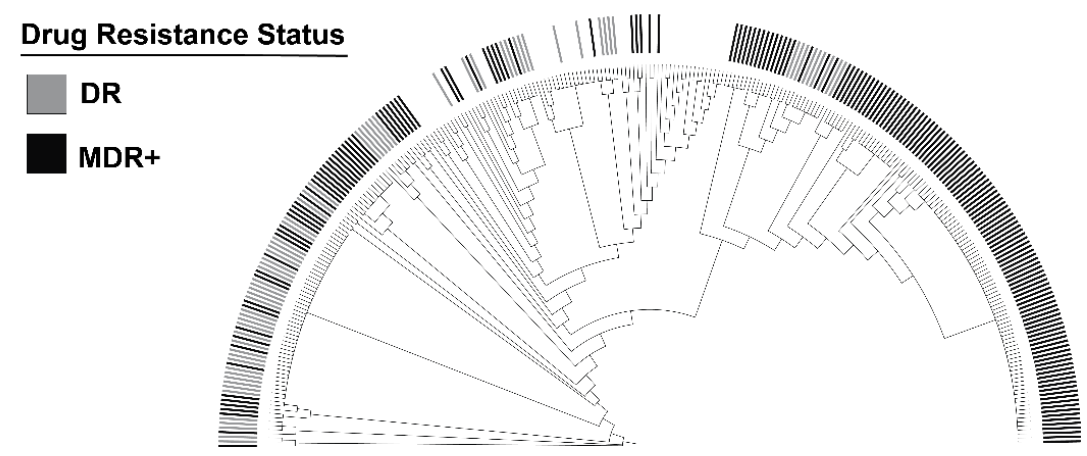

Figure 5: Partial loss-of-function mutations in ettA upregulate the whiB7 stress response and confer low-level, acquired, multidrug resistance

(A) Domain organization of EttA. ABC domains are highlighted in light blue. Walker A and Walker B motifs are shown in dark blue and orange, respectively. SNPs observed in clinical Mtb isolates that were experimentally tested are highlighted with red arrows and the dominant lineage $(L)$ in which that SNP is found is indicated.

(B) Growth of ettA mutant and control strains. The ettA CRISPRi strain was complemented with an empty vector or CRISPRi-resistant alleles harboring the indicated SNPS. NT = non-targeting; WT = wild-type; $\mathrm{KD}=$ knockdown; CR = CRISPRi-resistant.

(C) Drug resistance phenotypes for strains harboring ettA SNPs. MIC values for the indicated drugs were measured for the strains shown in Figure 5B. Data represent mean \pm SEM for technical triplicates. Results are representative data from at least two independent experiments. 
bioRxiv preprint doi: https://doi.org/10.1101/2021.11.27.469863; this version posted November $27,2021$. The copyright holder for this preprint (which was not certified by peer review) is the author/funder, who has granted bioRxiv a license to display the preprint in perpetuity. It is made available under aCC-BY-ND 4.0 International license.

(D) Quantification of indicated gene mRNA levels by qRT-PCR. Strains were grown in the presence of ATc for $\sim 5$ generations prior to harvesting RNA. Error bars are SEM of three technical replicates. Statistical significance was calculated as $p$-value with Student's t-test. ${ }^{*}, p<0.05 ;{ }^{* *}, p<0.01 ;{ }^{* *}$, $p<0.001,{ }^{* * *}, p<0.0001$.

(E) MIC values for the indicated drugs were measured for ettA single and dual knockdown strains. Data represent mean \pm SEM for technical triplicates. NT = non-targeting.

(F) Phylogenetic tree of 291 Mtb clinical strains harboring the ettA Gly41Glu variant (Supplemental Data 7). Genotypically predicted drug-resistance status are shown. DR = resistance-conferring SNPs to RIF, INH, PZA, or EMB present; MDR+ = resistance-conferring SNPs to a minimum of RIF and INH.

\section{A loss-of-function mutation in whiB7 renders an endemic Indo-Oceanic clade of $M$. tuberculosis hypersusceptible to macrolides}

Since partial loss of ettA function appears to confer acquired drug resistance by constitutive activation of whiB7, we next mined our clinical strain genome database to identify putative gain-of-function whiB7 mutations that may be associated with acquired drug resistance (Reeves et al., 2013). We identified numerous putative gain-of-function mutations in the whiB7 promoter, 5'UTR, and upstream ORF (UORF), most of which have not been previously recognized as potential determinants of acquired drug resistance (Figure 6A; Supplemental Data 7) (Chakravorty et al., 2015; Kaur et al., 2016; Reeves et al., 2013). Unexpectedly, however, the most common whiB7 variant in our database was a putative loss-of-function allele. This allele, Gly64delG, harbors a single nucleotide deletion at codon Gly64 and represents nearly one-third $(n=851 / 3,186)$ of all whiB7 variants in our database (Figure 6A) (Merker et al., 2020; Vargas et al., 2021; Warit, 2015). The Gly64delG frameshift results in a premature stop codon and truncation of the critical DNA binding AT-hook element (Supplemental Figure 9A) (Burian et al., 2013), thus presumably rendering WhiB7 inactive in these strains. whiB7-mediated intrinsic drug resistance typically renders macrolides ineffective to treat TB. We next sought to explore the possibility that the common Gly64delG mutation may render this subset of Mtb strains hypersusceptible to and treatable with macrolides.

Lineage calling identified the Gly64delG SNP as uniquely present in all lineage 1.2.1 (L1.2.1) Mtb isolates, a major sublineage of the L1 Indo-Oceanic clade (Figure 6A; Supplemental Figure 9B; Supplemental Data 8) (Netikul et al., 2021). Using a reference set of Mtb clinical strains (Borrell et al., 2019), we first validated the presence of the whiB7 Gly64delG frameshift mutation in L1.2.1 by Sanger sequencing (Figure 6B). All other clinical isolates in this set were wild-type for whiB7. Consistent with loss of whiB7 function, the L1.2.1 isolate was hypersusceptible to clarithromycin as well as other macrolides, ketolides, and lincosamides, whereas all other clinical isolates were intrinsically resistant (Figure 6C; Supplemental Figure 9C-E). The whiB7 Gly64delG allele failed to complement intrinsic clarithromycin resistance in an H37Rv $\Delta$ whiB7 knockout strain, confirming that Gly64delG is a loss-of-function allele (Supplemental Figure 9F). To confirm L1.2.1 macrolide susceptibility in vivo, we infected mice with H37Rv or L1.2.1 Mtb by low-dose aerosol exposure. Both strains showed similar growth kinetics in vivo (Supplemental Figure 10A,B). We next tested drug efficacy in an acute infection model, with drug dosing designed to mimic human pharmacokinetics in the treatment of TB (rifampicin, isoniazid) and non-tuberculous mycobacteria (clarithromycin) (Rodvold, 1999). We isolated a spontaneous clarithromycin resistant L1.2.1 isolate (harboring a 23S A2297G mutation) as a control (Supplemental Figure 10C-E). Consistent with the in vitro data, L1.2.1 was sensitive to macrolide therapy whereas H37Rv was intrinsically resistant (Figure 6D,E; Supplemental Figure 10F-I) (Luna-Herrera et al., 1995; Truffot-Pernot et al., 1995). Therapeutic drug monitoring confirmed equivalent drug exposures in both the H37Rv and L1.2.1 infections (Supplemental Figure 10J,K). Interestingly, L1.2.1 was also more sensitive than H37Rv to rifampicin in the mouse model (Supplemental Figure 10H,I), which could reflect whiB7-dependent upregulation of the tap efflux pump in H37Rv but not L1.2.1 during induced tolerance in vivo (Adams et al., 2011)

To estimate the potential clinical impact of this finding, we next examined the geographic distribution of the L1.2.1 sublineage. This sublineage is found predominantly in Southeast Asia, including the high TB burden countries Indonesia, Thailand, and the Philippines (Figure 6F,G) (Palittapongarnpim et al., 2018). L1.2.1 is particularly prevalent in the Philippines, accounting for approximately $80 \%$ of all Mtb isolates in this country 
560 (Phelan et al., 2019). Of note, the Philippines has one of the highest TB incidence rates in the world, including a high burden of drug-resistant TB, and TB is a leading cause of death in this country (WHO, 2021). A recent analysis of the global burden of TB caused by L1.2.1 estimates that this sublineage causes approximately 600,000 cases of active TB per year (Netikul et al., 2021), of which $\sim 43,000$ are estimated to be MDR-TB based on the frequencies of drug resistance in our clinical strain genome database. Thus, clarithromycin, an effective, orally available, safe, and generic antibiotic, could potentially be repurposed to treat a major sublineage of TB.

A

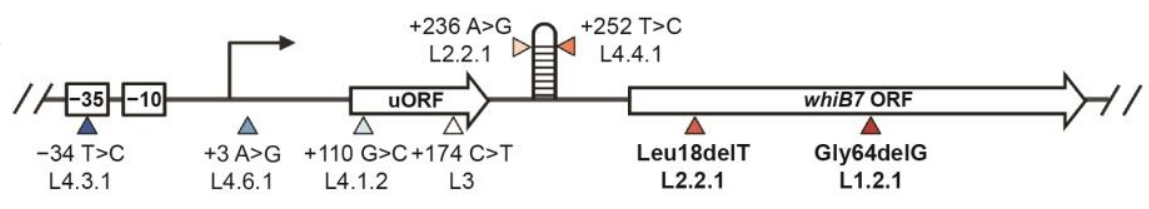

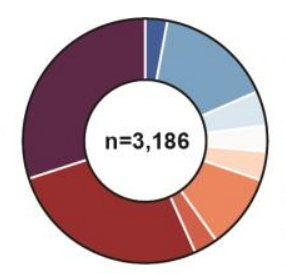

C

B
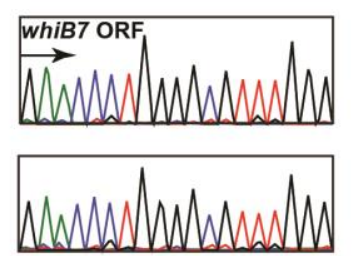

L1.1.1 (China)

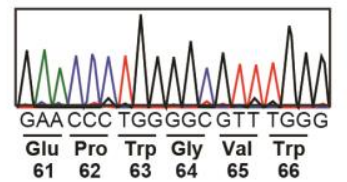

L1.1.2 (India)

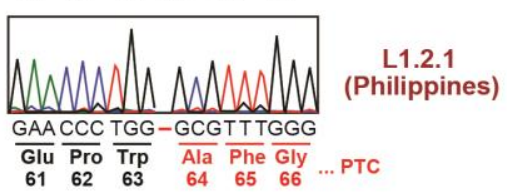

L1.2.1
(Philippines)

\begin{tabular}{ccccccc}
\hline Glu & Pro & Trp & Ala & Phe & Gly & \\
61 & 62 & 63 & 64 & 65 & 66 & ... PTC
\end{tabular}

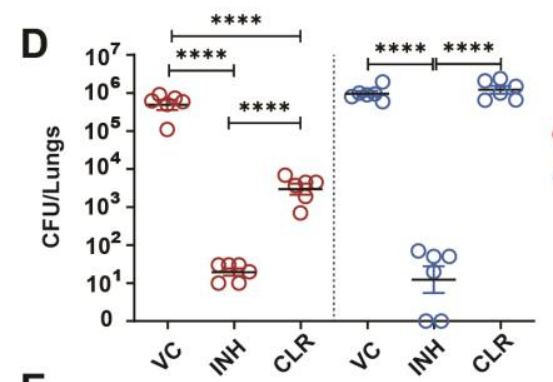

E

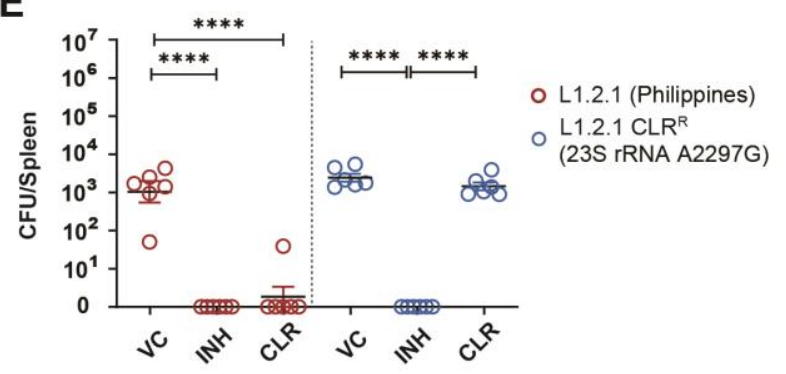

○ L1.2.1 (Philippines)

- L1.2.1 CLRR

(23S rRNA A2297G)
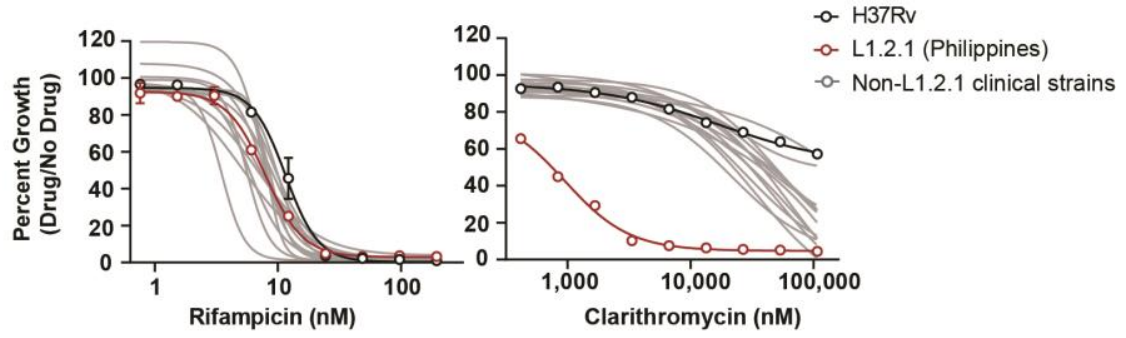

F

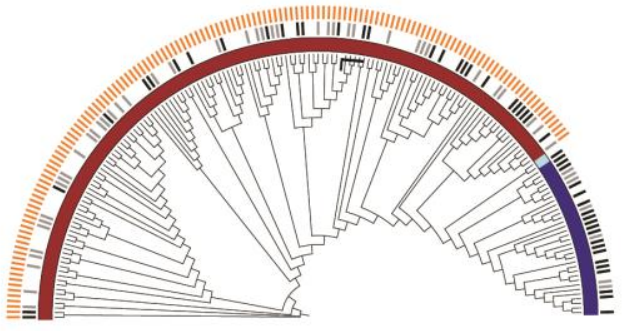

$\underline{\text { Drug Resistance Status }}$

$\square \mathrm{DR}$

a MR+

- L1.2.1

$\square \mathrm{L} 2$

- L4

$\square$ whiB7 Gly64-delG

G

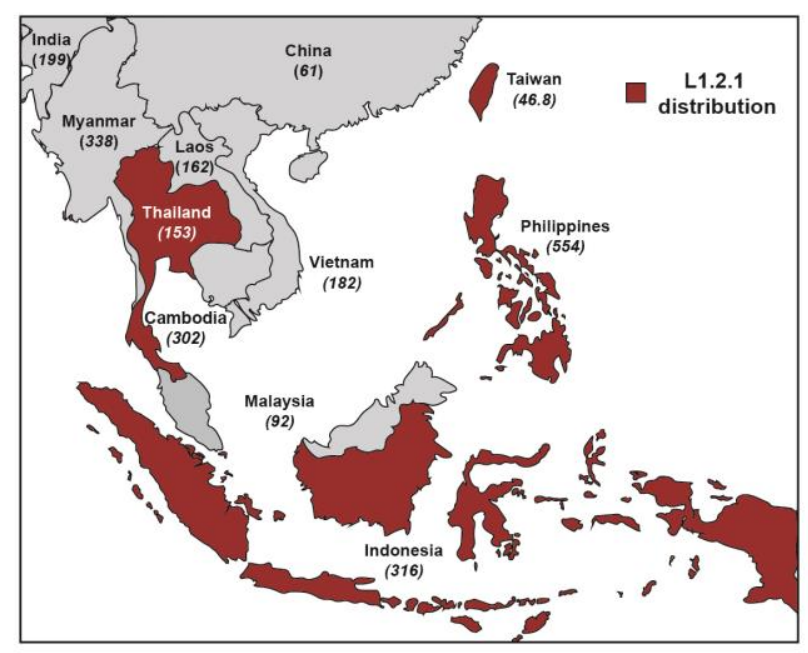

Figure 6: A loss-of-function mutation in whiB7 renders an endemic Indo-Oceanic lineage of $M$. tuberculosis hypersusceptible to macrolides.

(A) Diagram of Mtb whiB7. The eight most common whiB7 variants observed in our Mtb clinical strain genome database are highlighted with arrows and the dominant lineage (L) in which those SNPs are found is indicated. The pie chart depicts the observed frequencies of each indicated variant in our database. 
bioRxiv preprint doi: https://doi.org/10.1101/2021.11.27.469863; this version posted November $27,2021$. The copyright holder for this preprint (which was not certified by peer review) is the author/funder, who has granted bioRxiv a license to display the preprint in perpetuity. It is made available under aCC-BY-ND 4.0 International license.

(B) Sanger sequencing traces of whiB7 from the indicated Mtb clinical strains and their country of origin. $\mathrm{PTC}=$ premature termination codon.

(C) MIC values for RIF and CLR were measured for a reference set of Mtb clinical strains. Error bars represent the standard error of the mean (SEM) for technical triplicates. Results are representative data from at least two independent experiments.

$(\mathrm{D}, \mathrm{E})$ Mean lung (D) and spleen (E) Mtb CFU ( \pm SEM) in BALB/c mice after isoniazid (INH; $25 \mathrm{mg} / \mathrm{kg})$, or clarithromycin (CLR; $200 \mathrm{mg} / \mathrm{kg}$ ) treatment. Mice were infected with approximately 100-200 CFU of aerosolized Mtb. After 10 days to allow the acute infection to establish, chemotherapy was initiated. Following 24 days of drug therapy, Mtb bacterial load of lungs and spleen were determined. Statistical significance was assessed by one-way ANOVA followed by Tukey's post-hoc test. ${ }^{* * *}, p<0.0001$. VC = vehicle control. CLR $^{\mathrm{R}}=$ clarithromycin-resistant.

(F) Phylogenetic tree of 178 Mtb clinical strains isolated during the 2012 nationwide drug resistance survey in the Philippines (Phelan et al., 2019) (Supplemental Data 8). The presence of the whiB7 Gly64delG mutation and genotypically predicted drug resistance status are shown. DR = resistanceconferring SNPs to RIF, INH, PZA, or EMB present; MDR+ = resistance-conferring SNPs to a minimum of RIF and INH.

(G) Map showing the distribution of the L1.2.1 sub-lineage in Southeast Asia (WHO, 2021). Tuberculosis incidence rates are listed in parentheses beneath each country name.

\section{DISCUSSION}

A deeper understanding of the bacterial pathways that govern drug efficacy in Mtb is needed to develop more potent therapies, identify new mechanisms of acquired drug resistance, and reveal overlooked therapeutic opportunities. To address this challenge, we developed a CRISPRi platform to define the genetic determinants that alter bacterial fitness in the presence of different drugs, and then overlay these chemical-genetic results with comparative genomics of Mtb clinical isolates. Illustrating the power of this dataset to derive new, clinically relevant biological insight, we uncover diverse mechanisms of intrinsic drug resistance that can be targeted to potentiate therapy, describe new mechanisms of acquired drug resistance associated with the emergence of MDR-TB, and make the unexpected discovery of an "acquired drug sensitivity" that could enable the repurposing of clarithromycin to treat an Mtb sublineage.

Alternative functional-genomics methods such as TnSeq have been successfully applied to generate chemical-genetic interaction profiles for a number of drugs in Mtb (Sassetti et al., 2020; Xu et al., 2017). While powerful, TnSeq as currently implemented in Mtb is restricted to the analysis of in vitro non-essential genes and thus cannot assess some of the most compelling drug targets, essential genes. The recent development of barcoded degron libraries in Mtb, in which regulated proteolysis is used to tune target protein levels, now allows the chemical-genetic assessment of hundreds of essential genes (Johnson et al., 2019; Koh et al., 2021). This approach is likely to be expanded to include nearly all essential genes in the near future. The degron library has been used to identify numerous new inhibitor-target pairs in large-scale, target-based whole cell screens. The degron approach is extremely powerful but suffers from the fact that not all proteins tolerate the degron tag, the approach fails to assess chemical-genetic interactions for nonessential genes, and the laborious nature of mutant construction functionally restricts analysis to a single Mtb reference strain (H37Rv). By being able to robustly tune knockdown for both essential and nonessential genes, the CRISPRi approach taken here provides the most comprehensive chemical-genetic map available, successfully generating distinct profiles for two translation inhibitors that bind within angstroms of each other. Moreover, the portability of CRISPRi libraries will allow chemical-genetic screening across diverse Mtb clinical isolates (Bosch et al., 2021). While more comprehensive and portable, our current CRISPRi approach is low throughput compared to degron libraries, and thus the development of optimized, compact CRISPRi libraries to increase screen throughput remains a priority. CRISPRi has wellknown limitations (Bosch et al., 2021), including the polar effect of CRISPRi knockdown. As with any genetic approach, genetic inhibition of a target is not the same as inhibition of a target with a small molecule (Knight and Shokat, 2007), highlighting the importance of validating chemical-genetic interactions with small molecule inhibitors (Cokol et al., 2017). Lastly, any pooled screening approach may miss effects where the 
631 phenotype can be complemented in trans (e.g. cross-feeding), although recent TnSeq results suggest that

632 only $1-3 \%$ of all S. pneumoniae Tn mutants show differential fitness phenotypes when grown as pools vs in 633 isolation, suggesting this type of phenotypic masking is rare (Thibault et al., 2019).

One proposed route to improving TB chemotherapy is to develop more potent drug combinations by leveraging drug synergies (Cokol et al., 2017). By identifying hundreds of genes that contribute to intrinsic drug resistance in Mtb, the results presented here can be used to inform drug development efforts to identify synergistic drug combinations that disarm intrinsic drug resistance. Our results confirm that one of the richest sources of potentially synergistic targets is the mycobacterial envelope, consistent with the longappreciated understanding of the envelope as a barrier to antibiotic efficacy (Batt et al., 2020; Jarlier and Nikaido, 1994; Xu et al., 2017). mAGP disruption may increase envelope permeability and antibacterial uptake (McNeil et al., 2019; Piddock et al., 2000), as confirmed for kasA and mtrAB; alternatively, the chemical-genetic results may indicate a more mechanism-specific interaction, whereby knockdown of mAGP biosynthetic or regulatory genes is synthetic lethal with subinhibitory concentrations of an antibacterial compound (Xu et al., 2017). It is tempting to speculate that potentiation of rifampicin could, at least in part, explain the clinical success of ethambutol. Long-thought to be included in the standard regimen primarily to minimize the emergence of drug resistance to isoniazid, pyrazinamide, and rifampicin (Zimmerman et al., 2017), ethambutol may have "won" in early clinical trials due to its ability to effectively penetrate lung lesions (Zimmerman et al., 2017) and potentiate rifampicin (Cokol et al., 2017; Piddock et al., 2000). Chemical-genetic profiling of an expanded set of antibacterials to identify those compounds potentiated by mAGP disruption, or other types of molecules for which uptake can be monitored, may allow derivation of the permeability "rules" of the Mtb cell envelope, which could then be used to guide drug development to increase compound permeability (Davis et al., 2014).

Beyond the Mtb cell envelope, our results uncover both shared and unique intrinsic resistance and sensitivity mechanisms, as highlighted by the chemical-genetic profiles for the three ribosome targeting antibiotics. Future biochemical studies will identify the molecular mechanisms by which these factors operate, knowledge which could then be used to guide medicinal chemistry efforts to improve these drugs. For example, aminoglycoside scaffolds could be designed to improve BacA-mediated uptake (Domenech et al., 2009; Rempel et al., 2020). Similarly, our results suggest that Rv1473 serves as an antibiotic resistance ABC-F protein, capable of displacing oxazolidinones and phenicols from the Mtb ribosome (Supplemental Figure 6). Next generation oxazolidinone analogs could be designed that are recalcitrant to the potential drug-displacing activity of Rv1473, analogous to the third-generation tetracycline analogues which are resistant to the drug-displacing activity of the ABC-F protein TetM (Jenner et al., 2013). In light of our findings, we suggest designating $r v 1473$ as oprA (oxazolidinone phenicol resistance $\underline{\mathbf{A}}$ ). Finally, these results show that trans-translation may be a target for synergistic drug combinations (Brunel et al., 2018), which could be important in increasing the potency and decreasing toxicity of oxazolidinones.

In addition to guiding rational development of synergistic drug combinations, our results illustrate the power of combining chemical-genetics with comparative genomics to discover new mechanisms of acquired drug resistance. In recent decades, many drug resistance mutations in Mtb have been mapped and characterized. However, our knowledge of the genetic basis of acquired drug resistance remains incomplete, particularly for mutations outside of the drug target or drug activator and which typically confer low to intermediate levels of drug resistance (Carter, 2021; Hicks et al., 2018; Walker et al., 2015). Lowlevel drug resistance has been associated with TB treatment failure (Colangeli et al., 2018), and could serve as a stepping stone to allow additional, high-level drug resistance mutations to evolve (Dick and Dartois, 2018). We make a number of findings that may be important for diagnosing and treating drug resistant TB. First, we show inhibition of $t s n R$ increases fitness in the presence of linezolid, and thus mutations in this gene could be monitored as linezolid use is expanded in the clinic. Second, we find that LOF mutations in the ABC importer bacA confer resistance to four important second-line TB drugs: streptomycin, kanamycin, amikacin, and capreomycin. These mutations may be a source of unexplained resistance amongst clinical Mtb strains. Third, we show that partial loss-of-function mutations in the essential gene ettA result in constitutive activation of the whiB7 stress response and low-level acquired multidrug resistance. This phenotype is consistent with the TB patient described in (Faksri et al., 2016), whereby serial Mtb isolates acquired a Trp135Gly mutation in ettA directly preceding the transition from MDR-TB to extensively drug- 
686 resistant XDR-TB. 3.1\% ( $n=1,393 / 45,473)$ of all Mtb strains in our genome database harbor a missense

687 SNP in ettA, suggesting that ettA-mediated acquired drug resistance could be highly prevalent. Our focus

688 on the ettA-Gly41Glu mutation shows that it is highly prevalent and that it likely facilitated the evolution of an

689 MDR-TB outbreak concentrated in Peru, a country with one of the highest MDR-TB burdens in South

690 America (WHO, 2021). Our results demonstrate that while streptomycin and amikacin may be less effective

691 against ettA variants, capreomycin may remain effective and should be considered for treatment. In addition

692 to bacA and ettA, our analytical pipeline revealed numerous additional genes as candidates for previously

693 unrecognized mechanisms of acquired drug resistance in Mtb (Supplemental Data 9), although further

694 work is necessary to validate these predictions. An increased understanding of acquired drug resistance will

695

696

697

698

699

700

701

702

703

704

705

706

707

708

709

710 guide development of more effective molecular diagnostics and personalized TB therapy to reduce treatment failure and the subsequent evolution of additional resistance alleles.

In the search for gain-of-function whiB7 mutations that confer acquired drug resistance, we made the unexpected discovery of common loss-of-function whiB7 alleles (Merker et al., 2020; Vargas et al., 2021), which we refer to as an "acquired drug sensitivity." In addition to whiB7, we identified several predicted lossof-function alleles in other genes that could confer acquired drug sensitivity in other Mtb clinical strains (Supplementary Table 2), and validate LOF alleles in a L1 and L7 isolate that confer hypersusceptibility to bedaquiline and the anti-leprosy drug clofazimine (Supplemental Figure 11) (Carter, 2021). Phylogenetic dating suggests that the whiB7 mutation arose approximately 900 years ago, well before the introduction of TB chemotherapy (O'Neill et al., 2019). Since macrolides and lincosamides have not historically been used to treat TB, there has likely been little selective pressure against whiB7 loss-of-function mutants. Whether the Gly64delG mutation provides or provided a selective benefit to L1.2.1 in Southeast Asia, enriched as a passenger mutation due to strong linkage disequilibrium in Mtb, enriched as a result of epistatic interactions with the L1.2.1 genotype that negate the selective benefit of the whiB7 stress response, or was simply the product of genetic drift remains unclear. We find that the entire L1.2.1 Mtb sublineage (Merker et al., 2020) is a whiB7 loss-of-function mutant which renders this strain susceptible to macrolides, both in vitro and in vivo. L1.2.1 could be identified by molecular diagnostics such as Genexpert (Walker et al., 2015). These results pave the way for further preclinical efficacy studies to support that clarithromycin be repurposed to treat this major Mtb sublineage ( 600,000 active TB cases per year, $\sim 43,000$ MDR TB cases, $80 \%$ of all TB in the Philippines) in Southeast Asia.

In summary, we combine genome-scale CRISPRi chemical-genetics and comparative genomics of Mtb clinical strains to define bacterial mechanisms that limit drug efficacy. This chemical-genetic map provides a rich resource to guide development of more potent drugs and drug combinations, identify previously unrecognized mechanisms of acquired drug resistance, and highlights overlooked therapeutic opportunities. Chemical-genetic profiling of antibacterials not traditionally used to treat TB may identify additional acquired drug sensitivities that could be leveraged to repurpose such drugs to treat TB. Profiling of lead compounds early in drug discovery, in addition to providing (or refuting) evidence for on-target activity (Figure 1B-D), may allow the identification of relevant bacterial intrinsic resistance mechanisms, knowledge which could then be used to modify the leads to evade intrinsic resistance (Lee et al., 2014). Future iterations of this approach should address additional bacterial mechanisms that contribute to treatment failure, including drug tolerance and persistence (Hicks et al., 2018). Moreover, it is well appreciated that chemical-genetic interactions can be strongly influenced by genetic background and growth environment (Bosch et al., 2021; Koh et al., 2021). This work sets the stage for expanded chemical-genetic studies in different Mtb clinical strains and different growth environments, including in vivo infection models.

\section{ACKNOWLEDGEMENTS}

We thank members of the Rock laboratory, Sabine Ehrt, Justin Pritchard, Alexandre Gouzy and Shipra Grover for comments on the manuscript and/or helpful discussions. We thank Carolina Trujillo, Josh Wallach, Sophie Lavalette-Levi, and Sabine Ehrt for technical assistance, Jenny Xiang and Dong Xu of the Weill Cornell Genomics Core for sequencing, the animal technical and analytical teams of the Center for Discovery and Innovation for animal work, and Sarah Schrader for sharing the M. smegmatis whiB7 knockout strain. We thank Ruby Froom and Viviana LaSalle for scientific illustration. We thank Cliff Barry for kindly sharing the bacA deletion strain used in this work. This work was supported by a Harvey L. Karp 
bioRxiv preprint doi: https://doi.org/10.1101/2021.11.27.469863; this version posted November 27, 2021. The copyright holder for this preprint (which was not certified by peer review) is the author/funder, who has granted bioRxiv a license to display the preprint in perpetuity. It is made available under aCC-BY-ND 4.0 International license.

741 Postdoctoral Fellowship (S.L.), the Potts Memorial Foundation (M.D. and S.L.), the Bill and Melinda Gates 742 Foundation (INV-010616 and INV-004761 to D.S.), the Department of Defense (PR192421 to J.R.), an NIH 743 Shared Instrumentation Grant (S10-OD023524 to V.D.), and an NIH/NIAID New Innovator Award

744 (1DP2Al144850-01, J.R.).

\section{AUTHOR CONTRIBUTIONS}

748 Conceptualization, S.L., N.C.P., N.R., D.S. and J.M.R.; Methodology, S.L., N.C.P., J.S.C., Z.A.A., M.A.D., 749 and J.M.R.; Investigation, S.L., N.C.P., N.R., M.D.Z., B.B., C. E., D.S., K.P., M.G. and K.R.; Validation: S.L. 750 and N.C.P.; Software \& Formal Analysis: J.S.C., M.A.D., Z.A.A. and K.E.; Data Curation: J.S.C., M.A.D., 751 Z.A.A., K.E. and J.M.R.; Writing - Original Draft, S.L., N.C.P. and J.M.R.; Writing - Review \& Editing, S.L., 752 N.C.P., J.S.C., M.A.D., K.E., B.B., M.G., V.D., D.S. and J.M.R.; Funding Acquisition, V.D., D.S. and J.M.R.; 753 Resources, M.D.Z., M.G., V.D.; Supervision, J.M.R.

757 All authors declare no competing interests. 
bioRxiv preprint doi: https://doi.org/10.1101/2021.11.27.469863; this version posted November 27, 2021. The copyright holder for this preprint (which was not certified by peer review) is the author/funder, who has granted bioRxiv a license to display the preprint in perpetuity. It is made available under aCC-BY-ND 4.0 International license.

\section{Supplemental Figures}

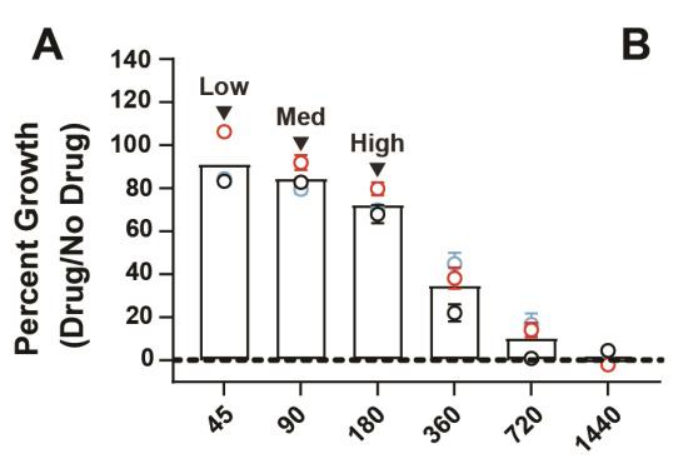

Bedaquiline (nM)

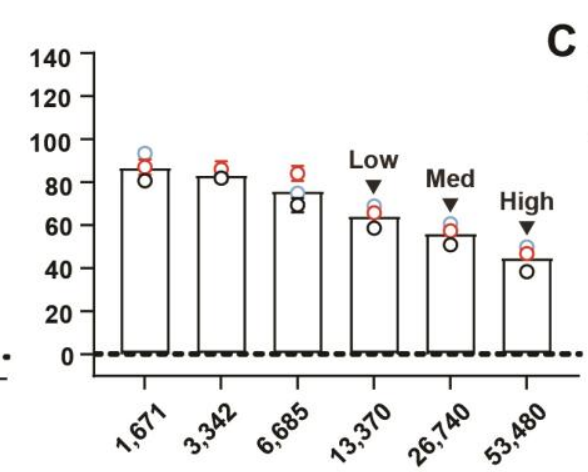

Clarithromycin (nM)

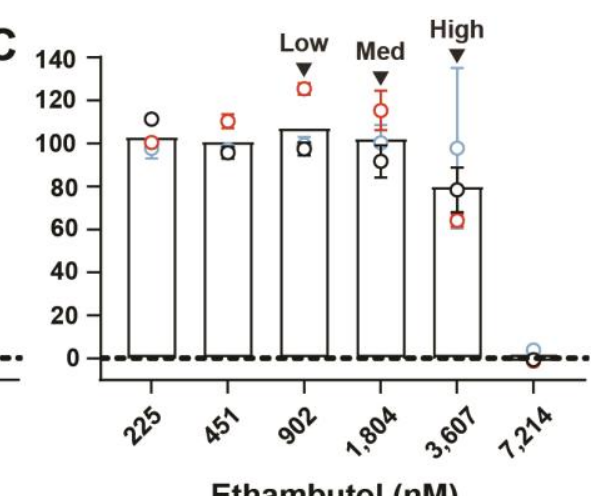

Ethambutol (nM)
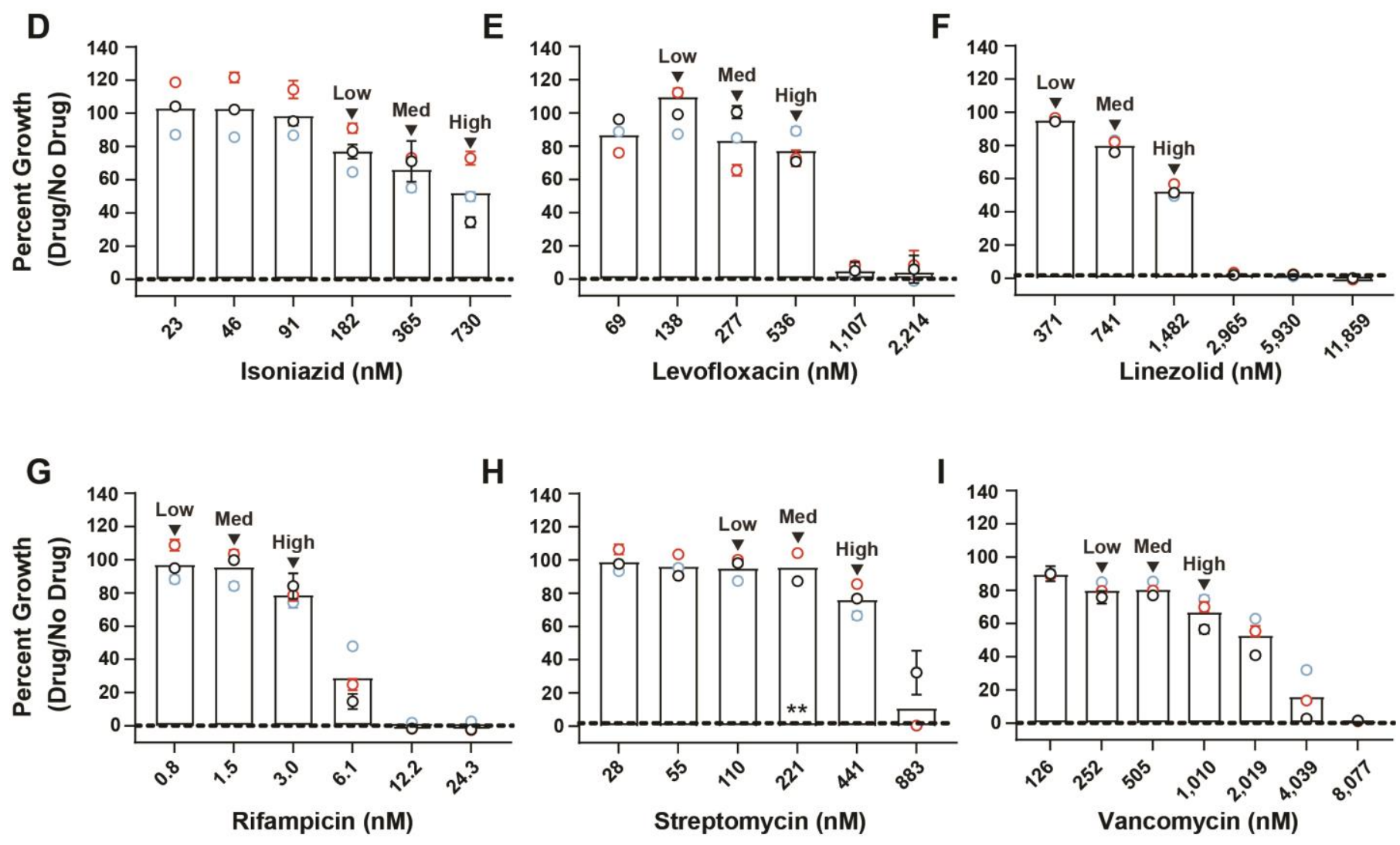

\section{Supplemental Figure 1: Growth of the Mtb CRISPRi library during drug selection}

(A-I) Normalized growth of the Mtb CRISPRi library in the drug screens. Error bars represent the SEM for biological triplicates. Samples harvested for sgRNA deep sequencing are marked as "High", "Med", and "Low", denoting the three descending doses of partially inhibitory drug concentrations analyzed in these screens. ${ }^{* *}$ : 10-day sample was lost for the $221 \mathrm{nM}$ ("Med") streptomycin screen. 
bioRxiv preprint doi: https://doi.org/10.1101/2021.11.27.469863; this version posted November 27, 2021. The copyright holder for this preprint (which was not certified by peer review) is the author/funder, who has granted bioRxiv a license to display the preprint in perpetuity. It is made available under aCC-BY-ND 4.0 International license.

A

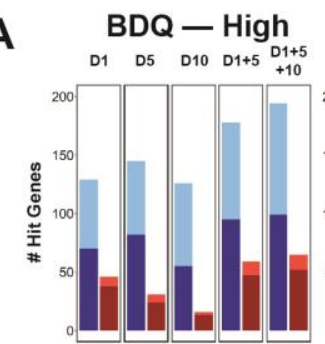

B

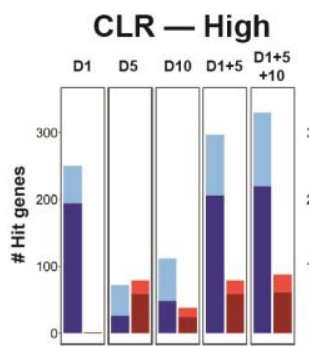

C
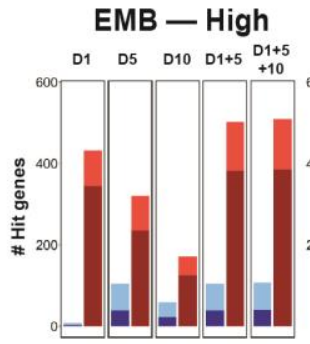

D

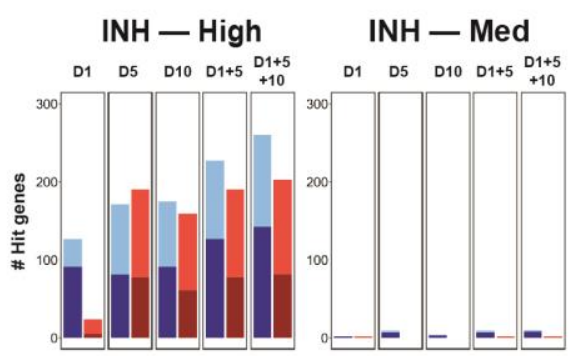

$\mathbf{E}$
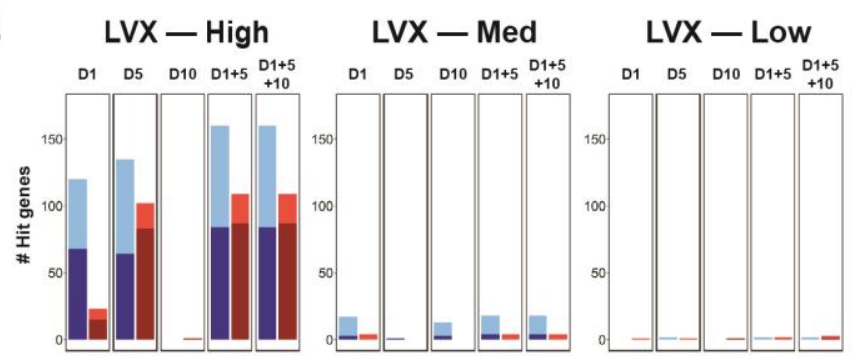

Depleted Essential Hit

nepleted Non-Essenti
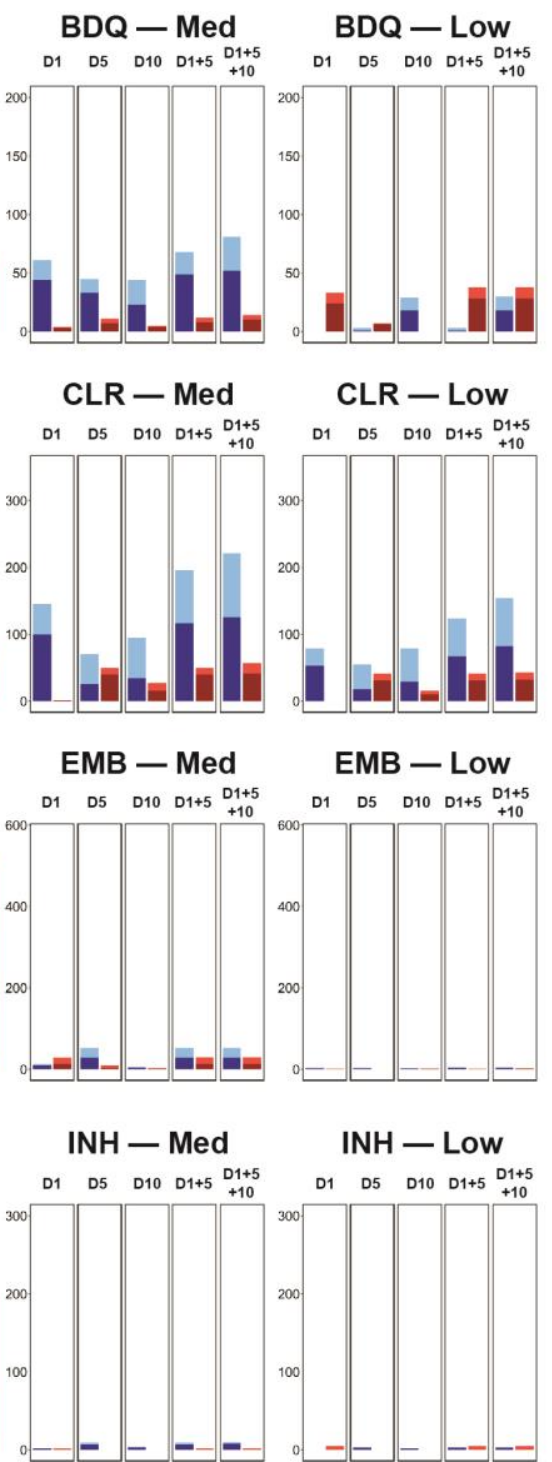

H

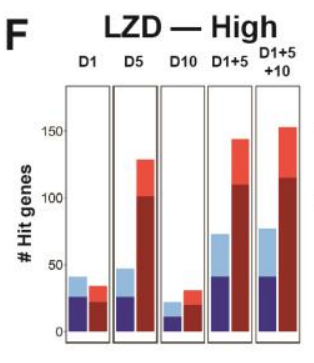

G
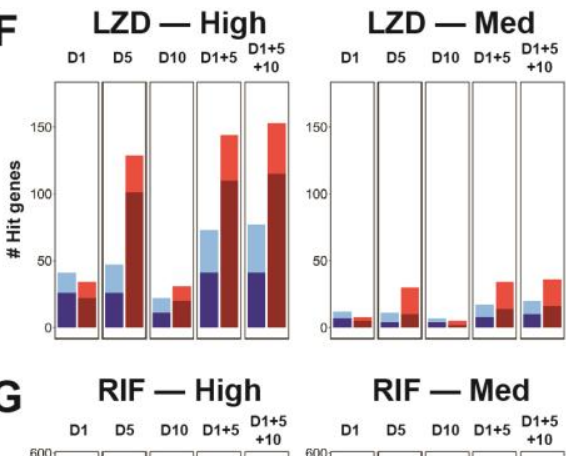

LZD - Low

D1 D5 $\quad \mathrm{D} 10 \quad \mathrm{D} 1+5 \begin{gathered}\mathrm{D} 1+5 \\ +10\end{gathered}$

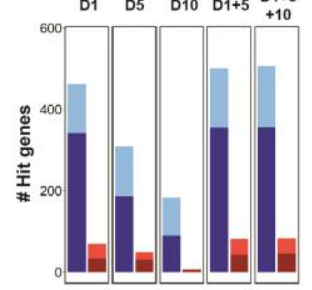

RIF - Med
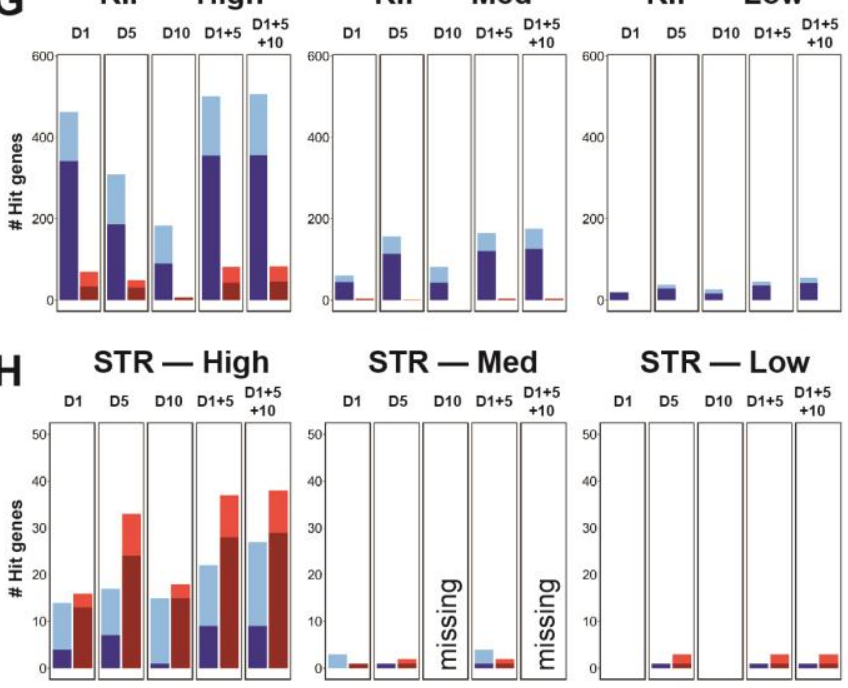

STR - Low

I

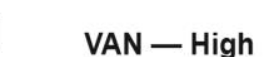

VAN - Med

VAN - Low

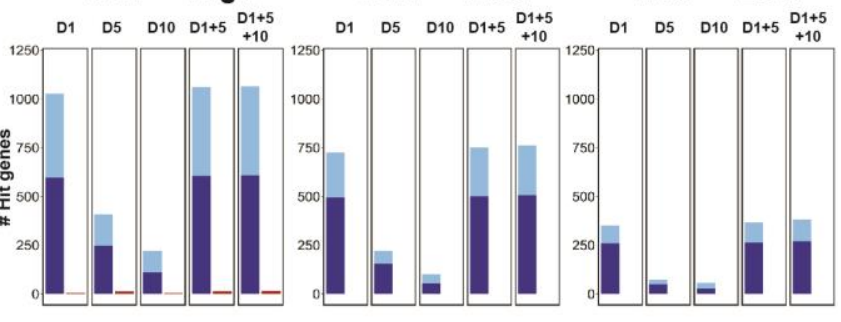

J
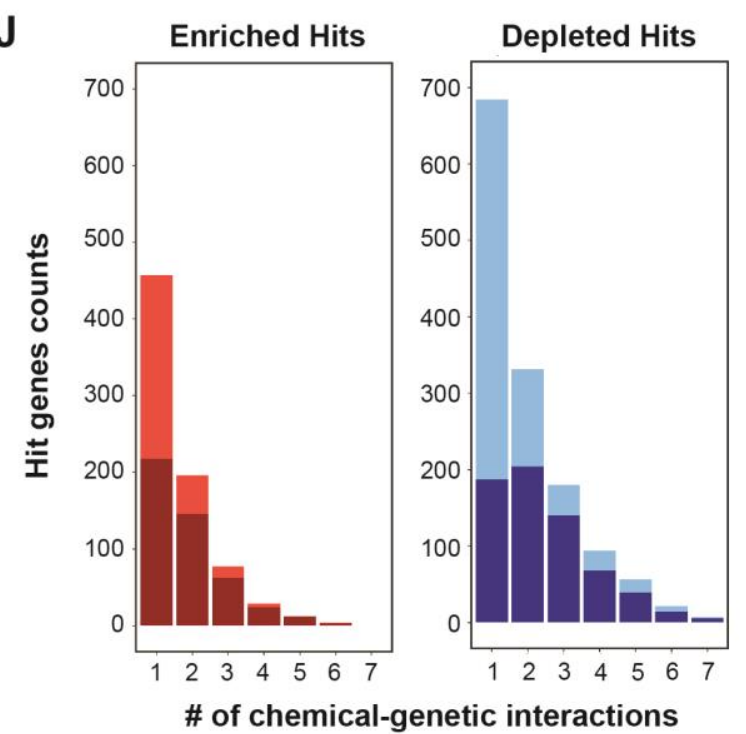

\section{Supplemental Figure 2: Summary of hits from chemical-genetic screens}

(A-I) Bar graphs showing number of hit genes identified across all conditions. Gene essentiality calls were defined by CRISPRi as in (Bosch et al., 2021). D1, D5, and D10 indicate the number of days the CRISPRi library was treated with ATc prior to drug exposure; D1+5 = hit genes defined as the union of 
bioRxiv preprint doi: https://doi.org/10.1101/2021.11.27.469863; this version posted November 27, 2021. The copyright holder for this preprint (which was not certified by peer review) is the author/funder, who has granted bioRxiv a license to display the preprint in perpetuity. It is made available under aCC-BY-ND 4.0 International license.

1 and 5-day CRISPRi library pre-depletion results; D1+5+10: hit genes defined as the union of 1, 5 and 10 day CRISPRi library pre-depletion results. Note that the 10-day sample was lost for the "Med" streptomycin screen and thus the D10 containing results for "STR-Med" are labelled "missing".

(J) Histogram depicting the number of unique chemical-genetic interactions for enriching and depleting hits. Hit genes were defined as the union of 1 and 5-day CRISPRi library pre-depletion results. 
bioRxiv preprint doi: https://doi.org/10.1101/2021.11.27.469863; this version posted November 27, 2021. The copyright holder for this preprint (which was not certified by peer review) is the author/funder, who has granted bioRxiv a license to display the preprint in perpetuity. It is made available under aCC-BY-ND 4.0 International license.

A

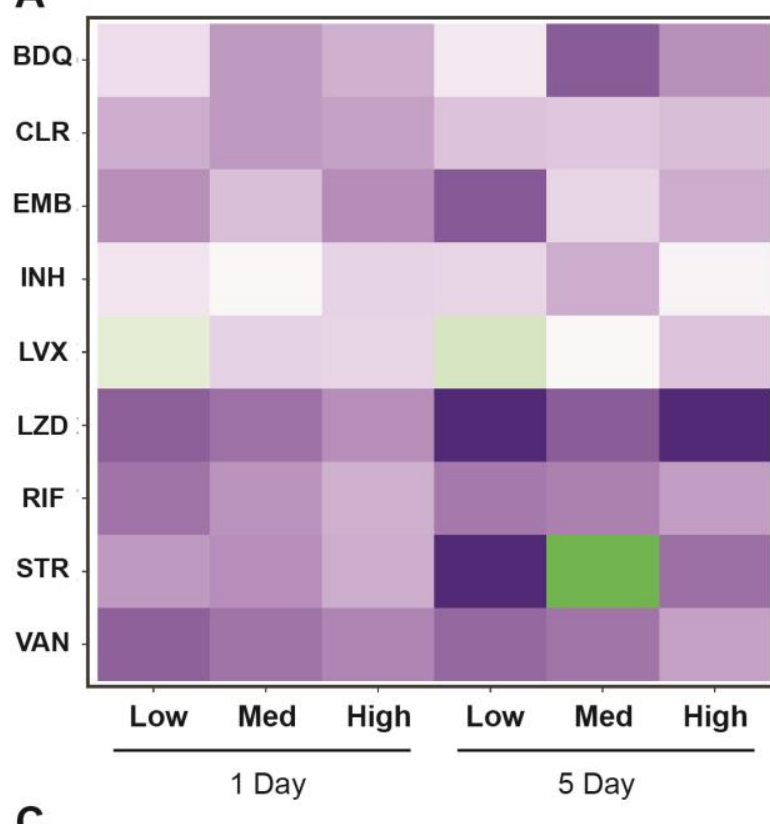

B

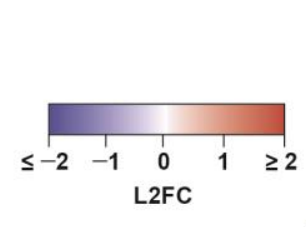

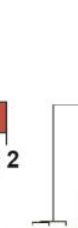

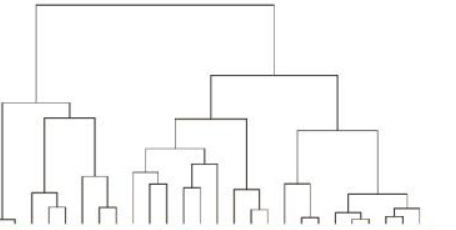

Enrichment log odds ratio

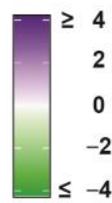

$c$

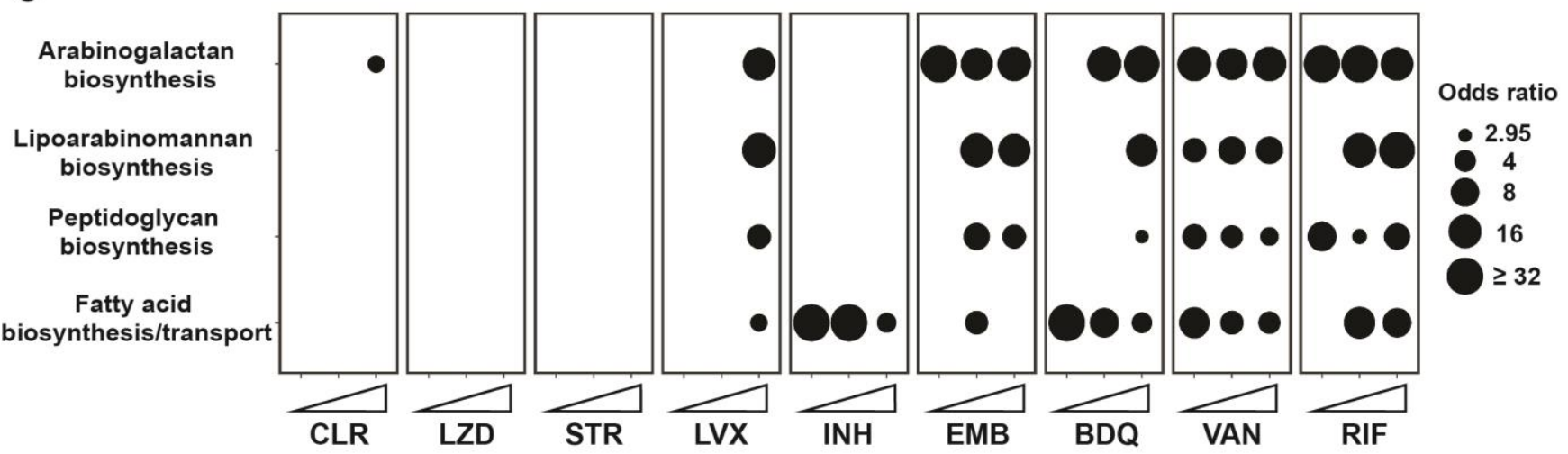

D
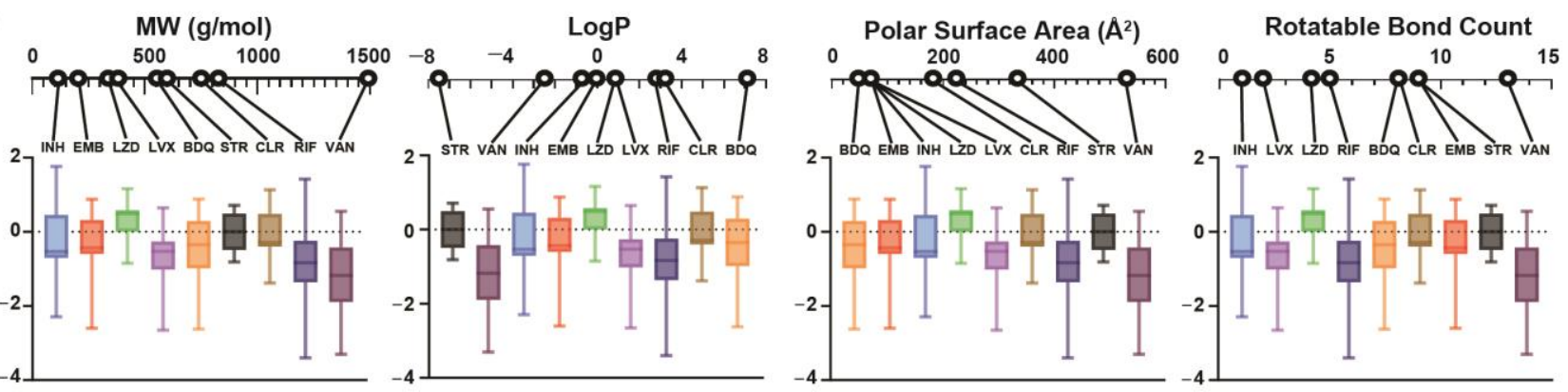

Hydrogen Bond Acceptors

Hydrogen Bond Donors

$0 \quad 10 \quad 20 \quad 30$
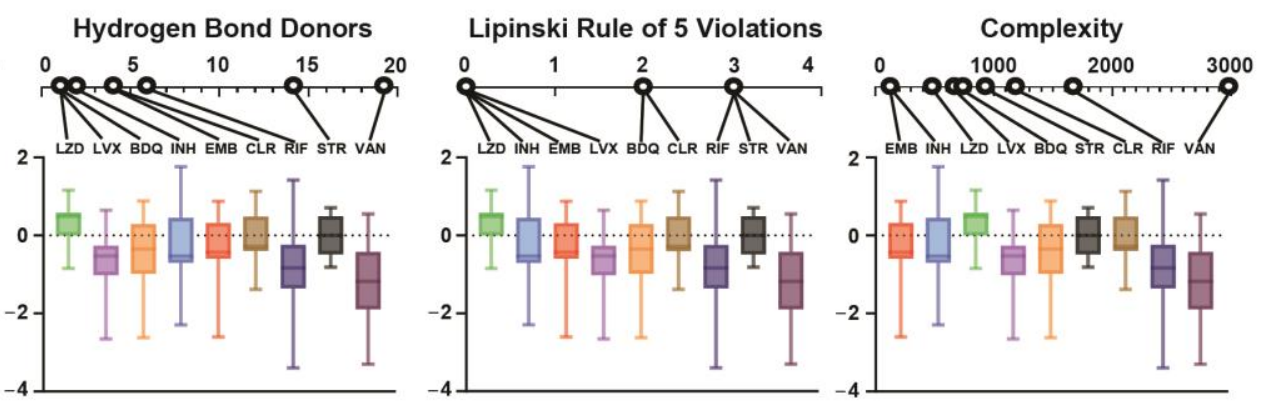

\section{Supplemental Figure 3: Clustering \& enrichment analysis of chemical-genetic profiles}

(A) Heatmap of odds-ratios showing enrichment of essential gene targeting sgRNAs as hits in the chemical-genetic screen. A Fisher exact test was used to evaluate enrichment of essential gene 
targeting sgRNAs relative to non-essential gene targeting sgRNAs amongst hit genes (FDR $<0.01$, $|\mathrm{L} 2 \mathrm{FC}|>1)$ in the chemical genetic screen.

(B) Heatmap showing clustered chemical-genetic profiles from the 5-day CRISPRi library pre-depletion screen. Genes are clustered along the vertical axis; for simplicity, only genes that hit in at least two drugs are shown ( $n=676$ genes). Ascending drug concentrations ("Low", "Med", "High" indicated by white triangles) are clustered along the horizontal axis. The median L2FC for each gene following drug selection (relative to vehicle control) is indicated on the color scale. If a gene was not a significant hit (FDR > 0.01), the L2FC value was plotted as 0 for the corresponding condition. The full dataset is available in Supplemental Data 1.

(C) Bubble plot of the enriched $(P<0.05)$ KEGG categories for hit genes for the indicated drugs. KEGG annotations were manually updated to include the mycolic acid-arabinogalactan-peptidoglycan (mAGP) complex-associated genes described in (Jankute et al., 2015; Maitra et al., 2019).

(D) Correlation of mAGP signature and physiochemical properties. For each drug, the distribution of L2FC values ("High" concentration, 5-day CRISPRi library pre-depletion) is shown for a select group of 78 genes involved in mAGP assembly and regulation as described in (Jankute et al., 2015; Maitra et al., 2019). In each plot the drugs are arranged based on their numerical value for each given

807

808

809

810

811

812

813

814

815

816

817

818

819

820

821

822

823 physiochemical property. 
A

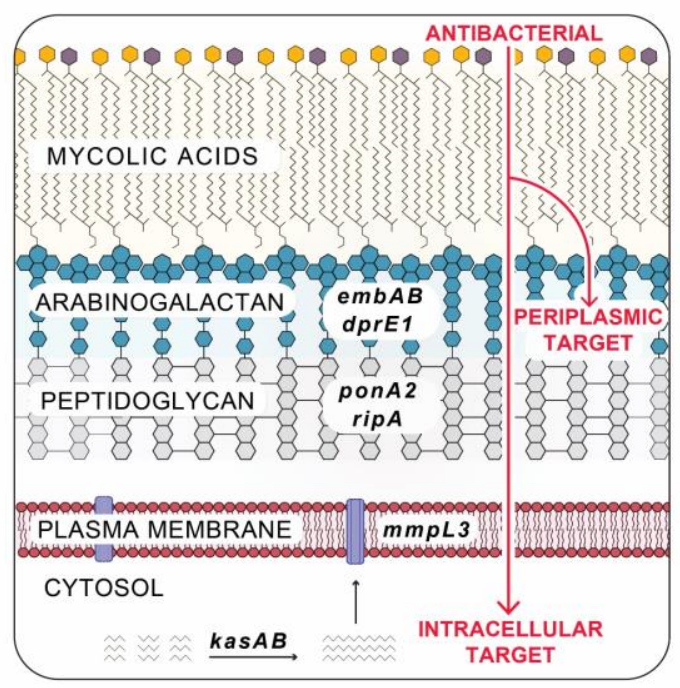

C

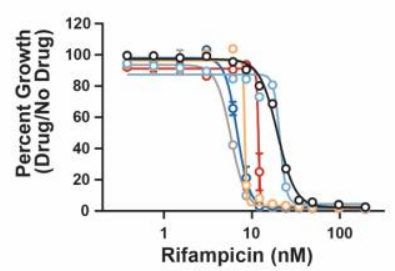

D

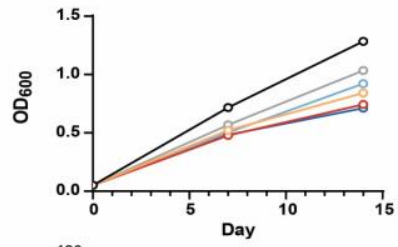

$\mathbf{F}$

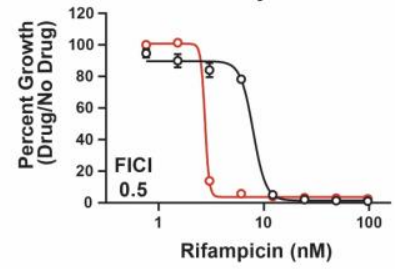

G

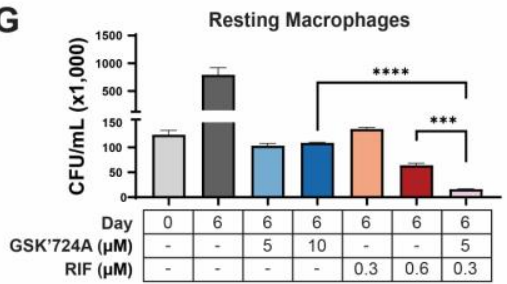

$\ldots$ k 0 asA KD

$m m p L 3 \mathrm{KD}$

- $\mathrm{e} m b B K D$

- ripA KD
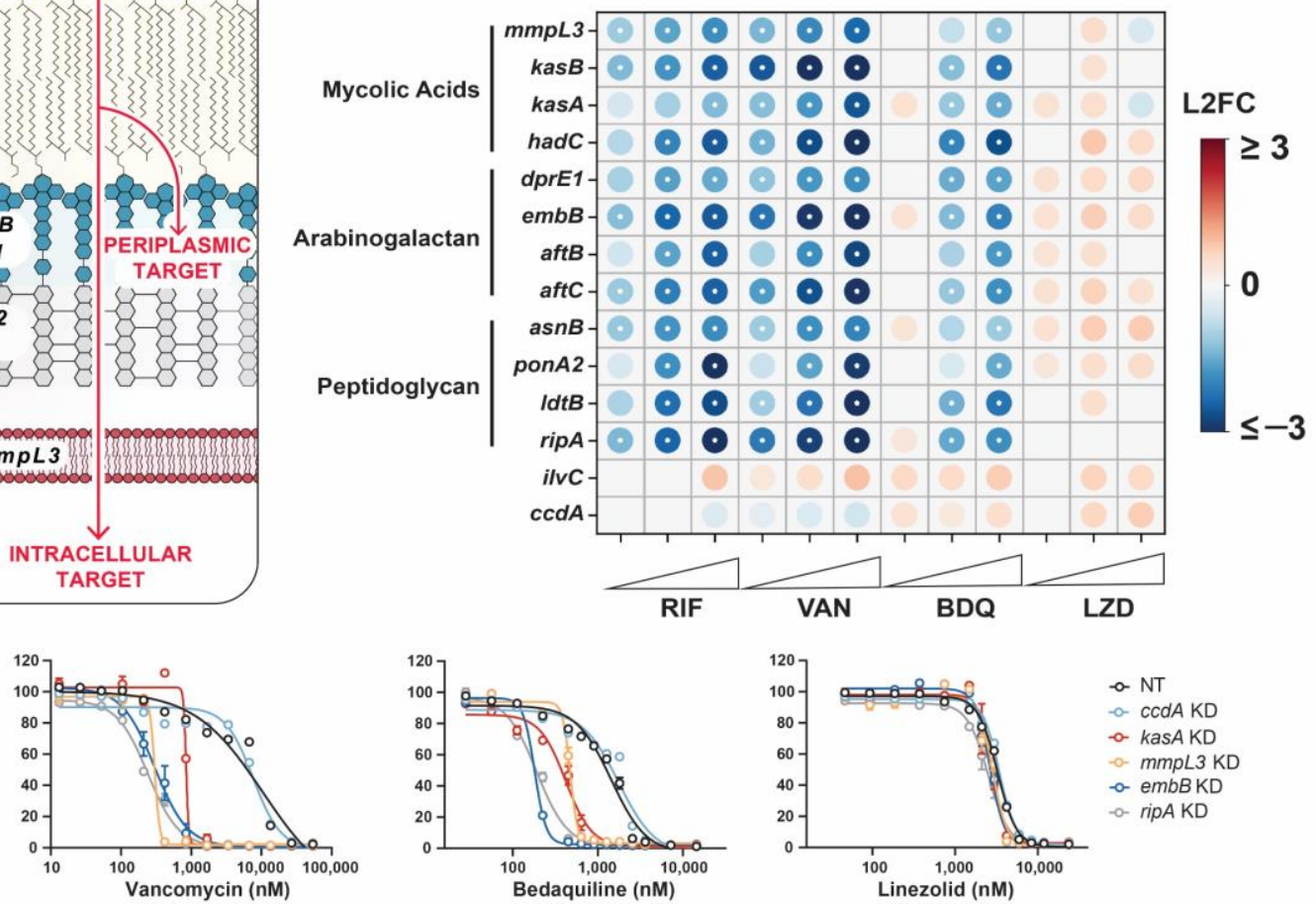

E
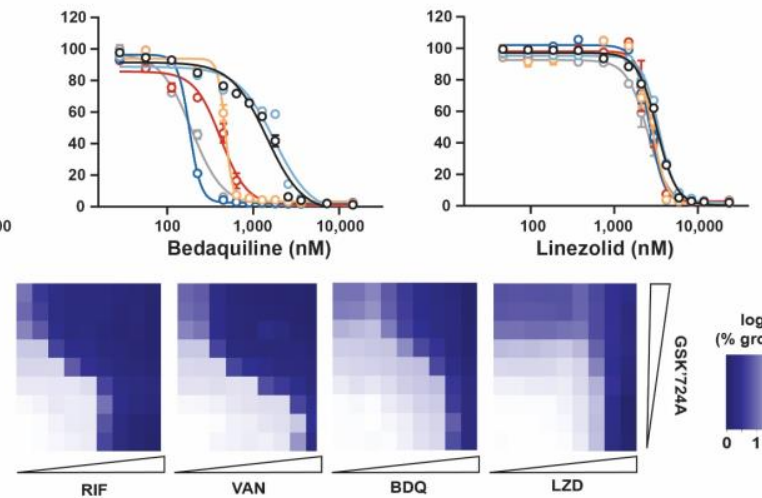

$-\mathrm{NT}$
$-\operatorname{ccd} A$

- $\operatorname{ccd}$ asA KD

- $m m p L 3 \mathrm{KD}$

- embBKD

- $\operatorname{ripA} \mathrm{KD}$
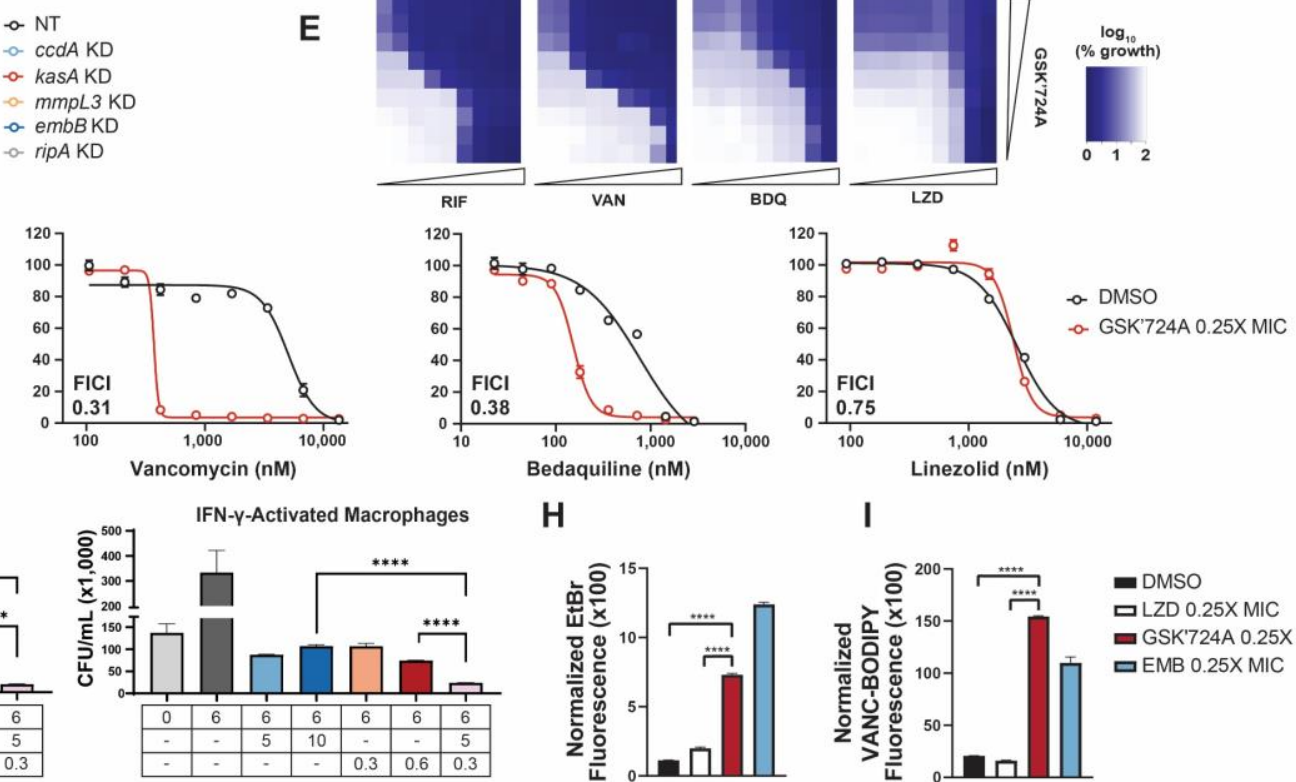

H
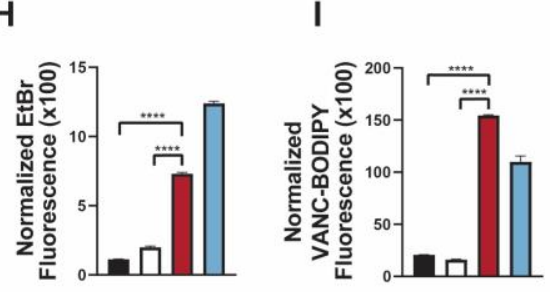

842

843

844

845

846

847

848

849

850

851

852

853

854

\section{Supplemental Figure 4: The Mtb envelope mediates intrinsic resistance to a subset of drugs}

(A) Diagram of the mycobacterial mAGP complex. Select genes involved in mycolic acid synthesis and transport (kas $A B, m m p L 3)$, arabinogalactan biosynthesis (embAB, dprE1), and peptidoglycan remodeling (ponA2, ripA) are highlighted.

(B) Feature-expression heatmap of select chemical-genetic hit genes for the indicated drugs from the 5day CRISPRi library pre-depletion screen. The color of each circle represents the gene-level L2FC. A white dot represents an FDR $<0.01$ and a $|\mathrm{L} 2 \mathrm{FC}|>1$. ilvC and $\operatorname{ccd} A$ are included as non-hit controls.

(C-D) Single strain validation of MAGP-associated hits. MIC values (C) for the indicated drugs were measured for hypomorphic CRISPRi strains targeting kasA, mmpL3, embB, ripA, and the non-hit essential gene $c c d A$. Growth curves (D) are derived from the vehicle control samples. NT corresponds to a CRISPRi strain harboring a non-targeting sgRNA. Data represent mean \pm SEM for technical triplicates. Data are representative of at least two independent experiments. KD = knockdown. 
bioRxiv preprint doi: https://doi.org/10.1101/2021.11.27.469863; this version posted November 27, 2021. The copyright holder for this preprint (which was not certified by peer review) is the author/funder, who has granted bioRxiv a license to display the preprint in perpetuity. It is made available under aCC-BY-ND 4.0 International license.

855 (E-F) KasA inhibitor (GSK'724A) checkerboard assays to quantify drug-drug interactions. MIC curves are shown for each drug in the absence (DMSO) or presence of $0.25 X \mathrm{MIC}_{80} \mathrm{GSK}^{\prime} 724 \mathrm{~A}$. The fractional inhibitory concentration index (FICl) values listed represent the lowest value obtained from each checkerboard assay. Error bars represent the SEM for technical triplicates. Data are representative of at least two independent experiments.

(G) GSK'724A synergy with rifampicin in resting and IFN-y-activated murine bone marrow derived macrophages. Mtb-infected macrophages were treated with the indicated concentrations of GSK'724A or rifampicin for 6 days prior to plating for colony forming units (CFU). Data represent mean \pm SEM for technical triplicates. Results from an unpaired t-test are shown: ${ }^{* * *}, p<0.001,{ }^{* * * *}, p<0.0001$. Data are representative of two independent experiments.

$(\mathrm{H}-\mathrm{I})$ Ethidium bromide $(\mathrm{H})$ and Vancomycin-BODIPY $(\mathrm{I})$ uptake of $\mathrm{H} 37 \mathrm{Rv}$ pre-treated for two days with DMSO or subinhibitory linezolid, GSK'724A, or ethambutol. Data represent mean \pm SEM for 4 replicates. Results from an unpaired t-test are shown: ${ }^{\star * \star}, p<0.0001$. 

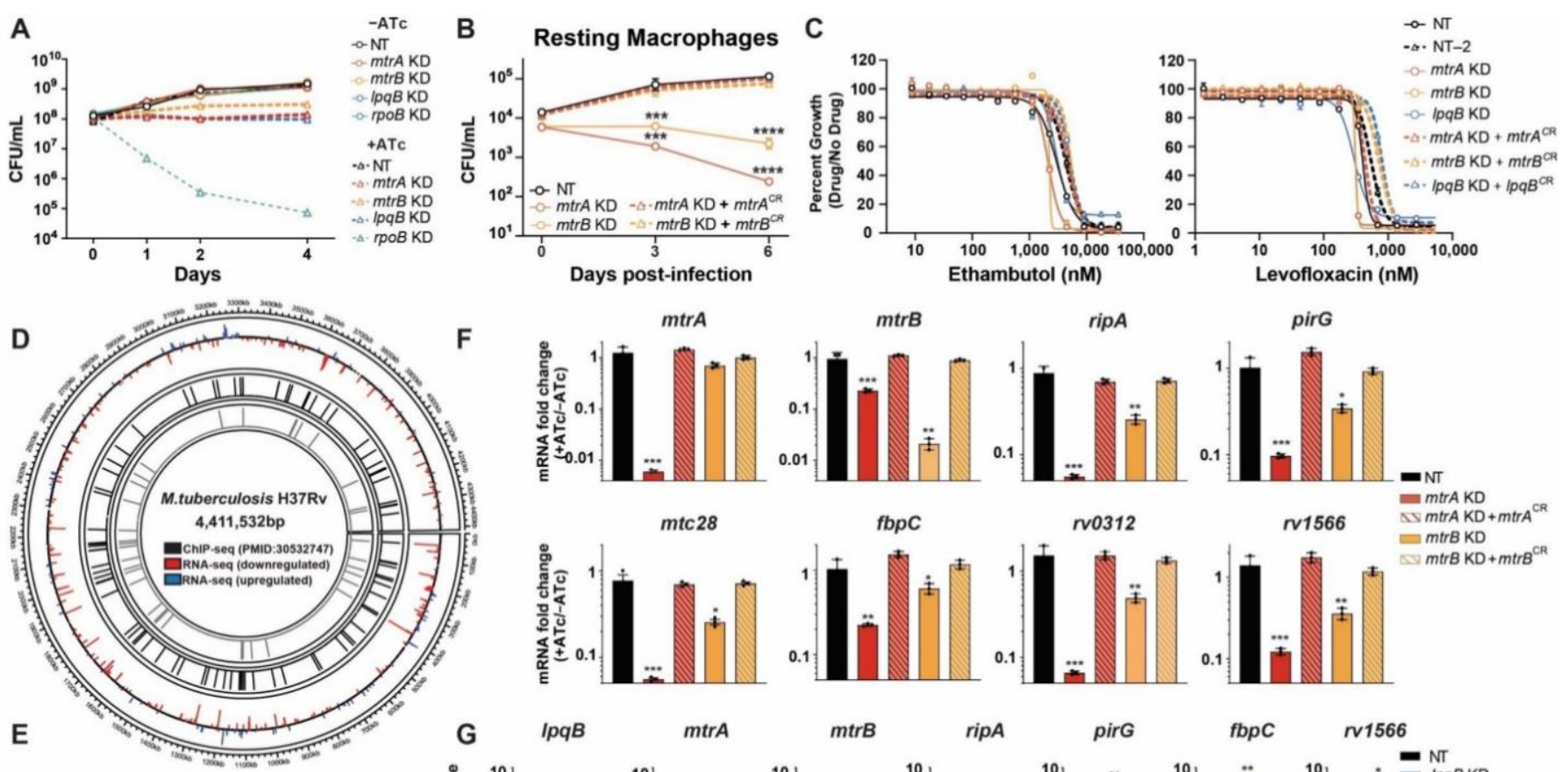

IpqB $\quad$ mtrA mtrB ripA ripA pirG

fbpc $\quad r 1566$
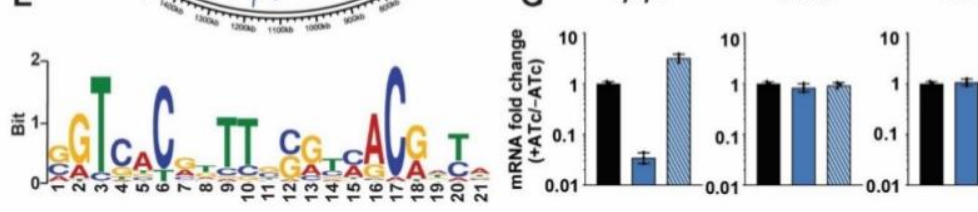

H

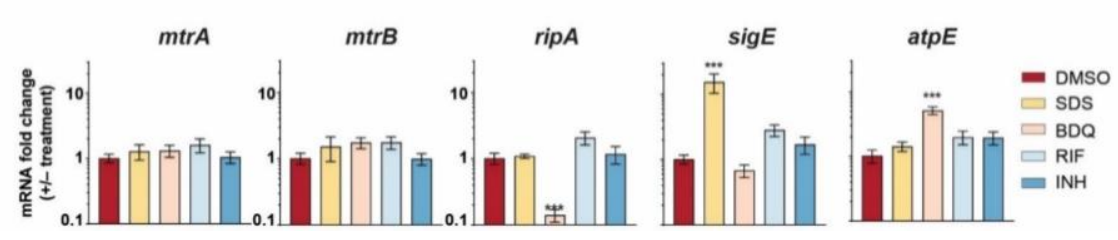

\section{Supplemental Figure 5: The MtrAB two-component system is critical for multi-drug intrinsic} resistance in Mtb

(A) Time-kill curves for the indicated CRISPRi strains. Data represent mean \pm SEM for technical triplicates. Data are representative of at least two independent experiments. NT = non-targeting; KD = knockdown; CR = CRISPRi-resistant.

882

883

(B) Growth of the indicated CRISPRi strains in resting murine bone marrow derived macrophages.

Bacterial strains were exposed to ATc $(100 \mathrm{ng} / \mathrm{mL})$ for 24 hours prior to macrophage infection. 3 and 6 days after infection, bacteria were harvested and quantified by CFU. Data represent mean \pm SEM for technical triplicates. Significance was determined by two-way ANOVA and adjusted for multiple comparisons. ${ }^{* * *}, \mathrm{p}<0.001 ;{ }^{* * * *}, \mathrm{p}<0.0001$.

(C) MIC values for the indicated drugs were measured against the indicated strains. Data represent mean \pm SEM for technical triplicates. Data are representative of at least two independent experiments.

(D) Circos plot depicting overlapping genes identified by RNA-seq (Figure 2F) and MtrA ChIP-seq (Gorla et al., 2018). Outer track: the H37Rv genome by nucleotide position; middle track: lines mark genes with a significant L2FC values (padj< 0.05) upon mtrA knockdown (blue = positive L2FC; red = negative L2FC); inner tracks: black lines mark genes defined as interacting with MtrA by ChIP-seq (Gorla et al., 2018), and grey lines highlight genes which display both a significant L2FC (padj< 0.05 ; $|\mathrm{L} 2 \mathrm{FC}|>1$ ) by mtrA RNAseq and are found to interact with MtrA by ChIP-seq.

(E) Identification of an MtrA consensus binding motif. MEME analysis (Bailey et al., 2009) was performed on the promoter regions of candidate genes found to both be downregulated upon mtrA silencing (Figure 2F) and bound by MtrA by ChIP-seq (Gorla et al., 2018) ( $\mathrm{n}=25$ genes).

$(F, G)$ Quantification of indicated gene mRNA levels by qRT-PCR. Strains were grown in the presence of ATc for $\sim 3$ generations prior to harvesting RNA. Error bars are SEM of three technical replicates. 
bioRxiv preprint doi: https://doi.org/10.1101/2021.11.27.469863; this version posted November 27, 2021. The copyright holder for this preprint (which was not certified by peer review) is the author/funder, who has granted bioRxiv a license to display the preprint in perpetuity. It is made available under aCC-BY-ND 4.0 International license.

Statistical significance was calculated as $p$-value with unpaired T-test. *, $p<0.05 ;{ }^{* *}, p<0.01 ;{ }^{* \star *}$, $\mathrm{p}<0.001$.

(H) Quantification of indicated gene mRNA levels by qRT-PCR. Wild-type H37Rv was grown in the presence of the indicated stress (RIF/BDQ/INH: $4 \times I_{50}$, SDS: $0.2 \%$, DMSO: $0.5 \%$ ) for 3 hours prior to harvesting RNA. Error bars are SEM of three technical replicates. Statistical significance was calculated as $p$-value with unpaired T-test. ${ }^{* \star *}, p<0.001$. 
A

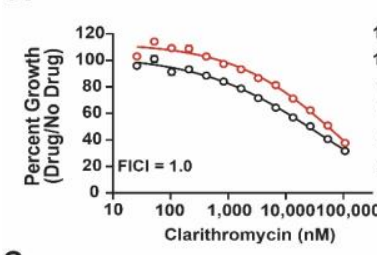

C

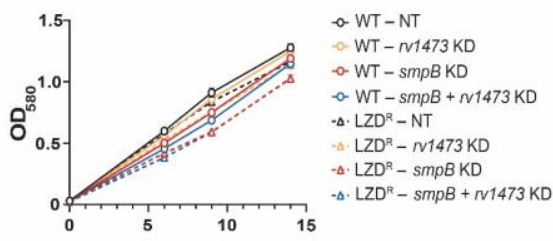

D

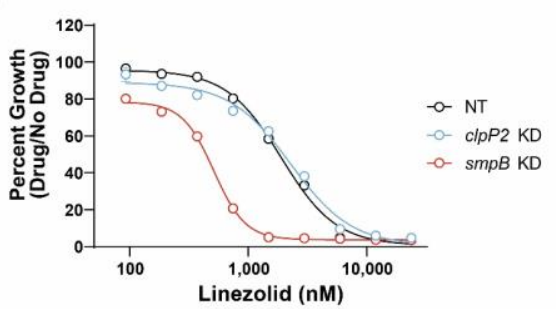

E

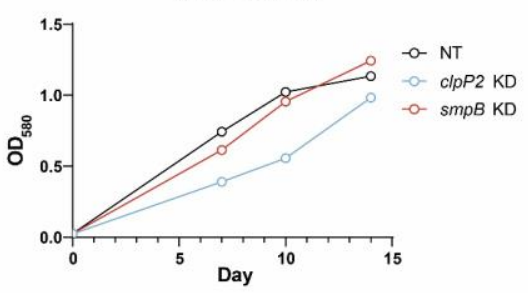

G

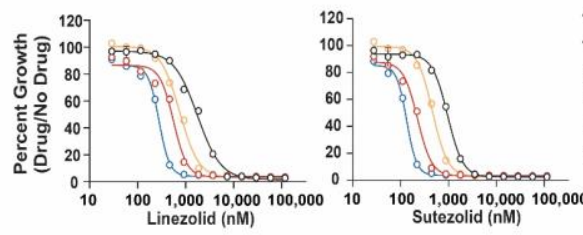

B

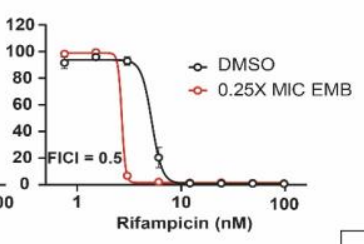

906

907

908

909

910

911

912

913

914

915

916

917

918

919

920

921

922

923

924

925

926

Supplemental Figure 6: Mtb encodes diverse mechanisms of intrinsic resistance to ribosometargeting antibiotics
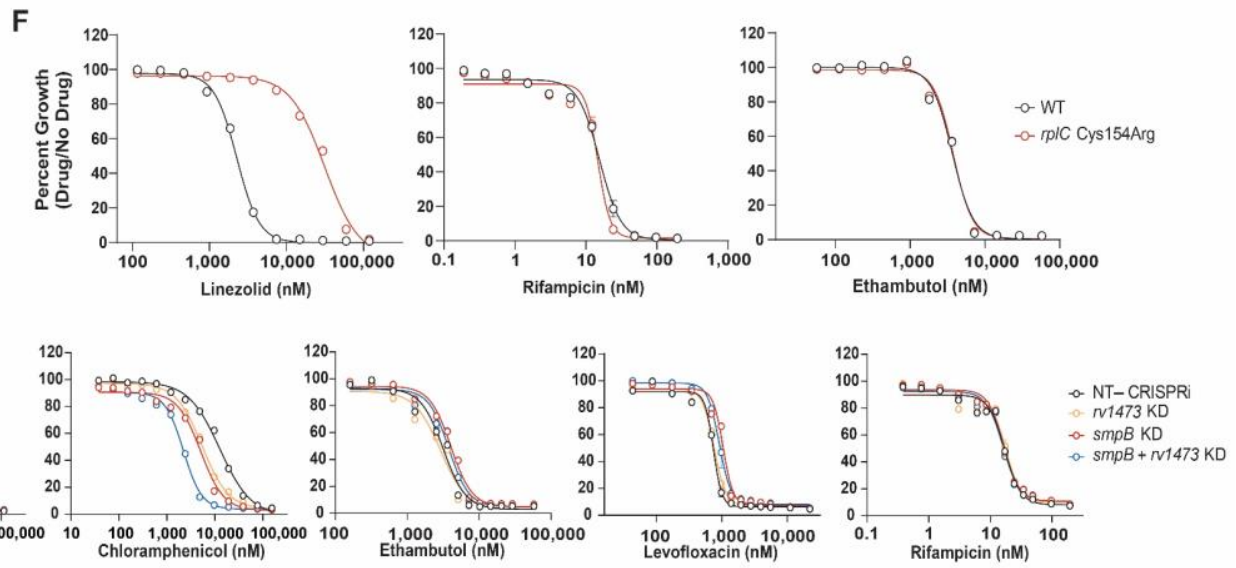
(A) Ethambutol checkerboard assays to quantify drug-drug interactions. MIC curves are shown for each drug in the absence (DMSO) or presence of $0.25 \mathrm{X} \mathrm{MIC}_{80}$ of EMB. Fractional inhibitory concentration index (FICl) values listed represent the lowest value obtained from each checkerboard assay. Data represent mean \pm SEM for technical triplicates.

(B) Phylogenetic tree of antibiotic resistance (ARE) ABC-F proteins from the indicated species. Figure adapted from (Sharkey et al., 2016). Bootstrap values (500 replicates) are indicated at each node.

(C) Growth curves for the LZD-associated hit genes and control strains shown in Figure 3D. Curves are derived from the vehicle control samples of the MIC assay. Data represent mean \pm SEM for technical triplicates. Results are representative data from at least two independent experiments. NT = nontargeting; KD = knockdown.

(D) MIC values for LZD were measured for CRISPRi knockdown strains targeting smpB and $c / p P 2$ in wildtype H37Rv. Data represent mean \pm SEM for technical triplicates.

(E) Growth curves for the strains shown in (D). Curves are derived from the vehicle control samples of the MIC assay. Data represent mean \pm SEM for technical triplicates.

(F) MIC curves of WT H37Rv and an isogenic rp/C-Cys154Arg mutant for LZD, RIF, and EMB. Data represent mean \pm SEM for six technical replicates.

(G) MIC values for the indicated drugs were measured for the indicated CRISPRi strains. Data represent mean \pm SEM for technical triplicates. 
bioRxiv preprint doi: https://doi.org/10.1101/2021.11.27.469863; this version posted November 27, 2021. The copyright holder for this preprint (which was not certified by peer review) is the author/funder, who has granted bioRxiv a license to display the preprint in perpetuity. It is made available under aCC-BY-ND 4.0 International license.

\section{A}
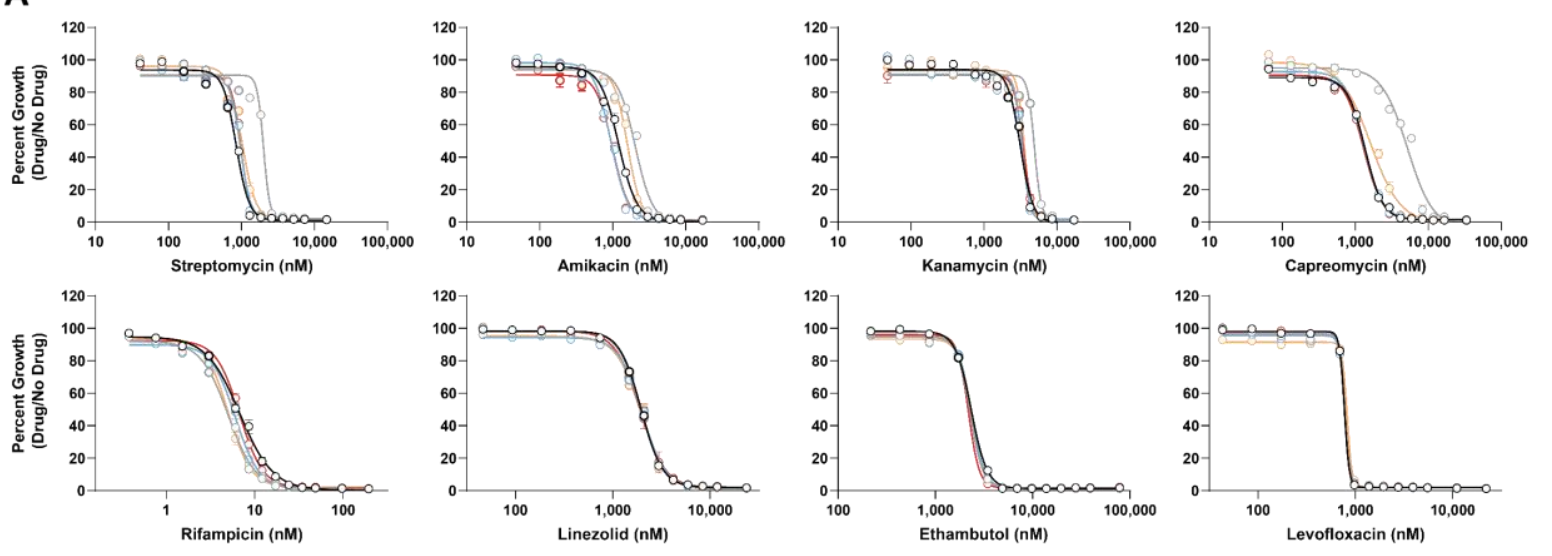

$W T+E V$

bacA KO + bacA WT

bacA KO + bacA Val118Ala

B
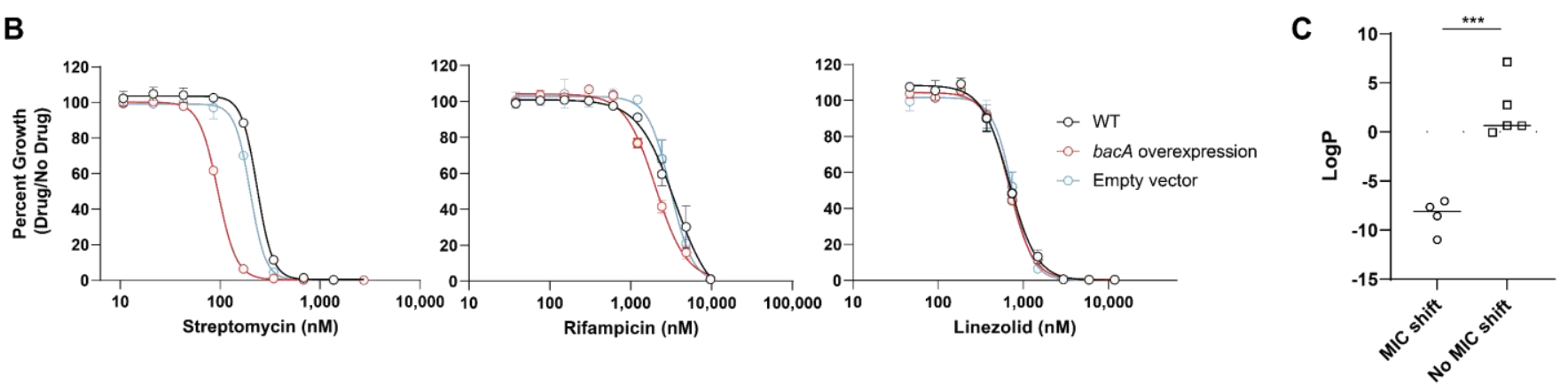

\section{Supplemental Figure 7: Loss-of-function mutations in bacA confer resistance to aminoglycosides} and capreomycin

(A) MIC values for the indicated drugs were measured for the indicated strains. Data represent mean \pm SEM for technical triplicates. Results are representative data from at least two independent experiments.

(B) Overexpression of Mtb bacA confers streptomycin sensitivity in M. smegmatis. MIC values for the indicated drugs were measured for the three indicated strains. Data represent mean $\pm \mathrm{SEM}$ for technical triplicates.

(C) LogP values for the antibiotics to which bacA mutants show an increased MIC (STR, AMK, CAP, KAN) or no MIC change (RIF, EMB, LVX, LZD). Results from an unpaired t-test are shown: ${ }^{* \star *}$, 
bioRxiv preprint doi: https://doi.org/10.1101/2021.11.27.469863; this version posted November 27, 2021. The copyright holder for this preprint (which was not certified by peer review) is the author/funder, who has granted bioRxiv a license to display the preprint in perpetuity. It is made available under aCC-BY-ND 4.0 International license.

A

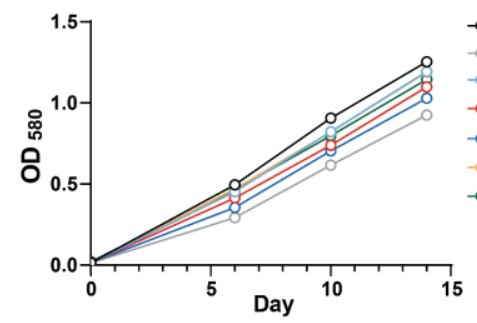

B

- - NT + EV

ettA KD + EV

ettA KD + ettA ${ }^{\mathrm{CR}} \mathrm{WT}$

- ettA KD + ettA ${ }^{\mathrm{CR}} \mathrm{Gly} 41 \mathrm{Glu}$

- ettA KD + ettA ${ }^{\mathrm{CR}}$ Trp135Gly

ettA KD + ettA ${ }^{C R}$ Val426Met

- ettA KD + ettA ${ }^{C R}$ Val426Ala
M. tuberculosis (P9WQK3) Y P G A I G VVG P NG:AGK S S VLR E. coli (P0A9W3) F P G AK I G V L G L NGA GKS T L L R c. diptheriae (A0A1J5XJ55) Y P G A K I G V VG P NG:A G K S S I L K

s. coelicolor (A0A6M9XLQ6) L P G AK I GVVGP NG: A GKS T V L K

s. pyogenes (WP_136296549.1) H D F D R I G I I G V NG T G K T T L L D

P. aeruginosa (A0A1C7BHV9) F P G AK I G V L G L NG: A G K S T L L R

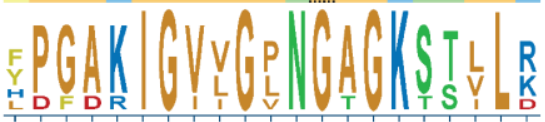

C
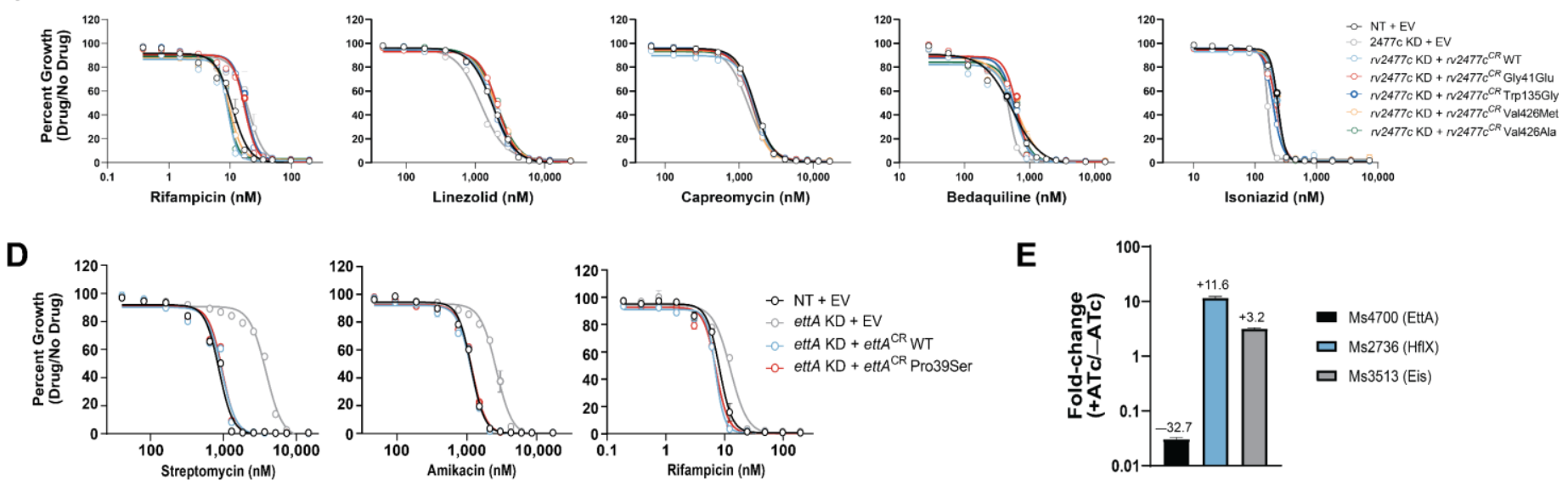

$\mathbf{F}$

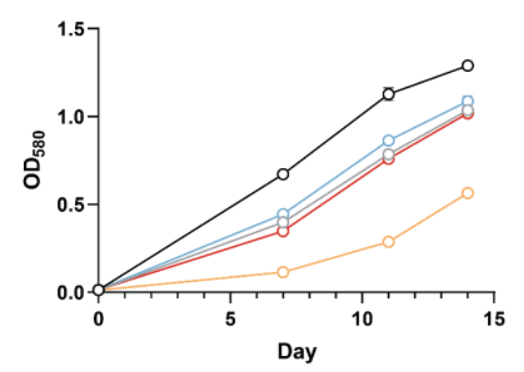

- NT

ettA KD

ettA + whiB7 KD

$-0-$ ettA + tap KD

-0 ettA + eis KD

\section{Supplemental Figure 8: Partial loss-of-function mutations in ettA confer low-level multidrug} resistance and are associated with an MDR outbreak in South America
(A) Growth curves for the strains shown in Figure 5C. Curves are derived from the vehicle control samples of the MIC assay. Data represent mean \pm SEM for technical triplicates. Results are representative data from at least two independent experiments.

(B) Amino acid alignment for EttA orthologs from the indicated species for the region surrounding the $\mathrm{N}$ terminal Walker A motif. The Mtb EttA Gly41 residue is boxed. Accession numbers are listed next to each species.

(C) MIC values for the indicated drugs were measured for the strains shown in Figure 5C. Data represent mean \pm SEM for technical triplicates. Results are representative data from at least two independent experiments.

(D) The Pro39Ser mutation in ettA does not confer antibiotic resistance. MIC values for the indicated drugs were measured as in Figure $5 \mathrm{C}$. Data represent mean \pm SEM for technical triplicates.

(E) Quantitative mass spectrometry results from experiments described in (Bosch et al., 2021). Values indicate protein level fold-change following CRISPRi knockdown of $m s 4700$. Data represent mean \pm SEM four technical replicates derived from two biological replicates. Ms4700 could only be detected in two replicates and, thus, the mean \pm SEM for duplicates is shown.

964 Growth curves for the strains shown in Figure 5E. Curves are derived from the vehicle control samples of the MIC assay. Data represent the mean \pm SEM for technical triplicates. 
bioRxiv preprint doi: https://doi.org/10.1101/2021.11.27.469863; this version posted November 27, 2021. The copyright holder for this preprint (which was not certified by peer review) is the author/funder, who has granted bioRxiv a license to display the preprint in perpetuity. It is made available under aCC-BY-ND 4.0 International license.

A
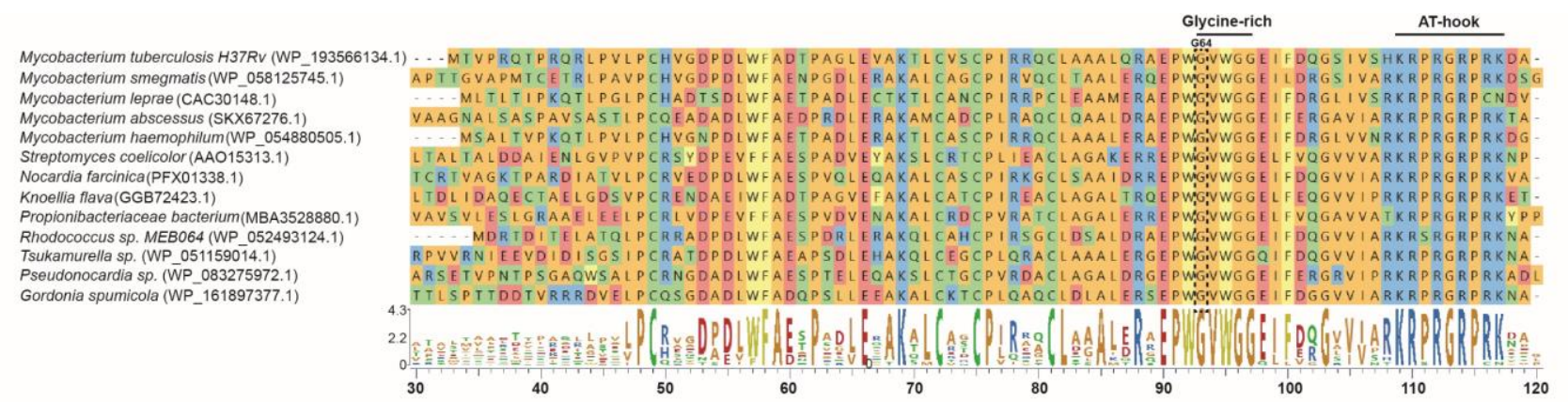

B
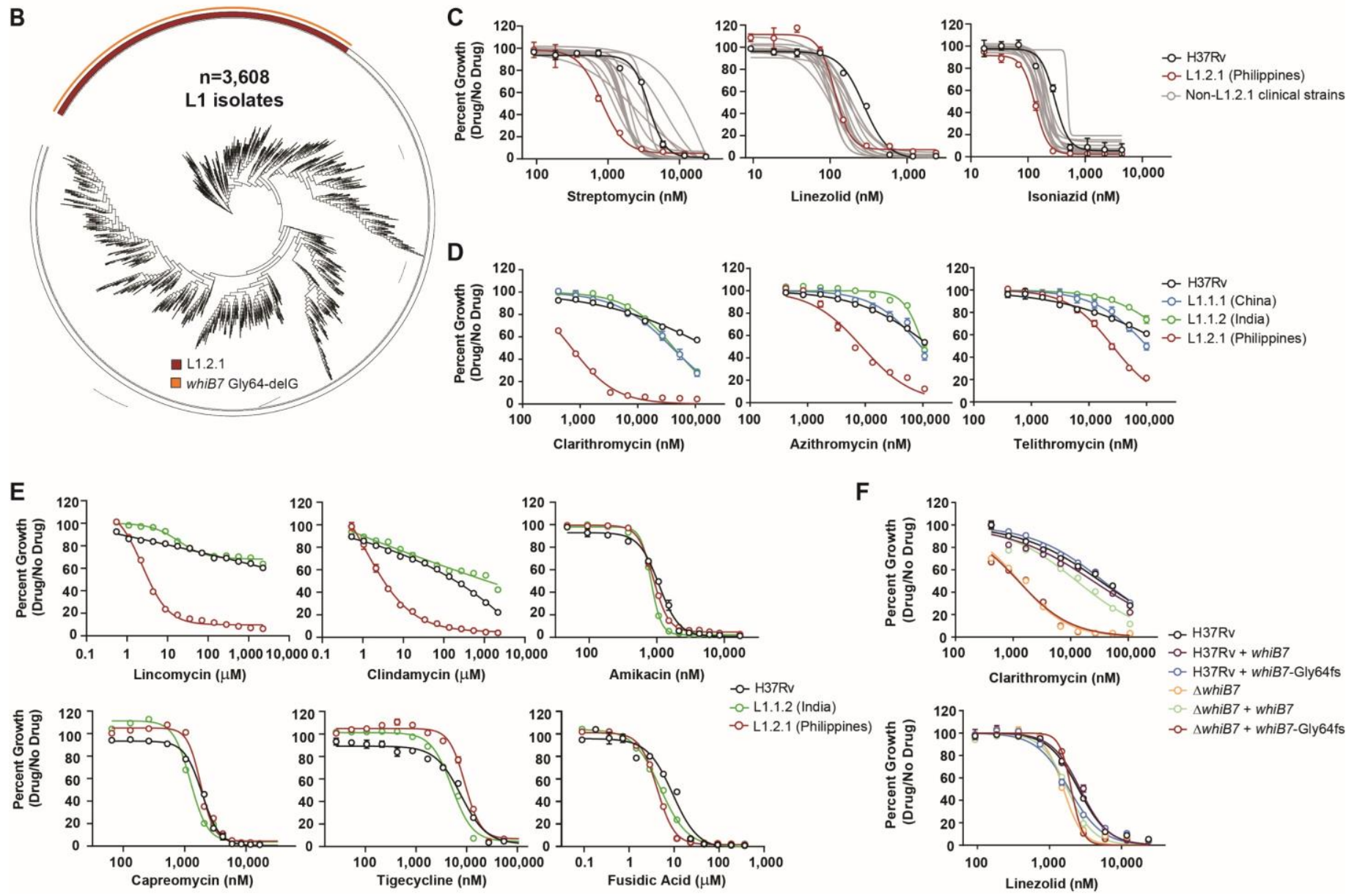

L1.2.1 (Philippines) - Non-L1.2.1 clinical strains

\section{Supplemental Figure 9: The L1.2.1 sub-lineage has a loss-of-function mutation in whiB7 that} renders it hypersusceptible to macrolides, ketolides, and lincosamides

(A) Alignment of WhiB7 orthologues from representative actinobacteria. Accession numbers are listed next to each species. The conserved glycine-rich motif and DNA binding AT-hook element are highlighted.

(B) Phylogenetic tree of all L1 Mtb clinical isolates $(n=3,608)$ in our WGS database (Supplemental Data 4). L1.2.1 and the whiB7 Gly64delG mutation are highlighted.

(C-E) MIC values the indicated drugs were measured for a reference set of Mtb clinical strains. Error bars represent the standard error of the mean (SEM) for technical triplicates. Results are representative data from at least two independent experiments.

(F) H37Rv was transformed with an integrating plasmid to express either the H37Rv whiB7 allele or the L1.2.1 whiB7 Gly64-delG allele in trans from its native promoter. The resulting strains were then used to measure MIC values for the indicated drugs. Error bars represent the SEM for technical triplicates. Results are representative data from at least two independent experiments. 
bioRxiv preprint doi: https://doi.org/10.1101/2021.11.27.469863; this version posted November 27, 2021. The copyright holder for this preprint (which was not certified by peer review) is the author/funder, who has granted bioRxiv a license to display the preprint in perpetuity. It is made available under aCC-BY-ND 4.0 International license.
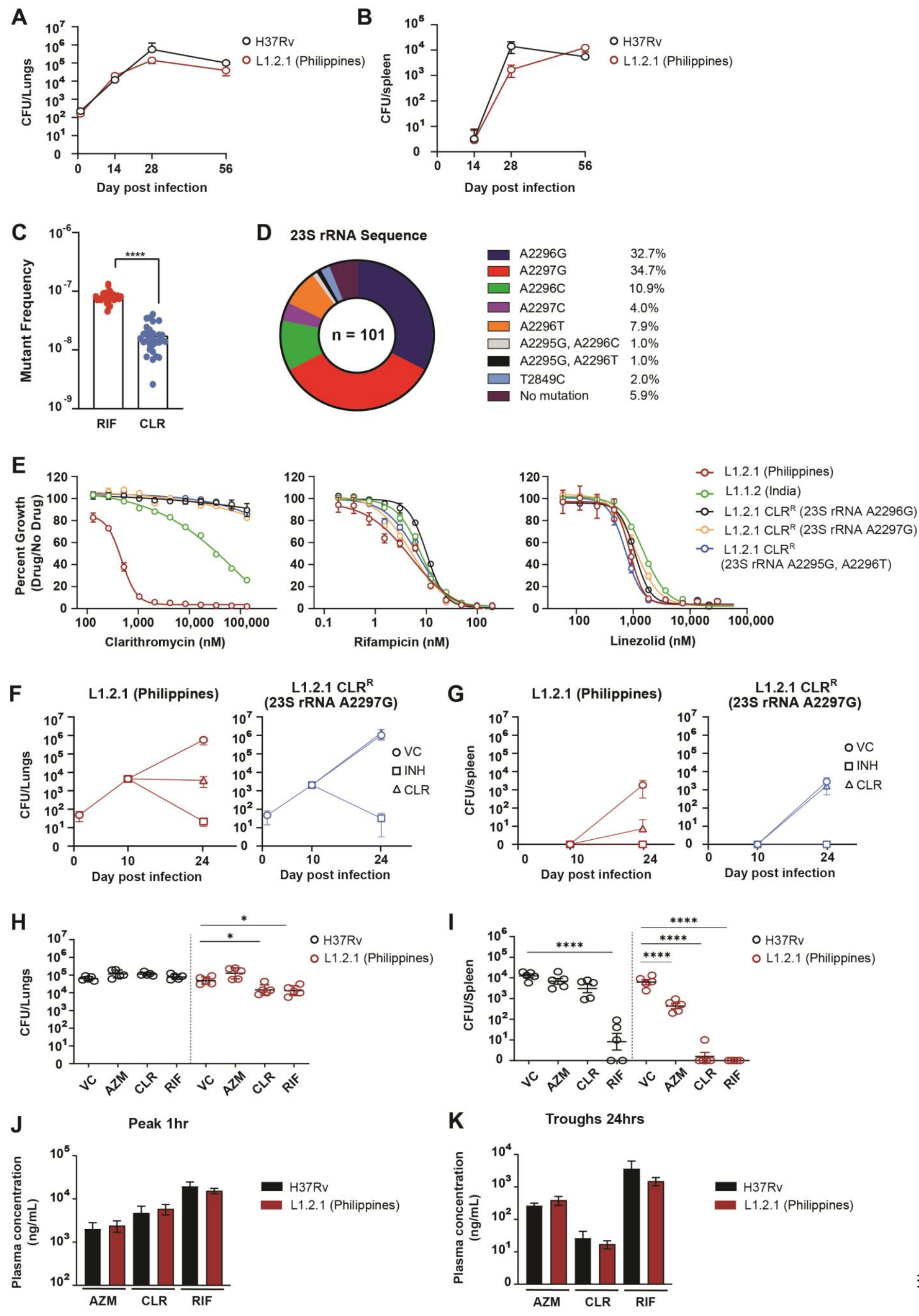
bioRxiv preprint doi: https://doi.org/10.1101/2021.11.27.469863; this version posted November 27, 2021. The copyright holder for this preprint (which was not certified by peer review) is the author/funder, who has granted bioRxiv a license to display the preprint in perpetuity. It is made available under aCC-BY-ND 4.0 International license.

984 Supplemental Figure 10: The L1.2.1 sublineage is susceptible to clarithromycin in vivo

$(A, B)$ Growth kinetics of H37Rv and L1.2.1 in vivo. BALB/c mice were infected with approximately 100200 CFU by aerosol and killed over the course of infection at indicated time points. Mean lung $(A)$ and spleen (B) Mtb CFU ( \pm SEM) in BALB/c mice were determined after primary infection

(C) Rifampicin and clarithromycin mutation frequency analysis with the L1.2.1 strain.

(D) Distribution of 23S rRNA mutations from in vitro-selected, clarithromycin-resistant L1.2.1 isolates from panel $(\mathrm{C})$.

(E) MIC profiles of representative CLR-resistant L1.2.1 isolates. Error bars represent the standard error of the mean (SEM) for technical triplicates. Results are representative data from at least two independent experiments.

$(F, G)$ Mean lung $(F)$ and spleen $(G)$ Mtb CFU ( \pm SEM) in BALB/c mice after isoniazid (INH; $25 \mathrm{mg} / \mathrm{kg})$, or clarithromycin (CLR; $200 \mathrm{mg} / \mathrm{kg}$ ) treatment. Mice were infected with approximately 100-200 CFU of aerosolized Mtb. After ten days to allow the acute infection to establish, chemotherapy was initiated. Mtb bacterial load of lungs and spleen were determined at the indicated time points. VC = vehicle control. CLR $^{\mathrm{R}}=$ clarithromycin-resistant.

$(\mathrm{H}, \mathrm{I})$ Mean lung $(\mathrm{F})$ and spleen $(\mathrm{G})$ Mtb colony-forming units (CFU; $\pm \mathrm{SEM})$ in BALB/c mice after azithromycin (AZM; $200 \mathrm{mg} / \mathrm{kg}$ ), clarithromycin (CLR; $200 \mathrm{mg} / \mathrm{kg}$ ), or rifampicin (RIF; $25 \mathrm{mg} / \mathrm{kg}$ ) treatment. Mice were infected with approximately 100-200 CFU of aerosolized Mtb. After two weeks to allow the acute infection to establish, chemotherapy was initiated. Following two weeks of drug therapy, Mtb bacterial load of lungs and spleen were determined. Statistical significance was assessed by one-way ANOVA followed by Tukey's post-hoc test. ${ }^{*}, p<0.05$; ${ }^{* \star *}, p<0.0001$.

$(\mathrm{J}, \mathrm{K})$ Monitoring of plasma drug concentrations after 2 weeks of therapy, prior to CFU enumeration in lungs and spleen. Blood was collected at $1 \mathrm{~h}(\mathrm{~J})$ and $24 \mathrm{~h}(\mathrm{~K})$ post-dose after 13 daily doses, from 4 mice in each infection and treatment group described in $(\mathrm{H}, \mathrm{I})$. Drug concentrations were measured in plasma using high pressure liquid chromatography coupled to tandem mass spectrometry. Mean and standard deviation (error bars) are shown. 
bioRxiv preprint doi: https://doi.org/10.1101/2021.11.27.469863; this version posted November 27, 2021. The copyright holder for this preprint (which was not certified by peer review) is the author/funder, who has granted bioRxiv a license to display the preprint in perpetuity. It is made
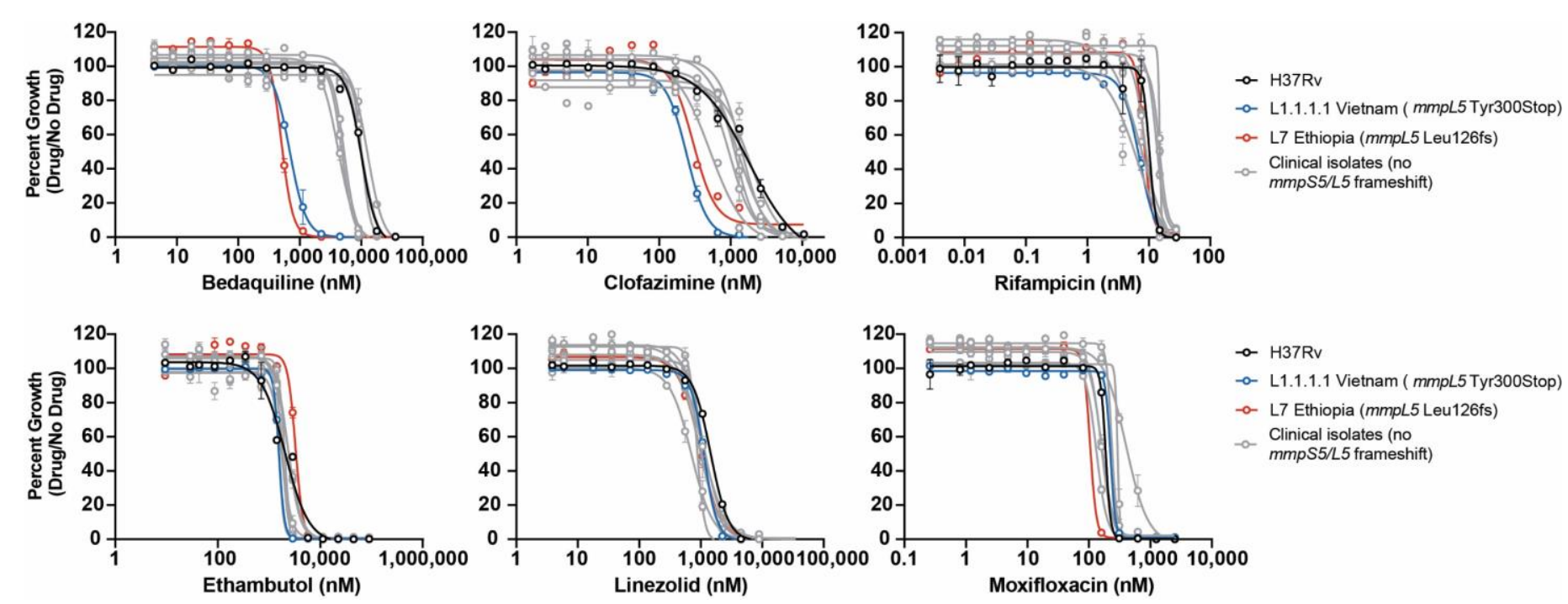

Supplemental Figure 11: Loss-of-function mutations on MmpL5 renders it sensitive to Bedaquiline and Clofazimine

MIC values the indicated drugs were measured for a reference set of Mtb clinical strains. Error bars represent the standard error of the mean (SEM) for technical triplicates. Results are representative data from at least two independent experiments. 
bioRxiv preprint doi: https://doi.org/10.1101/2021.11.27.469863; this version posted November 27, 2021. The copyright holder for this preprint (which was not certified by peer review) is the author/funder, who has granted bioRxiv a license to display the preprint in perpetuity. It is made available under aCC-BY-ND 4.0 International license.

\section{SUPPLEMENTAL INFORMATION}

Supplemental Table 1: List of plasmids and primers used in this work

\section{Plasmids used in this work}

\begin{tabular}{|c|c|c|c|c|c|}
\hline $\begin{array}{l}\text { Fig. } \\
\text { used }\end{array}$ & $\begin{array}{l}\text { Plasmid } \\
\text { Name }\end{array}$ & $\begin{array}{c}\text { Plasmid } \\
\text { genotype }\end{array}$ & Plasmid description & Plasmid Map & $\begin{array}{l}\text { Resistance } \\
\text { marker }\end{array}$ \\
\hline $\begin{array}{l}2,3,4,5.54 \\
\text { S5, S6, } \\
\text { S7,S8, } \\
\text { S9,S10 }\end{array}$ & pIRL58 & $\begin{array}{l}\text { Ptet(gB73)-Sth1 } \\
\text { dCas9 Ptet(gB52)- } \\
\text { Sth1 sgRNA } \\
\text { P(gB37)- } \\
\text { TetRCO(tetON) L5 } \\
\text { attP only v1::Kan } \\
\end{array}$ & $\begin{array}{l}\text { Sth1 dCas9 CRISPRi plasmid } \\
\text { optimized for use in M. tuberculosis. } \\
\text { Sth1 dCas9 and the sgRNA are } \\
\text { induced in the presence of ATc. This } \\
\text { plasmid lacks the full L5 integrase and } \\
\text { must be co-transformed plRL19 }\end{array}$ & $\begin{array}{l}\text { https://benchling.com/s/seq- } \\
\text { Gv9EfPn1vM7OMu6HPyU3 }\end{array}$ & Kanamycin \\
\hline $\begin{array}{l}2,3,4,5.54 \\
\text { S5, S6, } \\
\text { S7,S8, } \\
\text { S9,S10 }\end{array}$ & pIRL19 & $\begin{array}{l}\text { Pmop-L5 Int AmpR } \\
\text { (suicide plasmid) }\end{array}$ & $\begin{array}{l}\text { The L5 phage Int protein is expressed } \\
\text { from the mycobacterial optimized } \\
\text { promoter (MOP). This backbone is } \\
\text { non-replicating and non-integrating in } \\
\text { mycobacteria. }\end{array}$ & $\begin{array}{l}\text { https://benchling.com/s/seq- } \\
\text { BAF0JelwBQN6D2dw5alf }\end{array}$ & Ampicillin \\
\hline 2, S5, S9 & plRL60 & $\begin{array}{l}\text { pDE43-MCZtq26 } \\
\text { Tweety attP::Zeo } \\
\text { (empty vector) }\end{array}$ & $\begin{array}{l}\text { Tweety::Zeo integration backbone. } \\
\text { Contrains the Tweety Int with a zeocin } \\
\text { resistance cassette. }\end{array}$ & $\begin{array}{l}\text { https://benchling.com/s/seq- } \\
\text { s6M31jHfAUSXmCl90JQc }\end{array}$ & $\begin{array}{c}\text { Chloramphenicol } \\
\text { Zeocin }\end{array}$ \\
\hline $2, \mathrm{~S} 5$ & plRL141 & $\begin{array}{l}\text { pIRL60-PmtrA- } \\
\text { mtrB Tweety } \\
\text { attP::Zeo }\end{array}$ & $\begin{array}{l}\text { CRISPRi resistant allele of the mtrB } \\
\text { ORF under the expression of the } \\
\text { endogenous mtrA promoter ( } 300 \mathrm{bp} \\
\text { upstream of the mtrA translational start } \\
\text { site). Cloned by Gibson assembly into } \\
\text { EcoRV and Xbal-digested pIRL60. }\end{array}$ & $\begin{array}{l}\text { https://benchling.com/s/seq- } \\
\text { BaNN2970G1ukBaFnqZ3b }\end{array}$ & $\begin{array}{c}\text { Chloramphenicol } \\
\text { Zeocin }\end{array}$ \\
\hline 2, S5 & plRL142 & $\begin{array}{l}\text { pIRL60-Phsp60- } \\
\text { IpqB Tweety } \\
\text { attP::Zeo }\end{array}$ & $\begin{array}{l}\text { CRISPRi resistant allele of the IpqB } \\
\text { ORF under the expression of the hsp60 } \\
\text { promoter.. Cloned by Gibson assembly } \\
\text { into EcoRV and Xbal-digested pIRL60. }\end{array}$ & $\begin{array}{l}\text { https://benchling.com/s/seq- } \\
\text { n98842nj4uVFdah5COhw }\end{array}$ & $\begin{array}{c}\text { Chloramphenicol } \\
\text { Zeocin }\end{array}$ \\
\hline 4,5, S7, S8 & plRL133 & $\begin{array}{l}\text { pIRL133 Giles } \\
\text { attP::Zeo (empty } \\
\text { vector) }\end{array}$ & $\begin{array}{l}\text { Vector used for bacA and ettA } \\
\text { experiments. Integrating vector } \\
\text { containing the Giles attP site and } \\
\text { expressing a zeocin resistnace casstte. } \\
\text { Must be co-transformed with pIRL } 40 \text {. } \\
\text { Contains barcode random barcode } \\
\text { sequence AAATAAAAACCACTCTCC }\end{array}$ & $\begin{array}{l}\text { https://benchling.com/s/seq- } \\
\text { m7KsnT49GbAKHZOruvjn }\end{array}$ & Zeocin \\
\hline $4, S 7$ & pINP411 & $\begin{array}{l}\text { pIRL133-Phsp60- } \\
\text { bacA WT Giles } \\
\text { attP::Zeo }\end{array}$ & $\begin{array}{l}\text { pIRL133 backbone expressing the WT } \\
\text { bacA allele under the hsp60 promoter. } \\
\text { Contains random barcode sequence } \\
\text { TCGGGAATTCTCACGCGT }\end{array}$ & $\begin{array}{l}\text { https://benchling.com/s/seq- } \\
\text { xm930WSRuZg57YePOv6V }\end{array}$ & Zeocin \\
\hline 4 & pINP412 & $\begin{array}{l}\text { pIRL133-Phsp60- } \\
\text { bacA Trp153Ser } \\
\text { Giles attP::Zeo }\end{array}$ & $\begin{array}{l}\text { plRL133 backbone expressing the } \\
\text { Trp153Ser bacA allele under the hsp60 } \\
\text { promoter. Contains random barcode } \\
\text { sequence ATCAGTGTTTCATACAAG }\end{array}$ & $\begin{array}{l}\text { https://benchling.com/s/seq- } \\
\text { xSOHjAjil3meB6dNLvRZ }\end{array}$ & Zeocin \\
\hline 4 & pINP413 & $\begin{array}{l}\text { pIRL133-Phsp60- } \\
\text { bacA Tyr288Stop } \\
\text { Giles attP::Zeo }\end{array}$ & $\begin{array}{l}\text { pIRL133 backbone expressing the } \\
\text { Tyr288Stop bacA allele under the } \\
\text { hsp60 promoter. Contains random } \\
\text { barcode sequence } \\
\text { GCCGTTTGGGACTCGTCT }\end{array}$ & $\begin{array}{l}\text { https://benchling.com/s/seq- } \\
\text { wc5ZxwPFHxRtKA64bRKt }\end{array}$ & Zeocin \\
\hline S7 & pINP415 & $\begin{array}{l}\text { pIRL133-Phsp60- } \\
\text { bacA Asp546Ala } \\
\text { Giles attP::Zeo }\end{array}$ & $\begin{array}{l}\text { pIRL133 backbone expressing the } \\
\text { Asp546Ala bacA allele under the hsp60 } \\
\text { promoter. Contains random barcode } \\
\text { sequence ATACTCAAGTTTATATAT }\end{array}$ & $\begin{array}{l}\text { https://benchling.com/s/seq- } \\
\text { vLyBVRz5sgy98D3Kevt6 }\end{array}$ & Zeocin \\
\hline 4 & pINP416 & $\begin{array}{l}\text { pIRL133-Phsp60- } \\
\text { bacA Leu551fs } \\
\text { Giles attP::Zeo }\end{array}$ & $\begin{array}{l}\text { plRL133 backbone expressing the } \\
\text { Leu551fs bacA allele under the hsp60 } \\
\text { promoter. Contains random barcode } \\
\text { sequence GGGAGTCTGTCTCTACCA }\end{array}$ & $\begin{array}{l}\text { https://benchling.com/s/seq- } \\
\text { 7qlml27CxTswBCArMKaw }\end{array}$ & Zeocin \\
\hline
\end{tabular}


bioRxiv preprint doi: https://doi.org/10.1101/2021.11.27.469863; this version posted November 27, 2021. The copyright holder for this preprint (which was not certified by peer review) is the author/funder, who has granted bioRxiv a license to display the preprint in perpetuity. It is made available under aCC-BY-ND 4.0 International license.

\begin{tabular}{|c|c|c|c|c|c|}
\hline 4 & pINP417 & $\begin{array}{l}\text { pIRL133-Phsp60- } \\
\text { bacA Gly554fs } \\
\text { Giles attP::Zeo }\end{array}$ & $\begin{array}{l}\text { plRL133 backbone expressing the } \\
\text { Gly554fs bacA allele under the hsp60 } \\
\text { promoter. Contains random barcode } \\
\text { sequence TTGGTACCCCGTTATAGT }\end{array}$ & $\begin{array}{l}\text { https://benchling.com/s/seq- } \\
\text { PjFZhXAUmUCuo0V1kSwi }\end{array}$ & Zeocin \\
\hline S7 & plNP422 & $\begin{array}{l}\text { pIRL133-Phsp60- } \\
\text { bacA Val118Ala } \\
\text { Giles attP::Zeo }\end{array}$ & $\begin{array}{l}\text { pIRL133 backbone expressing the } \\
\text { Val118Ala bacA allele under the hsp60 } \\
\text { promoter. Contains random barcode } \\
\text { sequence TTGCTCATATTCGCGGTA }\end{array}$ & $\begin{array}{l}\text { https://benchling.com/s/seq- } \\
\text { 2gsmPyD9adel4O452V1c }\end{array}$ & Zeocin \\
\hline S7 & pINP370 & $\begin{array}{l}\text { Ptet(gB52)-bacA } \\
\text { L5 attP: Kan }\end{array}$ & $\begin{array}{l}\text { L5 integrating plasmid constitutively } \\
\text { expressing the Mtb bacA allele under } \\
\text { the synthetic Ptet(gB52) promoter in } \\
\text { the absence of a Tet repressor }\end{array}$ & $\begin{array}{l}\text { https://benchling.com/s/seq- } \\
\text { WDve9cLzU2bhPwCEhNCM }\end{array}$ & Kanamycin \\
\hline S7 & plNP371 & $\begin{array}{l}\text { Ptet(gB52)-Empty } \\
\text { L5 attP: Kan }\end{array}$ & $\begin{array}{l}\text { L5 integrating plasmid with the } \\
\text { synthetic Ptet(gB52) promoter and no } \\
\text { downstream gene. As with pINP370 } \\
\text { this plasmid lacks a Tet repressor }\end{array}$ & $\begin{array}{l}\text { https://benchling.com/s/seq- } \\
\text { 84uPVQxdtoa9RgPuli6N }\end{array}$ & Kanamycin \\
\hline 5, S8 & plRL134 & $\begin{array}{l}\text { pIRL133-PettA-ettA } \\
\text { WT Giles attP::Zeo }\end{array}$ & $\begin{array}{c}\text { pIRL133 backbone expressing a } \\
\text { CRISPRi resistant WT allele of ettA } \\
\text { under its endogenous promoter. } \\
\text { Contains random barcode sequence } \\
\text { TCGGGAATTCTCACGCGT }\end{array}$ & $\begin{array}{l}\text { https://benchling.com/s/seq- } \\
\text { kKKtvttIAOgThvBiZoD7 }\end{array}$ & Zeocin \\
\hline 5, S8 & plRL136 & $\begin{array}{l}\text { pIRL133-PettA-ettA } \\
\text { Gly41Glu Giles } \\
\text { attP::Zeo }\end{array}$ & $\begin{array}{l}\text { plRL133 backbone expressing a } \\
\text { CRISPRi resistant Gly41Glu allele of } \\
\text { ettA under its endogenous promoter. } \\
\text { Contains random barcode sequence } \\
\text { GCCGTTTGGGACTCGTCT }\end{array}$ & $\begin{array}{l}\text { https://benchling.com/s/seq- } \\
\text { 2YfWjMdXzrg5u8DjRT3U }\end{array}$ & Zeocin \\
\hline 5, S8 & plRL137 & $\begin{array}{l}\text { pIRL133-PettA-ettA } \\
\text { Trp135Gly Giles } \\
\text { attP::Zeo }\end{array}$ & $\begin{array}{l}\text { plRL133 backbone expressing a } \\
\text { CRISPRi resistant Trp135Gly allele of } \\
\text { ettA under its endogenous promoter. } \\
\text { Contains random barcode sequence } \\
\text { ATACTCAAGTTTATATAT }\end{array}$ & $\begin{array}{l}\text { https://benchling.com/s/seq- } \\
\text { HMeozzDPogc92G7zvBbR }\end{array}$ & Zeocin \\
\hline s9 & plRL145 & $\begin{array}{c}\text { pBR322- } \\
\text { whiB7::Amp }\end{array}$ & $\begin{array}{l}\text { Backbone: pBR322. Cloned } \\
\text { whiB7+5'UTR region, as PCR template } \\
\text { for generating whiB7 KO mutant in } \\
\text { Mtb.Cloned by Gibson assembly into } \\
\text { Clal and Hindlll-digested pIRL39. }\end{array}$ & $\begin{array}{l}\text { https://benchling.com/s/seq- } \\
\text { 8HUz8kLA4QtU3gEkTirl }\end{array}$ & Ampicillin \\
\hline s9 & plRL146 & $\begin{array}{l}\text { pIRL60-PwhiB7- } \\
\text { whiB7- } \\
\text { Gly64delG(fs) } \\
\text { Tweety attP::Zeo }\end{array}$ & $\begin{array}{l}\text { whiB7-Gly64delG mutant ORF under } \\
\text { the expression of the endogenous } \\
\text { whiB7 promoter ( } 500 \text { bp upstream of } \\
\text { the whiB7 translational start site } \\
\text { including the 5'UTR region). Cloned by } \\
\text { Gibson assembly into EcoRV and } \\
\text { Xbal-digested plRL60. }\end{array}$ & $\begin{array}{l}\text { https://benchling.com/s/seq- } \\
\text { EYD2RXXj3Zk3Rojw5ruG }\end{array}$ & $\begin{array}{c}\text { Chloramphenicol } \\
\text { Zeocin }\end{array}$ \\
\hline
\end{tabular}

1046 1047 1048

\section{sgRNAs used in this work}

\begin{tabular}{|c|c|c|c|c|c|}
\hline Fig. used & sgRNA ID & $\begin{array}{c}\text { Gene } \\
\text { targeted }\end{array}$ & $\begin{array}{l}\text { Gene } \\
\text { name }\end{array}$ & $\begin{array}{c}\text { sgRNA targeting sequence } \\
\left(5^{\prime}-3^{\prime}\right)\end{array}$ & $\begin{array}{c}\text { PAM } \\
\left(5^{\prime}-3^{\prime}\right)\end{array}$ \\
\hline $\begin{array}{c}2,3,4,5,6 \text { S4, S5,S6, S7, } \\
\text { S8 }\end{array}$ & Non-Targeting control & NA & NA & GCATCCGGAGCCCGTCCGTTAA & NA \\
\hline S4 & $c c d A$ sgRNA PAM 15 & rv0527 & $\operatorname{ccd} A$ & ATCAGCACGCCTCCGACCCGCT & $\begin{array}{c}\text { GCAGCA } \\
\text { G }\end{array}$ \\
\hline S4 & kasA sgRNA PAM 22 & rv2245 & kas $A$ & ATGTCGTGCTTCAGTAACGCCCG & $\begin{array}{c}\text { AAGGCA } \\
\text { A }\end{array}$ \\
\hline S4 & $m m p L 3$ sgRNA PAM 15 & rv0206c & $m m p L 3$ & AACATCCGCACCACGGTCGCGT & $\begin{array}{c}\text { CCAGCA } \\
\text { G }\end{array}$ \\
\hline S4 & embB sgRNA PAM 8 & rv3795 & $e m b B$ & GACAGCGAACCGTCGACGGTGG & $\begin{array}{c}\text { GCAGGA } \\
T\end{array}$ \\
\hline
\end{tabular}


bioRxiv preprint doi: https://doi.org/10.1101/2021.11.27.469863; this version posted November 27, 2021. The copyright holder for this preprint (which was not certified by peer review) is the author/funder, who has granted bioRxiv a license to display the preprint in perpetuity. It is made available under aCC-BY-ND 4.0 International license.

1049

1050

1051

1052

\begin{tabular}{|c|c|c|c|c|c|}
\hline S4 & ripA sgRNA PAM 10 & $r v 1477$ & ripA & GCTGCAGGTTGGCCATCACCGCT & $\begin{array}{l}\text { TGGGAA } \\
\text { C }\end{array}$ \\
\hline 2, S5 & $m t r A$ sgRNA PAM 4 & $r v 3246 c$ & $m t r A$ & GGTGAGCATCACGATCGGAACA & $\begin{array}{c}\underset{T}{\text { CCGGAA }} \\
\text { P }\end{array}$ \\
\hline 2, S5 & $m t r B$ sgRNA PAM 2 & $r v 3245 c$ & $m t r B$ & $\begin{array}{c}\text { GTCCCGATGATCAGGGCCGGCC } \\
\text { C }\end{array}$ & $\begin{array}{l}\text { GGAGAA } \\
\text { A }\end{array}$ \\
\hline 2, S5 & IpqB sgRNA PAM 1 & $r v 3244 c$ & IpqB & ACCCCCACATCCGAGAGCGAGC & $\begin{array}{c}\text { CGAGAA } \\
T\end{array}$ \\
\hline $3, \mathrm{~S} 6$ & smpB sgRNA PAM 15 & rv3100c & $s m p B$ & GTGTCGATCTGGCGGCGATGCA & $\begin{array}{c}\text { ACAGCA } \\
\text { G }\end{array}$ \\
\hline 3, S6 & rv1473 sgRNA PAM 1 & $r v 1473$ & $r v 1473$ & GCATAGGGTTCGACCTCCCCCG & $\begin{array}{l}\text { CCAGAA } \\
T\end{array}$ \\
\hline S6 & clpP2 sgRNA PAM 16 & rv2460c & clpP2 & GATGTACATGGTGATATCGCGG & $\begin{array}{c}\text { TCGGGA } \\
T\end{array}$ \\
\hline 5, S8 & ettA sgRNA PAM 2 & $r v 2477 c$ & ettA & $\begin{array}{c}\text { ACGACACCGATCTTGGCGCCCG } \\
\text { G }\end{array}$ & $\begin{array}{l}\text { ATAGAA } \\
\text { A }\end{array}$ \\
\hline 5 & $\begin{array}{l}\text { whiB7 promoter sgRNA } \\
\text { PAM } 6\end{array}$ & rv3197A & whiB7 & $\begin{array}{c}\text { GCCTGTACCGGCAAACGCGCAG } \\
\text { G }\end{array}$ & $\begin{array}{c}\text { TCAGAA } \\
\text { A }\end{array}$ \\
\hline 5 & tap sgRNA PAM 5 & $r v 1258 c$ & tap & $\begin{array}{c}\text { GCCCTCGCGCTGCAACACCAGC } \\
\text { C }\end{array}$ & $\begin{array}{l}\text { ACGGAA } \\
\text { A }\end{array}$ \\
\hline 5 & eis sgRNA PAM 1 & $r v 2416 c$ & eis & $\begin{array}{c}\text { GTCGGGCTACACAGGGTCACAGT } \\
\text { C }\end{array}$ & $\begin{array}{l}\text { ACAGAA } \\
T\end{array}$ \\
\hline
\end{tabular}

\section{qPCR primers used in this work}

\begin{tabular}{|c|c|c|c|c|}
\hline Fig. used & Target gene & Gene name & Forward primer (5'-3') & Reverse primer (5'-3') \\
\hline $2,5, \mathrm{~S} 5$ & rv2703 & $\operatorname{sig} A$ & GTGATTTCGTCTGGGATGAAGA & TACCTTGCCGATCTGTTTGAG \\
\hline 2, S5 & $r v 3246 c$ & $m t r A$ & CCATCGCCGACGTAGAAAT & AGCAGCACATCACGAGTAAA \\
\hline 2, S5 & $r v 3245 c$ & $m t r B$ & ACCACGCCGAACACAAA & AAACACCAGCTTCTCCTCAC \\
\hline $2, \mathrm{~S} 5$ & $r v 3244 c$ & IpqB & GTGCTGCGAGCGATACA & GTCACGGGACAGTTGAAGAT \\
\hline 2, S5 & $r v 1477$ & $\operatorname{rip} A$ & TACTCGGGTTCGCAGTACAA & TTCGGGCCGTAGAAGATGA \\
\hline 2, S5 & $r v 3810$ & pirG & AACGACGTGATGCAGGTG & TGCATGATCGACGGCATTAG \\
\hline 2, S5 & rv0040c & $m t c 28$ & CATCACACACGGCTACATTGA & CCTCGATGATTGATGACGGAAA \\
\hline 2, S5 & $r v 1158$ & $r v 1158$ & CCAACGCACCGCAAATC & TGGAAAGGTGGCGGTTATC \\
\hline 2, S5 & $r v 0312$ & $r v 0312$ & CCATTGACCGGCTTCATCTA & GACGAGTGTGGAACGAAAGA \\
\hline 2, S5 & $r v 1566$ & $r v 1566$ & CTGTCCTGGTTTACGGTCTG & AACCCGACGGTGTTGATG \\
\hline 2, S5 & rv0129c & $f b p C$ & GTGTTGCTGGACGGAACTAA & GGATGGCACCTGCAGATATT \\
\hline 5 & rv3197a & whiB7 & CAGACAAAGATTGCCGGTTT & ACACACAGTGTCTTGGCTAC \\
\hline 5 & $r v 1988$ & erm & CCGCCGTACGGGATTTC & CGTTGCGAGAAGCGAATTTAC \\
\hline 5 & $r v 2725 c$ & $h f l x$ & GCTGTGCAGGTTAAGGTTATTG & GCAGCATGTACTCCATCTGAG \\
\hline 5 & $r v 2416 c$ & eis & TCACGAAGTTGGCGAGTTT & CAGTACGTCCCGATCCATTTC \\
\hline
\end{tabular}

\section{Other primers used in this work}

\begin{tabular}{|c|c|c|c|c|}
\hline $\begin{array}{c}\text { Fig. } \\
\text { used }\end{array}$ & $\begin{array}{c}\text { Legacy } \\
\text { Name }\end{array}$ & Sequence (5'-3') & Notes & Description \\
\hline 3, S6 & oINP537 & GGTTGGGCAAGAGTTGACCGCG & $\begin{array}{c}\text { rplC Amplification } \\
\text { Fwd Primer }\end{array}$ & $\begin{array}{c}\text { rplC Amplification Fwd Primer, LZD- } \\
\text { resistant Mtb }\end{array}$ \\
\hline
\end{tabular}


bioRxiv preprint doi: https://doi.org/10.1101/2021.11.27.469863; this version posted November 27, 2021. The copyright holder for this preprint (which was not certified by peer review) is the author/funder, who has granted bioRxiv a license to display the preprint in perpetuity. It is made available under aCC-BY-ND 4.0 International license.

\begin{tabular}{|c|c|c|c|c|}
\hline 3, S6 & olNP538 & TCTGCTCTTGCGCAGCCATCAC & $\begin{array}{l}\text { rplC Amplification } \\
\text { Rev Primer }\end{array}$ & $\begin{array}{l}\text { rpIC Amplification Rev Primer, LZD- } \\
\text { resistant Mtb }\end{array}$ \\
\hline $\mathrm{S} 10$ & olNP531 & GCATACCAAGGCGTACGAGATAAC & $\begin{array}{l}\text { Rrl Amplification Fwd } \\
\text { Primer }\end{array}$ & $\begin{array}{l}\text { Rrl Amplification Fwd Primer, CLR-resistant } \\
\text { Mtb }\end{array}$ \\
\hline S10 & olNP532 & CTGATCTTGGAGAAGGTTTCCCG & $\begin{array}{l}\text { Rrl Amplification Rev } \\
\text { Primer }\end{array}$ & $\begin{array}{l}\text { Rrl Amplification Rev Primer, CLR-resistant } \\
\text { Mtb }\end{array}$ \\
\hline 6, S9 & $\begin{array}{c}\text { olLSQ56 } \\
4\end{array}$ & $\begin{array}{c}\text { GAGGCCCTTTCGTCTTCAAGCGCCGATCCG } \\
\text { GTGCCGGG }\end{array}$ & whiB7-mtb-500_fwd & whiB7-KO Mtb mutant construction \\
\hline 6, S9 & $\begin{array}{l}\text { olLSQ56 } \\
5\end{array}$ & $\begin{array}{c}\text { TGGATCCACTGCCGACACCAAATGCGTTGT } \\
\text { TGTCAATCAC }\end{array}$ & whiB7-mtb-500_rev & whiB7-KO Mtb mutant construction \\
\hline 6, S9 & $\begin{array}{l}\text { olLSQ56 } \\
7\end{array}$ & $\begin{array}{c}\text { GACGTCCGCGGGCGCGCCATAACTTCGTAT } \\
\text { AG }\end{array}$ & whiB7-mtb-hyg_rev & whiB7-KO Mtb mutant construction \\
\hline 6,59 & $\begin{array}{l}\text { olLSQ56 } \\
8\end{array}$ & ATGGCGCGCCCGCGGACGTCCGCGCAAG & whiB7-mtb-500_fwd & whiB7-KO Mtb mutant construction \\
\hline 6, S9 & $\begin{array}{c}\text { olLSQ56 } \\
9 \\
\end{array}$ & $\begin{array}{l}\text { GTGATAAACTACCGCATTAATGCTGCTGCCC } \\
\text { GACGGCC }\end{array}$ & whiB7-mtb-500_rev & whiB7-KO Mtb mutant construction \\
\hline 6, S9 & $\begin{array}{l}\text { olLSQ45 } \\
7\end{array}$ & $\begin{array}{c}\text { CCTCTAGGGTCCCCAGCTGGCCGGCATCG } \\
\text { GTGCCCGCA }\end{array}$ & WhiB7+500-gibson- $F$ & Build whiB7 WT allele for complementation \\
\hline 6,59 & $\begin{array}{l}\text { olLSQ45 } \\
8\end{array}$ & $\begin{array}{l}\text { GTGGCAGGGCGGGGCGTAATCTATGCAACA } \\
\text { GCATCCTTGCGCGG }\end{array}$ & WhiB7+500-gibson-R & Build whiB7 WT allele for complementation \\
\hline 6,59 & $\begin{array}{l}\text { olLSQ66 } \\
9\end{array}$ & $\begin{array}{l}\text { CCTCTAGGGTCCCCAGCTGGCCGGCATCG } \\
\text { GTGCCCGCA }\end{array}$ & pwhiB7-whiB7fs-F1 & $\begin{array}{l}\text { Build Mtb whiB7-fs(Gly64delG) allele for } \\
\text { complementation }\end{array}$ \\
\hline 6,59 & olNP514 & ATCCTATGCCAGCTGGACGC & $\begin{array}{l}\text { whiB7 Amplification } \\
\text { Fwd Primer }\end{array}$ & whiB7 Amplification Fwd Primer \\
\hline 6,59 & olNP546 & CCCGCAAGCTGGAACAATAC & $\begin{array}{l}\text { whiB7 Amplification } \\
\text { Rev Primer }\end{array}$ & whiB7 Amplification Rev Primer \\
\hline
\end{tabular}

Supplemental Table 2: Additional acquired drug sensitivity candidates

\begin{tabular}{|c|c|c|c|c|c|}
\hline $\begin{array}{l}\text { Ge } \\
\text { ne }\end{array}$ & $\begin{array}{c}\text { Dru } \\
\text { g }\end{array}$ & $\begin{array}{l}\text { Muta } \\
\text { tion }\end{array}$ & Sublineage & $\begin{array}{l}\text { Occurr } \\
\text { ences }\end{array}$ & Notes \\
\hline $\begin{array}{l}\text { whi } \\
\text { B7 }\end{array}$ & CLR & $\begin{array}{l}\text { Leu18 } \\
\text { fs }\end{array}$ & lineage2.2.1: 100/6719 & 100 & \\
\hline $\begin{array}{l}\text { whi } \\
\text { B7 }\end{array}$ & CLR & $\begin{array}{c}\text { Ala60f } \\
s\end{array}$ & lineage4: 2/814, lineage4.8: 18/3234 & 20 & \\
\hline$h f I X$ & CLR & $\begin{array}{c}\text { Glu20 } \\
6 f s\end{array}$ & lineage4.9: 93/2941 & 93 & \\
\hline$h f I X$ & CLR & $\begin{array}{l}\operatorname{Arg} 23 \\
7 f s\end{array}$ & lineage4.9: 12/2941 & 12 & \\
\hline$h f I X$ & CLR & $\begin{array}{l}\text { Gln36 } \\
\text { 7Stop }\end{array}$ & lineage4.2.1: 117/666, lineage4.6: 2/187 & 119 & \\
\hline $\begin{array}{l}r v 23 \\
69 c\end{array}$ & CLR & $\begin{array}{l}\text { Arg57 } \\
\text { fs }\end{array}$ & None: $12 / 3241$ & 12 & Possible polar effect with phoH1 \\
\hline $\begin{array}{l}r v 23 \\
69 c\end{array}$ & CLR & $\begin{array}{l}\text { Cys58 } \\
\text { fs }\end{array}$ & lineage3: 11/3537 & 11 & Possible polar effect with phoH1 \\
\hline $\begin{array}{l}r v 23 \\
69 c\end{array}$ & CLR & $\begin{array}{l}\text { Gln72 } \\
\text { Stop }\end{array}$ & lineage1.2.1: 2/164, lineage1.2.1.3: 78/435 & 80 & Possible polar effect with $\mathrm{phoH} 1$ \\
\hline $\mathrm{mm}$ & $\begin{array}{l}\mathrm{CLR} / \\
\mathrm{BDQ}\end{array}$ & $\begin{array}{l}\text { Asp13 } \\
2 \mathrm{fs}\end{array}$ & $\begin{array}{l}\text { None: } 48 / 3241 \text {, lineage1.2.1: } 1 / 164 \text {, lineage2.2.1: } \\
\text { 5/6719, lineage4.1.1.3: } 2 / 1178 \text {, lineage4.8: } 1 / 3166\end{array}$ & 57 & $\begin{array}{l}\text { Also observed by Merker et al., may also confer } \\
\text { clofazamine sensitivity(Merker et al., 2020) }\end{array}$ \\
\hline $\begin{array}{l}m m \\
p L 5\end{array}$ & $\begin{array}{l}\mathrm{CLR} / \\
\mathrm{BDQ} \\
\end{array}$ & $\begin{array}{c}\text { Arg20 } \\
2 f s\end{array}$ & lineage4: 55/807 & 55 & $\begin{array}{l}\text { Also observed by Merker et al., may also confer } \\
\text { clofazamine sensitivity(Merker et al., 2020) }\end{array}$ \\
\hline $\begin{array}{l}m m \\
p L 5\end{array}$ & $\begin{array}{l}\mathrm{CLR} / \\
\mathrm{BDQ}\end{array}$ & $\begin{array}{l}\text { Tyr30 } \\
\text { 0Stop }\end{array}$ & $\begin{array}{l}\text { lineage1.1.1: 4/54, lineage1.1.1.1: } 75 / 108, \text { lineage4.8: } \\
1 / 3166\end{array}$ & 80 & $\begin{array}{l}\text { Also observed by Merker et al., may also confer } \\
\text { clofazamine sensitivity(Merker et al., 2020) }\end{array}$ \\
\hline $\mathrm{mL}$ & $\begin{array}{l}\mathrm{CLR} / \\
\mathrm{BDQ}\end{array}$ & $\begin{array}{l}\text { Pro49 } \\
8 \mathrm{fs}\end{array}$ & lineage2.2.2: 1/747, lineage4.6: 59/187 & 60 & $\begin{array}{l}\text { Also observed by Merker et al., may also confer } \\
\text { clofazamine sensitivity(Merker et al., 2020) }\end{array}$ \\
\hline $\begin{array}{c}r v 38 \\
22\end{array}$ & $\mathrm{BDQ}$ & $\begin{array}{l}\text { Leu12 } \\
\text { 3fs }\end{array}$ & None: $40 / 2223$ & 40 & \\
\hline $\begin{array}{c}r v 38 \\
22\end{array}$ & $\mathrm{BDQ}$ & $\begin{array}{l}\text { Tyr20 } \\
8 f s\end{array}$ & lineage4: 4/814, lineage4.8: 36/3234 & 40 & \\
\hline
\end{tabular}


bioRxiv preprint doi: https://doi.org/10.1101/2021.11.27.469863; this version posted November 27, 2021. The copyright holder for this preprint (which was not certified by peer review) is the author/funder, who has granted bioRxiv a license to display the preprint in perpetuity. It is made available under aCC-BY-ND 4.0 International license.

\section{Supplemental Data 1: MAGeCK screen results}

Supplemental Data 2: Chemical-genetic hit overlap between CRISPRi and TnSeq

Supplemental Data 3: RNA-seq differential expression analysis results for Mtb mtrA CRISPRi knockdown mutant

Supplemental Data 4: Full list of NCBI accession numbers of WGS sequences used in this study

Supplemental Data 5: List of identified tsnR mutations from clinical isolate WGS database and cooccurrence with rp/C Cys154Arg Linezolid-resistant isolates

Supplemental Data 6: List of identified bacA mutations from clinical isolate WGS database

Supplemental Data 7: List of identified ettA mutations from clinical isolate WGS database

Supplemental Data 8: List of identified whiB7 mutations from clinical isolate WGS database

Supplemental Data 9: Acquired drug resistance candidate mutations 
1085 MATERIALS AND METHODS

1086

1087

1088

1089

1090

1091

1092

1093

1094

1095

1096

1097

1098

1099

1100

1101

1102

1103

1104

1105

1106

1107

1108

1109

1110

1111

1112

1113

1114

1115

1116

1117

1118

1119

1120

1121

1122

1123

1124

1125

1126

1127

1128

1129

1130

1131

1132

1133

1134

1135

1136

\section{Bacterial strains}

Mtb strains are derivatives of $\mathrm{H} 37 \mathrm{Rv}$ unless otherwise noted. A reference set of Mtb clinical strains was obtained from the Belgian Coordinated Collections of Microorganisms (BCCM) (Borrell et al., 2019). E. coli strains are derivatives of DH5alpha (NEB).

\section{Mycobacterial cultures}

Mtb was grown at $37^{\circ} \mathrm{C}$ in Difco Middlebrook $7 \mathrm{H} 9$ broth or on $7 \mathrm{H} 10$ agar supplemented with $0.2 \%$ glycerol (7H9) or $0.5 \%$ glycerol $(7 \mathrm{H} 10), 0.05 \%$ Tween- $80,1 \mathrm{X}$ oleic acid-albumin-dextrose-catalase (OADC) and the appropriate antibiotics. Where required, antibiotics or small molecules were used at the following concentrations: kanamycin at $20 \mu \mathrm{g} / \mathrm{mL}$; anhydrotetracycline (ATc) at $100 \mathrm{ng} / \mathrm{mL}$, and zeocin at $20 \mu \mathrm{g} / \mathrm{mL}$. Mtb cultures were grown standing in tissue culture flasks (unless otherwise indicated) at $37^{\circ} \mathrm{C}, 5 \% \mathrm{CO}_{2}$.

\section{Generation of individual CRISPRi and CRISPRi-resistant complementation strains}

Individual CRISPRi plasmids were cloned as previously described in (Bosch et al., 2021) using Addgene plasmid \#166886. Briefly, the CRISPRi plasmid backbone was digested with BsmBI-v2 (NEB \#R0739L) and gel purified. sgRNAs were designed to target the non-template strand of the target gene ORF. For each individual sgRNA, two complementary oligonucleotides with appropriate sticky end overhangs were annealed and ligated (T4 ligase NEB \# M0202M) into the BsmBI-digested plasmid backbone. Successful cloning was confirmed by Sanger sequencing.

Individual CRISPRi plasmids were then electroporated into Mtb. Electrocompetent cells were obtained as described in(Murphy et al., 2015). Briefly, a WT Mtb culture was expanded to an $\mathrm{OD}_{600}=0.8-1.0$ and pelleted $(4,000 \times \mathrm{g}$ for $10 \mathrm{~min})$. The cell pellet was washed three times in sterile $10 \%$ glycerol. The washed bacilli were then resuspended in $10 \%$ glycerol in a final volume of $5 \%$ of the original culture volume. For each transformation, $100 \mathrm{ng}$ plasmid DNA and $100 \mu \mathrm{L}$ of electrocompetent mycobacteria were mixed and transferred to a $2 \mathrm{~mm}$ electroporation cuvette (Bio-Rad \#1652082). Where necessary, $100 \mathrm{ng}$ of plasmid pIRL19 (Addgene plasmid \#163634) was also added. Electroporation was performed using the Gene Pulser $X$ cell electroporation system (Bio-Rad \#1652660) set at $2500 \mathrm{~V}, 700 \Omega$ and $25 \mu \mathrm{F}$. Bacteria were recovered in $7 \mathrm{H} 9$ for 24 hours. After the recovery incubation, cells were plated on $7 \mathrm{H} 10$ agar supplemented with the appropriate antibiotic to select for transformants.

To complement CRISPRi-mediated gene knockdown, synonymous mutations were introduced into the complementing allele at both the protospacer adjacent motif (PAM) and seed sequence (the 8-10 most PAM-proximal bases at the 3' end of the sgRNA targeting sequence) to prevent sgRNA targeting. Silent mutations were introduced into Gibson assembly oligoes to generate these "CRISPRi resistant" (CR) alleles. Complementation alleles were expressed from the endogenous or hsp60 promoters in a Tweety or Giles integrating plasmid backbone, as indicated in each figure legend and/or the relevant plasmid maps (Supplemental Table 1). These alleles were then transformed into the corresponding CRISPRi knockdown strain, with the pIRL40 Giles Int expressing plasmid where necessary.

The full list of sgRNA targeting sequences and complementation plasmids can be found in Supplemental Table 1.

\section{Construction of the $\Delta w h i B 7$ and complemented Mtb strains}

The Mtb $\Delta$ whiB7 strain was constructed by allelic exchange using a RecET-mediated recombineering approach as previously described(Murphy et al., 2015). Deletion of whiB7 was confirmed by PCR and whole-genome sequencing (BGI). The $\triangle$ whiB7 strain was complemented by reintroducing a wild-type copy of whiB7 under the control of its native promoter at the attL 5 site of the Mtb genome. Plasmid sequences and maps can be found in Supplemental Table 1. 


\section{Pooled CRISPRi chemical-genetic screening}

Chemical-genetic screens were initiated by thawing $5 \times 1 \mathrm{~mL}\left(1 \mathrm{OD}_{600}\right.$ unit per $\mathrm{mL}$ ) aliquots of the Mtb CRISPRi library (RLC12; Addgene \#163954) and inoculating each aliquot into $19 \mathrm{~mL}$ 7H9 supplemented with kanamycin $(10 \mu \mathrm{g} / \mathrm{ml})$ in a vented tissue culture flask flask (T-75; Falcon \#353136). The starting $\mathrm{OD}_{600}$ of each culture was approximately 0.05 . Cultures were expanded to $\mathrm{OD}_{600}=1.5$, pooled and passed through a $10 \mu \mathrm{m}$ cell strainer (pluriSelect \#43-50010-03) to obtain a single cell suspension. The single cell suspension was then treated with ATc (100 ng/mL final concentration) to initiate target pre-depletion. To generate 1 day pre-depletion culture, the single-cell suspension was diluted back to $O D_{600}=0.5$ in a total volume of $40 \mathrm{~mL} 7 \mathrm{H} 9$. The remaining single-cell suspension was used to generate a 5-day pre-depletion culture, with a starting $\mathrm{OD}_{600}=0.1(40 \mathrm{~mL} ; 100 \mathrm{ng} / \mathrm{mL}$ ATc). After 4 days, the 5-day pre-depletion start culture was further diluted back to a starting $\mathrm{OD}_{600}=0.05$ (40 mL; in $100 \mathrm{ng} / \mathrm{mL}$ ATc) and incubated for a further 5 days to generate the 10 day pre-depletion culture.

To initiate the chemical-genetic screen, we first harvested $10 \mathrm{OD}_{600}$ units of bacteria $\left(\sim 3 \times 10^{9}\right.$ bacteria; $\sim 30,000 X$ coverage of the CRISPRi library) from the 1, 5, or 10-day CRISPRi library pre-depletion cultures as input controls. Triplicate cultures were then inoculated at $\mathrm{OD}_{600}=0.05$ in $10 \mathrm{ml} 7 \mathrm{H} 9$ supplemented with ATc $(100 \mathrm{ng} / \mathrm{mL})$, kanamycin $(10 \mu \mathrm{g} / \mathrm{ml})$, and the indicated drug concentration or DMSO vehicle control (see Supplemental Figure 1). Pooled CRISPRi chemical-genetic screens were performed in vented tissue culture flasks (T-25; Falcon \#353109). Cultures were outgrown for 14 days at $37^{\circ} \mathrm{C}, 5 \% \mathrm{CO}_{2}$. ATc was replenished at $100 \mathrm{ng} / \mathrm{mL}$ at day 7 . After 14 days outgrowth, $O D_{600}$ values were measured for all cultures to empirically determine the MIC for each drug. Samples from three descending doses of partially inhibitory drug concentrations were processed for genomic DNA extraction, defined as "High", "Medium", and "Low" in Supplemental Figure 1, as described below. Due to an error during genomic DNA extraction, EMB 1,804 nM ("Med") Day 1 data reflects two biological replicates, one of which was sequenced twice to produce 3 replicates. Additionally, the 10-day sample was lost for the $221 \mathrm{nM}$ (“Med”) streptomycin screen.

\section{Genomic DNA extraction and library preparation for Illumina sequencing}

Genomic DNA was isolated from bacterial pellets using the CTAB-lysozyme method as previously described(Bosch et al., 2021). Briefly, Mtb pellets (5-30 OD 600 units) were resuspended in $1 \mathrm{~mL}$ of PBS + $0.05 \%$ Tween-80. Cell suspensions were centrifuged for $5 \mathrm{~min}$ at $4,000 \mathrm{xg}$ and the supernatant was removed. Pellets were resuspended in $800 \mu \mathrm{L}$ TE buffer $(10 \mathrm{mM}$ Tris $\mathrm{pH} 8.0,1 \mathrm{mM}$ EDTA $)+15 \mathrm{mg} / \mathrm{mL}$ lysozyme (Alfa Aesar J60701-06) and incubated at $37^{\circ} \mathrm{C}$ for 16 hours. Next, $70 \mu \mathrm{L}$ of $10 \%$ SDS (Promega V6551) and $5 \mu \mathrm{L}$ of proteinase $\mathrm{K}(20 \mathrm{mg} / \mathrm{mL}$, Thermo Fisher 25530049$)$ were added and samples were incubated at $65^{\circ} \mathrm{C}$ for $30 \mathrm{~min}$. Subsequently, $100 \mu \mathrm{L}$ of $5 \mathrm{M} \mathrm{NaCl}$ and $80 \mu \mathrm{L}$ of $10 \% \mathrm{CTAB}$ (Sigma Aldrich $\mathrm{H} 5882$ ) were added and samples were incubated for an additional $30 \mathrm{~min}$ at $65^{\circ} \mathrm{C}$. Finally, $750 \mu \mathrm{L}$ of icecold chloroform was added and samples were mixed. After centrifugation at 16,100 $\mathrm{xg}$ and extraction of the aqueous phase, samples were removed from the biosafety level 3 facility. Samples were then treated with $25 \mu \mathrm{g}$ of RNase A (Bio Basic RB0474) for $30 \mathrm{~min}$ at $37^{\circ} \mathrm{C}$ followed by an extraction with phenol:chloroform:isoamyl alcohol ( $\mathrm{pH}=8.0,25: 24: 1$ Thermo Fisher BP1752I-400) then chloroform. Genomic DNA was precipitated from the final aqueous layer $(600 \mu \mathrm{L})$ with the addition of $10 \mu \mathrm{L}$ of $3 \mathrm{M}$ sodium acetate and $360 \mu \mathrm{L}$ of isopropanol. DNA pellets were spun at $21,300 \times \mathrm{g}$ for $30 \mathrm{~min}$ at $4^{\circ} \mathrm{C}$ and washed $2 \mathrm{X}$ with $750 \mu \mathrm{L}$ of $80 \%$ ethanol. Pellets were dried and resuspended with elution buffer (Qiagen 19086) before spectrophotometric quantification.

The concentration of isolated genomic DNA was quantified using the DeNovix dsDNA high sensitivity assay (KIT-DSDNA-HIGH-2; DS-11 Series Spectrophotometer / Fluorometer). Next, the sgRNA-encoding region was amplified from 500 ng genomic DNA with 17 cycles of PCR using NEBNext Ultra II Q5 master Mix (NEB \#M0544L). Each PCR reaction contained a pool of forward primers ( $0.5 \mu \mathrm{M}$ final concentration) and a unique indexed reverse primer $(0.5 \mu \mathrm{M})$ (Bosch et al., 2021). Forward primers contain a P5 flow cell attachment sequence, a standard Read1 Illumina sequencing primer binding site, and custom stagger sequences to guarantee base diversity during Illumina sequencing. Reverse primers contain a P7 flow cell 
bioRxiv preprint doi: https://doi.org/10.1101/2021.11.27.469863; this version posted November $27,2021$. The copyright holder for this preprint (which was not certified by peer review) is the author/funder, who has granted bioRxiv a license to display the preprint in perpetuity. It is made available under aCC-BY-ND 4.0 International license.

1191 attachment sequence, a standard Read2 Illumina sequencing primer binding site, and unique barcodes to allow for sample pooling during deep sequencing.

1193 Following PCR amplification, each $\sim 230$ bp amplicon was purified using AMPure XP beads (BeckmanCoulter \#A63882) using one-sided selection (1.2 x). Bead-purified amplicons were further purified on a Pippin HT 2\% agarose gel cassette (target range 180-250 bp; Sage Science \#HTC2010) to remove carryover primer and genomic DNA. Eluted amplicons were quantified with Qubit 2.0 Fluorometer (Invitrogen) and amplicon size and purity was quality controlled by visualization on an Agilent 2100 Bioanalyzer (high sensitivity chip; Agilent Technologies \#5067-4626). Next, individual PCR amplicons were multiplexed into $10 \mathrm{nM}$ pools and sequenced on an Illumina sequencer according to the manufacturer's instructions. To increase sequencing diversity, a PhiX spike-in of $2.5-5 \%$ was added to the pools (PhiX Sequencing Control v3; Illumina \# FC-110-3001). Samples were run on the Illumina NextSeq 500, HiSeq 2500, or NovaSeq 6000 platform (Single-Read 1 x 85 cycles and 6 x i7 index cycles).

\section{NGS data processing, analysis, and hit calling}

Sequencing counts were obtained in the manner described by(Bosch et al., 2021). Counts were normalized for sequencing depth and an sgRNA limit of detection (LOD) cut-off was set at 100 counts in the DMSO condition. Only sgRNAs that made the LOD cut-off (i.e. counts $>100$ ) were analyzed further. Replicate screens were quality controlled to ensure that the Pearson correlation was $>0.95$ for both the non-targeting sgRNA sets and essential-gene targeting sgRNA(Dejesus et al., 2017) sets between each replicate screen. sgRNA counts were analyzed using MAGeCK analysis method (version 0.5.9.2) in python (version 2.7.16)(Li et al., 2014). Gene-level log2 fold change (L2FC) was calculated using the 'alphamedian' approach specified with the 'gene-lfc-method' parameter, which estimates the gene-level L2FC as the median of sgRNAs that are ranked above the default cut off in the Robust Rank Analysis used by MAGeCK. Negative control sgRNAs in the library were used to calculate the null distribution and to normalize counts using the '--control-sgrna' and '-normalization control' parameters, respectively. MAGeCK gene summary output results can be found in Supplemental Data 1.

Unless otherwise specified, a gene was determined to be a hit in a given condition if it had an FDR $<0.01$ and a L2FC $<-1$ in the negative selection or an FDR $<0.01$ and a $\mathrm{L} 2 \mathrm{FC}>1$ in the positive selection.

\section{Clustered heatmap}

L2FC values from the MAGeCK output (Supplemental Data 1) were used for the generation of clustered heatmap. Genes were clustered based on Euclidean distance using the Ward clustering criterion. Only genes that hit (FDR $<0.01 ; n=676$ genes) in two or more conditions are included in the heatmap. A gene's L2FC was only represented on the heatmap if the FDR was below 0.01 in the specific treatment condition; genes not meeting this significance threshold are shown as white in that treatment condition. Treatment conditions were clustered based on Pearson correlation using the Ward criterion. Clustering was done using the package hclust and the heatmap was generated using the heatmap.2 function from the package gplots (R version 4.0.5).

\section{Physiochemical property analysis}

The physiochemical properties shown in Supplemental Data 3D were obtained from PubChem (https://pubchem.ncbi.nlm.nih.gov/) and, where applicable, were computed by Cactvs 3.4.8.18. The L2FC distributions correspond to the values for the following mAGP-associated genes found in (Jankute et al., 2015; Maitra et al., 2019): rv1302, rv3265c, rv3782, rv3808c, rv1017c, rv3806c, rv3807c, rv3790, rv3791, rv3792, rv3794, rv3795, rv2673, rv0236c, rv3805c, rv3631, rv3779, rv2524c, rv3285, rv3280, rv0904c, rv2247, rv1483, rv2483, rv0533c, rv3799c, rv2245, rv2246, rv1483, rv0635, rv0636, rv0637, rv1484, rv0645c, rv0644c, rv0643c, rv0642c, rv0470c, rv3392c, rv0503c, rv3801c, rv3800c, rv2509, rv0206c, rv3804c, rv3802c, rv3436c, rv3441c, rv1018c, rv1315, rv0482, rv2152c, rv2155c, rv2158c, rv2157c, rv2156c, rv2153c, rv3818, rv3712, rv3713, rv2201, rv3910, rv2154c, rv0050, rv3682, rv3330, rv2911, 
bioRxiv preprint doi: https://doi.org/10.1101/2021.11.27.469863; this version posted November 27, 2021. The copyright holder for this preprint (which was not certified by peer review) is the author/funder, who has granted bioRxiv a license to display the preprint in perpetuity. It is made available under aCC-BY-ND 4.0 International license.

1243 rv0116c, rv2518c, rv1433, rv0192, rv0483, rv1477, rv1478, rv2190c, rv0867c, rv1009, rv1884c, rv2389c, 1244 rv2450c.

\section{Antibacterial activity measurements}

All compounds were dissolved in DMSO (VWR V0231) and dispensed using an HP D300e Digital

Dispenser in a 384 well plate format. DMSO did not exceed $1 \%$ of the final culture volume and was

maintained at the same concentration across all samples. CRISPRi strains were growth-synchronized and pre-depleted in the presence of ATc $(100 \mathrm{ng} / \mathrm{mL})$ for 5 days prior to assay for MIC analysis. Cultures were then back diluted to a starting $\mathrm{OD}_{580}$ of 0.05 and $50 \mu \mathrm{L}$ of cell suspension was plated in technical triplicate in wells containing the test compound and fresh ATc $(100 \mathrm{ng} / \mathrm{mL})$. For checkerboard assays and MIC assays (non-CRISPRi) cultures were growth-synchronized to late log-phase and back-diluted to an $\mathrm{OD}_{600}$ of 0.025 prior to plating (no ATc). Plates were incubated at $37^{\circ} \mathrm{C}$ with $5 \% \mathrm{CO}_{2} . \mathrm{OD}_{600}$ was evaluated using a Tecan Spark plate reader at 10-14 days post-plating and percent growth was calculated relative to the vehicle control for each strain. $I_{50}$ measurements were calculated using a non-linear fit in GraphPad Prism.

To quantify growth phenotypes on $7 \mathrm{H} 10$ agar, 10 -fold serial dilutions of Mtb cultures $\left(\mathrm{OD}_{600}=0.6\right)$ were spotted on $7 \mathrm{H} 10$ agar containing drugs at the indicated concentrations and/or ATc at $100 \mathrm{ng} / \mathrm{mL}$. Plates were incubated at $37^{\circ} \mathrm{C}$ and imaged after two weeks.

\section{Antimicrobial compounds}

All compounds used in this study were purchased from commercial manufacturers with the exception of GSK3011724A, which was synthesized at the Memorial Sloan Kettering Organic Synthesis core as described in(Kumar et al., 2018).

\begin{tabular}{|c|c|c|c|}
\hline Antibiotic & Use & Abbreviation & Product number \\
\hline Amikacin & Axenic culture & AMK & A0365900 (Sigma Aldrich) \\
\hline Anhydrotetracycline & Axenic culture & ATc & AC233135000 (Fisher Scientific) \\
\hline Azithromycin & Mouse efficacy studies & AZM & Epic Pharma Oral Suspension \\
\hline Azithromycin-dihydrate & Axenic culture & AZM & PZ0007 (Sigma Aldrich) \\
\hline Bedaquiline & Axenic culture & $\mathrm{BDQ}$ & AdooQ Biosciences (A12327-5) \\
\hline Capreomycin Sulfate & Axenic culture & CAP & PHR1716 (Sigma Aldrich) \\
\hline Chloramphenicol & Axenic culture & $\mathrm{CHL}$ & C-105-5 (GoldBio) \\
\hline Clarithromycin & Axenic culture & CLR & C9742 (Sigma Aldrich) \\
\hline Clarithromycin & Mouse efficacy studies & CLR & Sandoz Tablets \\
\hline Clindamycin hydrochloride & Axenic culture & CLI & C-175-10 (GoldBio) \\
\hline Clofazimine & Axenic culture & CLO & TCC2866 (VWR) \\
\hline Ethambutol dihydrochloride & Axenic culture & EMB & E4630 (Sigma Aldrich) \\
\hline Fusidic acid sodium salt & Axenic culture & FA & F0881 (Sigma Aldrich) \\
\hline GSK3011724A & $\begin{array}{l}\text { Axenic culture, macrophage } \\
\text { infection }\end{array}$ & GSK'724A & NA \\
\hline Isoniazid & Axenic culture & $\mathrm{INH}$ & I3377 (Sigma Aldrich) \\
\hline Kanamycin & Axenic culture & KAN & K-120-50 (GoldBio) \\
\hline Levofloxacin & Axenic culture & LFX & 28266 (Sigma Aldrich) \\
\hline Lincomycin hydrochloride & Axenic culture & LNC & 62143 (Sigma Aldrich) \\
\hline Linezolid & Axenic culture & LZD & SML1290 (Sigma Aldrich) \\
\hline Moxifloxacin & Axenic culture & MFX & Y0000703 (Sigma Aldrich) \\
\hline Rifampicin & $\begin{array}{c}\text { Axenic culture, macrophage } \\
\text { infection }\end{array}$ & RIF & R0079 (TCl) \\
\hline
\end{tabular}


bioRxiv preprint doi: https://doi.org/10.1101/2021.11.27.469863; this version posted November $27,2021$. The copyright holder for this preprint (which was not certified by peer review) is the author/funder, who has granted bioRxiv a license to display the preprint in perpetuity. It is made available under aCC-BY-ND 4.0 International license.

1268

1269

1270

1271

1272

1273

1274

1275

1276

1277

1278

1279

1280

1281

1282

1283

1284

1285

1286

1287

1288

1289

1290

1291

1292

1293

1294

1295

1296

1297

1298

1299

1300

1301

1302

1303

1304

1305

1306

1307

1308

1309

1310

1311

1312

1313

\begin{tabular}{|c|c|c|c|}
\hline Rifampicin & Mouse efficacy studies & RIF & Akorn Capsules \\
\hline Streptomycin sulfate & Axenic culture & STR & S-150-100 (GoldBio) \\
\hline Sutezolid & Axenic culture & SZD & PZ0035 (Sigma Aldrich) \\
\hline Telithromycin & Axenic culture & TLM & SML2162 (Sigma Aldrich) \\
\hline Tigecycline hydrate & Axenic culture & TGC & PZ0021 (Sigma Aldrich) \\
\hline Vancomycin hydrochloride & Axenic culture & VAN & V2002 (Sigma Aldrich) \\
\hline Zeocin & Axenic culture & ZEO & J67140-8EQ (Alfa Aesar) \\
\hline
\end{tabular}

\section{Bone marrow-derived macrophage infections}

Bone marrow-derived macrophages (BMDMs) were differentiated from wild-type, female C57BL/6NTAC mice (Taconic Farms, 6-8 weeks of age). All animal work was performed in accordance with the Guide for the Care and Use of Laboratory Animals of the National Institutes of Health, with approval from the Institutional Animal Care and Use Committee of Rockefeller University. Femurs and tibias were harvested and crushed with a sterile mortar and pestle as described(Trouplin et al., 2013). After red blood cell lysis and counter-selection of resident macrophages, bone marrow cells were incubated in the presence of DMEM (4.5 g/L glucose + L-glutamine + sodium pyruvate, Corning 10-013-CV) + 10\% FBS (Sigma Aldrich F4135, Lot no. 17B189) $+15 \%$ conditioned L929 cell medium (LCM) and differentiated for 7 days at $37^{\circ} \mathrm{C}$, $5 \% \mathrm{CO}_{2}$. Macrophages were then lifted using gentle cell scraping. For infection assays, BMDMs were seeded in 96 well plates at 75,000 cells/well two days prior to infection. 16 hours prior to infection, fresh $\mathrm{DMEM}+10 \% \mathrm{FBS}+10 \%$ LCM was added to cells, with or without IFN-y $(20 \mathrm{ng} / \mathrm{mL}$, Gemini Biosciences 300-311P). Mtb cultures were synchronized to late log-phase $\left(\mathrm{OD}_{600}\right.$ 0.6-0.8). For infections with CRISPRi strains, cultures were pre-depleted with $100 \mathrm{ng} / \mathrm{mL}$ ATc for 24 hours prior to infection. Mtb pellets were washed with PBS (Thermo Fisher 14190144) + 0.05\% Tyloxapol (Sigma Aldrich T0307) and single cell suspensions were generated by harvesting the suspended cells after gentle centrifugation (150 x $\mathrm{g}$ for 12 $\mathrm{min})$. Cell culture medium was removed from the macrophages and replaced with Mtb-containing medium at a multiplicity of infection of $\mathrm{MOI}$ of $1: 1$. After four hours of infection at $37^{\circ} \mathrm{C}$, media was removed and cells were washed $2 X$ with PBS. Wells were replenished with fresh media with or without drug. DMSO was normalized to $0.2 \%$. For CRISPRi infections, doxycycline (Sigma Aldrich D9891) was added at a concentration of $250 \mathrm{ng} / \mathrm{mL}$ to maintain target knockdown. For all infection assays, medium was replaced with fresh drug at day 3. At each indicated timepoint, after two PBS washes, cells were lysed with $100 \mu \mathrm{L}$ of Triton X-100 in water (Sigma Aldrich X100). Lysates were titrated in PBS $+0.05 \%$ Tween-80 and plated on 7H10. CFU were enumerated after 21-28 days of outgrowth.

\section{Selection of drug-resistant Mtb isolates}

For the selection of linezolid-resistant H37Rv Mtb mutants, two independent cultures were started at an $\mathrm{OD}_{600}$ of 0.001 . After one week of outgrowth, cultures were pelleted and roughly $3 \times 10^{9} \mathrm{CFU}$ were plated on complete $7 \mathrm{H} 10+11.9 \mu \mathrm{M}$ linezolid. Plates were incubated for 24 days. Colonies were picked and grown in complete $7 \mathrm{H} 9+11.9 \mu \mathrm{M}$ linezolid. Genomic DNA was harvested as described above? And Sanger sequencing was performed on purified PCR amplicons of $r r$ (23s rRNA) and $r p / C$ using the primers listed (Supplemental Table 1). Genomic DNA was also submitted for WGS (BGI, llumina HiSeq X Ten platform).

For selection of resistant isolates for the lineage 1.2.1 strain, thirty independent cultures of $20 \mathrm{~mL}$ were started at an $\mathrm{OD}_{600}$ of 0.001 . After growth to log-phase $\left(\mathrm{OD}_{600} 0.5-0.6\right)$ cultures were pelleted and plated on complete $7 \mathrm{H} 10+$ antibiotic $(\mathrm{CLR}=10 \mu \mathrm{g} / \mathrm{mL}$, RIF $=0.5 \mu \mathrm{g} / \mathrm{mL})$. After 28-35 days, colonies were enumerated. CLR-resistant colonies occurred at a frequency of $1.7 \times 10^{-8}$ and were picked and grown in complete $7 \mathrm{H} 9+\mathrm{CLR}(4 \mu \mathrm{g} / \mathrm{mL})$. Samples were heat lysed and whiB7 and $\mathrm{rr} /$ were PCR amplified and sequenced using the primers listed (Supplemental Table 1). Sanger sequencing revealed a wild-type whiB7 locus in all $(n=101)$ clarithromycin-resistant isolates. Instead, clarithromycin resistance was conferred by a variety of base substitutions in the 23S rRNA (Supplemental Figure 10C,D). Select samples were cultured further and purified genomic DNA was submitted for WGS. 
1314

1315

1316

1317

1318

1319

1320

1321

1322

1323

1324

1325

1326

1327

1328

1329

1330

1331

1332

1333

1334

1335

1336

1337

1338

1339

1340

1341

1342

1343

1344

1345

1346

1347

1348

1349

1350

1351

1352

1353

1354

1355

1356

1357

1358

1359

1360

1361

1362

1363

1364

1365

1366

1367

1368

\section{Total RNA extraction and qRT-PCR}

Total RNA extraction was performed as previously described (Bosch et al., 2021). Briefly, $2 \mathrm{OD}_{600}$ units of bacteria were added to an equivalent volume of GTC buffer ( $5 \mathrm{M}$ guanidinium thiocyanate, $0.5 \%$ sodium Nlauroylsarcosine, $25 \mathrm{mM}$ trisodium citrate dihydrate, and $0.1 \mathrm{M} 2$-mercaptoethanol), pelleted by centrifugation, resuspended in $1 \mathrm{~mL}$ TRIzol (Thermo Fisher Scientific; \#15596026) and lysed by zirconium bead beating (MP Biomedicals; \#116911050). $0.2 \mathrm{~mL}$ chloroform was added to each sample and samples were frozen at $-80^{\circ} \mathrm{C}$. After thawing, samples were centrifuged to separate phases, and the aqueous phase was purified by Direct-zol RNA miniprep (Zymo Research; \# R2052). Residual genomic DNA was removed by TURBO DNase treatment (Invitrogen Ambion; \# AM2238). After RNA cleanup and concentration (Zymo Research; \#R1017), $3 \mu \mathrm{g}$ of RNA per sample was reverse transcribed into cDNA with random hexamers (Thermo Fisher Scientific; \# 18-091-050) following manufacturer's instructions. RNA was removed by alkaline hydrolysis and cDNA was purified with PCR clean-up columns (Qiagen; \#28115). Next, knockdown of the targets was quantified by SYBR green dye-based quantitative real-time PCR (Applied Biosystems; \#4309155) on a Quantstudio System 5 (Thermofisher Scientific; \#A28140) using gene-specific qPCR primers $(5 \mu \mathrm{M})$, normalized to sigA (rv2703) and quantified by the $\triangle \triangle \mathrm{Ct}$ algorithm. All gene-specific qPCR primers were designed using the PrimerQuest tool from IDT

(https://www.idtdna.com/PrimerQuest/Home/Index) and then validated for efficiency and linear range of amplification using standard qPCR approaches. Specificity was confirmed for each validated qPCR primer pair through melting curve analysis.

\section{RNA-seq cDNA library construction and deep sequencing}

Triplicate cultures were grown to mid-log phase in $7 \mathrm{H} 9$ and diluted back to $\mathrm{OD}_{600}=0.2$ in $7 \mathrm{H} 9$ in the presence or the absence of ATc $(100 \mathrm{ng} / \mathrm{mL})$. Cultures were incubated for 48 hours, after which total RNA was extracted as described in "Total RNA extraction and qRT-PCR." Following RNA cleanup (Zymo Research; \#R1017), $2 \mu \mathrm{g}$ total RNA for each sample was depleted for rRNA using a Ribominus Transcriptome Isolation Kit (Yeast and Bacteria, Invitrogen, K1550-03). Following rRNA depletion, RNA was concentrated using an RNA Clean and Concentration-5 kit (Zymo Research, R1013). RNA quality was then confirmed by Bioanlayzer (Agilent RNA 6000 Pico kit, 5067-1513).

We used the NEB Next Ultra II Directional RNA Library Prep Kit (NEB, E7760 and E7765) to prepare cDNA libraries, following manufacturer's instructions. Briefly, $150 \mathrm{ng}$ of rRNA-depleted RNA was subjected to fragmentation by incubating samples at $94^{\circ} \mathrm{C}$ for $20 \mathrm{~min}$, followed by first strand cDNA synthesis $(10$ minutes at $25^{\circ} \mathrm{C}, 50$ minutes at $42^{\circ} \mathrm{C}, 15$ minutes at $70^{\circ} \mathrm{C}$, hold at $4^{\circ} \mathrm{C}$ ). Second-strand synthesis was performed at $16^{\circ} \mathrm{C}$ for 1.5 hours. DNA purification was performed with AMPure XP beads (Beckman Coulter, A63881). End repair was performed for 30 minutes at $20^{\circ} \mathrm{C}$, followed by 30 minutes at $65^{\circ} \mathrm{C}$. Repaired dsDNA was adaptor ligated $\left(15\right.$ minutes at $\left.37^{\circ} \mathrm{C}\right)$ and purified with AMPure XP beads. Eluted DNA was amplified by PCR using NGS primers supplied with the kit (NEBNext Multiplex Oligos for Illumina, Index Primers Set 1 and 2, E7335S, E7500S) for 12 cycles of amplification. Amplicons were purified with AMPure XP beads, quantified by Qubit dsDNA HS Assay kit (TheromoFisher Scientific, Q32851), and quality controlled by BioAnalzer (Agilent DNA 1000, 5067-1504). RNAseq libraries were sequenced on an Illumina NextSeq 500 (mid-output, 75 bp paired-end read).

\section{Processing and analysis of RNA-seq data}

Raw FASTQ files were aligned to the H37Rv genome (NC_018143.2) using Rsubread (version 2.0.1)(Liao et al., 2019) with default settings. Transcript abundances were calculated by processing the resulting BAM files with the summarizeOverlaps function of the R package GenomicAlignments (version 1.22.1)(Lawrence et al., 2013). Overlaps were calculated in the "Union" mode, ensuring reads were counted only if they overlap a portion of a single gene/feature. 16S, 23S, and 5S rRNA features (RVBD6018, 6019, and 6020, respectively) were manually removed from the count data to prevent confounding downstream differential gene expression analysis. Differential expression analysis was conducting using DESeq2 (version 1.30.1)(Love et al., 2014) with default parameters. 


\section{Cell wall permeability assay}

Cell envelope permeability was determined using the ethidium bromide $(\mathrm{EtBr})$ uptake assay as previously described(Xu et al., 2017). Briefly, mid-log-phase Mtb cultures were washed once in PBS $+0.05 \%$ Tween80 and adjusted to $\mathrm{OD}_{600}=0.8$ in PBS supplemented with $0.4 \%$ glucose. $100 \mu \mathrm{L}$ of bacterial suspension was added to a black 96-well clear-bottomed plate (Costar). After this, $100 \mu \mathrm{L}$ of $2 \mu \mathrm{g} / \mathrm{mL} \mathrm{EtBr}$ in PBS supplemented with $0.4 \%$ glucose was added to each well. EtBr fluorescence was measured (excitation: 530 nm/emission: $590 \mathrm{~nm}$ ) at $1 \mathrm{~min}$ intervals over a course of $60 \mathrm{~min}$. Experiments were performed in technical triplicate.

A similar assay was performed to determine envelope permeability to a fluorescent vancomycin analogue, except that: (1) the bacterial suspension was adjusted at $\mathrm{OD}_{600}=0.4$ in PBS supplemented with $0.4 \%$ glucose; (2) cells were incubated with $2 \mu \mathrm{g} / \mathrm{mL}$ BODIPY FL Vancomycin (Thermo Scientific, V34850); (3) $200 \mu \mathrm{L}$ sample aliquots were taken at different time points, washed twice with PBS, resuspended in $200 \mu \mathrm{L}$ PBS; and (4) fluorescence was measured (excitation: $485 \mathrm{~nm} / \mathrm{emission:} 538 \mathrm{~nm}$ ) and normalized to the $\mathrm{OD}_{600}$ of the final bacterial suspension.

\section{Whole genome sequencing data aggregation, alignment, SNP calling and annotation}

FASTQ data were downloaded from NCBI using the SRA Toolkit (version 2.9.6). A list of accession numbers of all analyzed FASTQ files is provided in Supplemental Data 4. FASTQ reads were aligned to the H37Rv genome (NC_018143.2) and SNPs were called and annotated using Snippy (version 3.2-dev) using default parameters (minimum mapping quality of 60 in BWA, SAMtools base quality threshold of 20 , minimum coverage of 10, minimum proportion of reads that differ from reference of 0.9 (Seemann, 2020). Mapping quality and coverage was further assessed using QualiMap with the default parameters (version 2.2.2-dev)(Okonechnikov et al., 2016). Samples with a mean coverage $<30$, mean mapping quality $<=45$, or GC content $<=50 \%$ or $>=70 \%$ were excluded. Spoligotypes were assigned using SpoTyping (version 2.1)(Xia et al., 2016). Drug resistance conferring SNPs were annotated using reference SNP lists from (Allix-Béguec et al., 2018; Sandgren et al., 2009) and Mykrobe v0.9.0 (Hunt et al., 2019).

Phylogenetic trees were built using FastTree (version 2.1.11 SSE3) (Price et al., 2010). A list of SNPs in essential genes was concatenated for the building phylogenetic trees. Indels, drug resistance-conferring SNPs, and SNPs in repetitive regions of the genome (PE/PPE genes, transposases and prophage genes) were excluded. Tree visualization was performed in iTol (https:/itol.embl.de/).

\section{Sublineage identification}

Mtb sublineages were assigned to each sample using a set of lineage identifying SNPs. Lineage identifying SNPs from(Coll et al., 2014; Palittapongarnpim et al., 2018) were combined and then reduced to a subset of synonymous SNPs occurring in essential genes. For each sample, the percentage of lineage identifying SNPs present was calculated for each possible sublineage. A threshold of $67 \%$ was set as the minimum percentage of sublineage identifying SNPs required in order to define a sublineage. For each sample, all sublineages meeting this threshold were then evaluated to determine if they formed a continuous line of descent from the highest sublineage to the lowest (e.g. lineage $1 \rightarrow$ lineage $1.2 \rightarrow$ lineage $1.2 .1 \rightarrow$ lineage1.2.1.1). Samples with a continuous line of descent were assigned the most specific sublineage (e.g. lineage1.2.1.1). If the set of sublineages included other sublineages that did not fit within the line of descent, the sublineage call was marked as "not confident" and considered as an undetermined sublineage. 
bioRxiv preprint doi: https://doi.org/10.1101/2021.11.27.469863; this version posted November $27,2021$. The copyright holder for this preprint (which was not certified by peer review) is the author/funder, who has granted bioRxiv a license to display the preprint in perpetuity. It is made available under aCC-BY-ND 4.0 International license.

\section{Mouse infection and drug treatment}

Female BALB/c mice (Charles Rivers Laboratory) 7-8 weeks old were infected with 100-200 CFU of Mtb using a whole-body inhalation exposure system (Glas-Col). After 10 days (Figure 6D, E) or 14 days (Supplemental Figure $\mathbf{1 0 H}, \mathrm{I}$ ), animals were randomly assigned to study groups and chemotherapy was initiated. CLR and RIF were stirred in $0.5 \% \mathrm{CMC} / 0.5 \%$ Tween- 80 to resuspend; INH was resuspended in water. AZM was resuspended in water. Liquid drug formulations were administered once daily by oral gavage for 14 consecutive days. After 13 days of drug treatment, blood samples of the mice were taken 1 hour and 24 hours post dosing (Supplemental Figure 10J,K). At designated time points (14 after starting chemotherapy), mice were euthanized, and lungs and spleens were aseptically removed, homogenized in 1 $\mathrm{mL}$ PBS $+0.05 \%$ Tween- 80 and plated on Middlebrook $7 \mathrm{H} 11$ agar supplemented with $10 \%$ OADC. Colonies were counted after 4-6 weeks of incubation at $37^{\circ} \mathrm{C}$. Mice were housed in groups of 5 in individually ventilated cages inside a certified ABSL-3 facility and had access to water and food ad libitum for the duration of the study. All experiments involving animals were approved by the Institutional Animal Care and Use Committee of the Center for Discovery and Innovation.

\section{Drug quantitation in plasma by high pressure liquid chromatography coupled to tandem mass spectrometry (LC-MS/MS)}

Neat $1 \mathrm{mg} / \mathrm{mL}$ DMSO stocks for rifampicin (RIF), azithromycin (AZM), and clarithromycin (CLR) were serial diluted in 50/50 (acetonitrile/water) to create neat spiking stocks. Standards and quality controls were created by adding $10 \mu \mathrm{L}$ of spiking stock to $90 \mu \mathrm{L}$ of drug free plasma. $10 \mu \mathrm{L}$ of control, standard, quality control, or study sample were added to $100 \mu \mathrm{L}$ of 50/50 (acetonitrile/methanol) protein precipitation solvent containing the stable labeled internal standards RIF-d8 (Toronto Research Chemicals; R508003), AZM-d5 (Toronto Research Chemicals; A927004) and CLR-13C-d3 (Cayman Chemical; 26678) at $10 \mathrm{ng} / \mathrm{mL}$. Extracts were vortexed for 5 min and centrifuged at $4,000 \mathrm{rpm}$ for $5 \mathrm{~min} .100 \mu \mathrm{L}$ of supernatant of RIF containing samples was combined with $5 \mu \mathrm{L}$ of $75 \mathrm{mg} / \mathrm{mL}$ ascorbic acid to stabilize RIF. $100 \mu \mathrm{L}$ of mixture was combined with $100 \mu \mathrm{L}$ of Milli-Q water prior to HPLC-MS/MS analysis. CD-1 mouse control plasma ( $\mathrm{K}_{2}$ EDTA) was sourced from Bioreclamation. RIF, AZM, and CLR were sourced from Sigma Aldrich.

LC-MS/MS analysis was performed on a Sciex Applied Biosystems Qtrap 6500+ triple-quadrupole mass spectrometer coupled to a Shimadzu Nexera X2 UHPLC system to quantify each drug in plasma.

Chromatography was performed on an Agilent SB-C8 $(2.1 \times 30 \mathrm{~mm}$; particle size, $3.5 \mu \mathrm{m})$ using a reverse phase gradient. Milli-Q deionized water with $0.1 \%$ formic acid was used for the aqueous mobile phase and $0.1 \%$ formic acid in acetonitrile for the organic mobile phase. Multiple-reaction monitoring of precursor/product transitions in electrospray positive-ionization mode was used to quantify the analytes. Sample analysis was accepted if the concentrations of the quality control samples were within $20 \%$ of the nominal concentration. The compounds were ionized using ESI positive mode ionization and monitored using masses RIF (823.50/791.60), AZM (749.38/591.30), CLR (748.38/158.20), RIF-d8 (831.50/799.60), AZM-d5 (754.37/596.30), and CLR-d4 (752.33/162.10). Data processing was performed using Analyst software (version 1.6.2; Applied Biosystems Sciex).

\section{DATA AVAILABILITY}

1466

Raw sequencing data will be deposited to the Short Read Archive (SRA) under project number 1468 
bioRxiv preprint doi: https://doi.org/10.1101/2021.11.27.469863; this version posted November 27, 2021. The copyright holder for this preprint (which was not certified by peer review) is the author/funder, who has granted bioRxiv a license to display the preprint in perpetuity. It is made available under aCC-BY-ND 4.0 International license.

\section{REFERENCES}

Abrahams, K.A., Chung, C.W., Ghidelli-Disse, S., Rullas, J., Rebollo-López, M.J., Gurcha, S.S., Cox, J.A.G., Mendoza, A., Jiménez-Navarro, E., Martínez-Martínez, M.S., et al. (2016). Identification of KasA as the cellular target of an anti-tubercular scaffold. Nat. Commun. 7.

Adams, K.N., Takaki, K., Connolly, L.E., Wiedenhoft, H., Winglee, K., Humbert, O., Edelstein, P.H., Cosma, C.L., and Ramakrishnan, L. (2011). Drug tolerance in replicating mycobacteria mediated by a macrophageinduced efflux mechanism. Cell 145, 39-53.

Alland, D., Steyn, A.J., Weisbrod, T., Aldrich, K., and Jacobs, W.R. (2000). Characterization of the Mycobacterium tuberculosis iniBAC promoter, a promoter that responds to cell wall biosynthesis inhibition. J. Bacteriol. 182, 1802-1811.

Allix-Béguec, C., Arandjelovic, I., Bi, L., Beckert, P., Bonnet, M., Bradley, P., Cabibbe, A.M., CancinoMuñoz, I., Caulfield, M.J., Chaiprasert, A., et al. (2018). Prediction of susceptibility to first-line tuberculosis drugs by DNA sequencing. N. Engl. J. Med. 379, 1403-1415.

Alumasa, J.N., Manzanillo, P.S., Peterson, N.D., Lundrigan, T., Baughn, A.D., Cox, J.S., and Keiler, K.C. (2017). Ribosome Rescue Inhibitors Kill Actively Growing and Nonreplicating Persister Mycobacterium tuberculosis Cells. ACS Infect. Dis. 3, 634-644.

Andries, K., Verhasselt, P., Guillemont, J., Göhlmann, H.W.H., Neefs, J.M., Winkler, H., Van Gestel, J., Timmerman, P., Zhu, M., Lee, E., et al. (2005). A diarylquinoline drug active on the ATP synthase of Mycobacterium tuberculosis. Science (80-. ). 307, 223-227.

Andries, K., Villellas, C., Coeck, N., Thys, K., Gevers, T., Vranckx, L., Lounis, N., De Jong, B.C., and Koul, A. (2014). Acquired resistance of Mycobacterium tuberculosis to bedaquiline. PLoS One 9.

Antonelli, A., D’Andrea, M.M., Brenciani, A., Galeotti, C.L., Morroni, G., Pollini, S., Varaldo, P.E., and Rossolini, G.M. (2018). Characterization of poxtA, a novel phenicol-oxazolidinone-tetracycline resistance gene from an MRSA of clinical origin. J. Antimicrob. Chemother. 73, 1763-1769.

Bailey, T.L., Boden, M., Buske, F.A., Frith, M., Grant, C.E., Clementi, L., Ren, J., Li, W.W., and Noble, W.S. (2009). MEME Suite: Tools for motif discovery and searching. Nucleic Acids Res. 37.

Balaban, N.Q., Helaine, S., Lewis, K., Ackermann, M., Aldridge, B., Andersson, D.I., Brynildsen, M.P., Bumann, D., Camilli, A., Collins, J.J., et al. (2019). Definitions and guidelines for research on antibiotic persistence. Nat. Rev. Microbiol. 17, 441-448.

Banerjee, A., Dubnau, E., Quemard, A., Balasubramanian, V., Um, K.S., Wilson, T., Collins, D., De Lisle, G., and Jacobs, W.R. (1994). inhA, a gene encoding a target for isoniazid and ethionamide in Mycobacterium tuberculosis. Science (80-. ). 263, 227-230.

Batt, S.M., Minnikin, D.E., and Besra, G.S. (2020). The thick waxy coat of mycobacteria, a protective layer against antibiotics and the host's immune system. Biochem. J. 447, 1983-2006.

Beckert, P., Hillemann, D., Kohl, T.A., Kalinowski, J., Richter, E., Niemann, S., and Feuerriegel, S. (2012). rpIC T460C identified as a dominant mutation in linezolid-resistant Mycobacterium tuberculosis strains. Antimicrob. Agents Chemother. 56, 2743-2745.

Bellerose, M.M., Baek, S.H., Huang, C.C., Moss, C.E., Koh, E.I., Proulx, M.K., Smith, C.M., Baker, R.E., Lee, J.S., Eum, S., et al. (2019). Common variants in the glycerol kinase gene reduce tuberculosis drug efficacy. MBio 10.

Blondiaux, N., Moune, M., Desroses, M., Frita, R., Flipo, M., Mathys, V., Soetaert, K., Kiass, M., Delorme, V., Djaout, K., et al. (2017). Reversion of antibiotic resistance in Mycobacterium tuberculosis by spiroisoxazoline SMARt-420. Science (80-. ). 355, 1206-1211.

Boël, G., Smith, P.C., Ning, W., Englander, M.T., Chen, B., Hashem, Y., Testa, A.J., Fischer, J.J., Wieden, H.J., Frank, J., et al. (2014). The ABC-F protein EttA gates ribosome entry into the translation elongation cycle. Nat. Struct. Mol. Biol. 21, 143-151.

Borrell, S., Trauner, A., Brites, D., Rigouts, L., Loiseau, C., Coscolla, M., Niemann, S., De Jong, B., 
bioRxiv preprint doi: https://doi.org/10.1101/2021.11.27.469863; this version posted November $27,2021$. The copyright holder for this preprint (which was not certified by peer review) is the author/funder, who has granted bioRxiv a license to display the preprint in perpetuity. It is made available under aCC-BY-ND 4.0 International license.

Yeboah-Manu, D., Kato-Maeda, M., et al. (2019). Reference set of Mycobacterium tuberculosis clinical strains: A tool for research and product development. PLoS One 14, 1-12.

Bosch, B., DeJesus, M.A., Poulton, N.C., Zhang, W., Engelhart, C.A., Zaveri, A., Lavalette, S., Ruecker, N., Trujillo, C., Wallach, J.B., et al. (2021). Genome-wide gene expression tuning reveals diverse vulnerabilities of M. tuberculosis. Cell 184(17), 4579-4592.

Bosne-David, S., Barro, V., Verde, S.C., Portugal, C., and David, H.L. (2000). Intrinsic resistance of Mycobacterium tuberculosis to clarithromycin is effectively reversed by subinhibitory concentrations of cell wall inhibitors. J. Antimicrob. Chemother. 46, 391-395.

Brunel, R., Descours, G., Durieux, I., Doublet, P., Jarraud, S., and Charpentier, X. (2018). KKL-35 exhibits potent antibiotic activity against legionella species independently of trans-translation inhibition. Antimicrob. Agents Chemother. 62, 1-10.

Burian, J., Yim, G., Hsing, M., Axerio-Cilies, P., Cherkasov, A., Spiegelman, G.B., and Thompson, C.J. (2013). The mycobacterial antibiotic resistance determinant WhiB7 acts as a transcriptional activator by binding the primary sigma factor SigA (RpoV). Nucleic Acids Res. 41, 10062-10076.

Campbell, E.A., Korzheva, N., Mustaev, A., Murakami, K., Nair, S., Goldfarb, A., and Darst, S.A. (2001). Structural mechanism for rifampicin inhibition of bacterial RNA polymerase. Cell 104, 901-912.

Carter, J.J. (2021). Quantitative measurement of antibiotic resistance in Mycobacterium tuberculosis reveals genetic determinants of resistance and susceptibility in a target gene approach. BioRxiv.

Chakravorty, S., Lee, J.S., Cho, E.J., Roh, S.S., Smith, L.E., Lee, J., Kim, C.T., Via, L.E., Cho, S.N., Barry, C.E., et al. (2015). Genotypic susceptibility testing of Mycobacterium tuberculosis isolates for amikacin and kanamycin resistance by use of a rapid sloppy molecular beacon-based assay identifies more cases of lowlevel drug resistance than phenotypic Lowenstein-Jensen testin. J. Clin. Microbiol. 53, 43-51.

Chen, B., Boël, G., Hashem, Y., Ning, W., Fei, J., Wang, C., Gonzalez, R.L., Hunt, J.F., and Frank, J. (2013). EttA regulates translation by binding the ribosomal $E$ site and restricting ribosome-tRNA dynamics. Nat. Publ. Gr.

Choudhary, E., Thakur, P., Pareek, M., and Agarwal, N. (2015). Gene silencing by CRISPR interference in mycobacteria. Nat. Commun. 6.

Cohen, K.A., Stott, K.E., Munsamy, V., Manson, A.L., Earl, A.M., and Pym, A.S. (2020). Evidence for expanding the role of streptomycin in the management of drug-resistant mycobacterium tuberculosis. Antimicrob. Agents Chemother. 64.

Cokol, M., Kuru, N., Bicak, E., Larkins-Ford, J., and Aldridge, B.B. (2017). Efficient measurement and factorization of high-order drug interactions in Mycobacterium tuberculosis. Sci. Adv. 3.

Colangeli, R., Jedrey, H., Kim, S., Connell, R., Ma, S., Venkata, U.D.C., Chakravorty, S., Gupta, A., Sizemore, E.E., Diem, L., et al. (2018). Bacterial factors that predict relapse after tuberculosis therapy. N. Engl. J. Med. 379, 823-833.

Coll, F., McNerney, R., Guerra-Assunção, J.A., Glynn, J.R., Perdigão, J., Viveiros, M., Portugal, I., Pain, A., Martin, N., and Clark, T.G. (2014). A robust SNP barcode for typing Mycobacterium tuberculosis complex strains. Nat. Commun. 5.

Conradie, F., Diacon, A.H., Ngubane, N., Howell, P., Everitt, D., Crook, A.M., Mendel, C.M., Egizi, E., Moreira, J., Timm, J., et al. (2020). Treatment of Highly Drug-Resistant Pulmonary Tuberculosis. N. Engl. J. Med. 382, 893-902.

Couvin, D., David, A., Zozio, T., and Rastogi, N. (2019). Macro-geographical specificities of the prevailing tuberculosis epidemic as seen through SITVIT2, an updated version of the Mycobacterium tuberculosis genotyping database. Infect. Genet. Evol. 72, 31-43.

Dartois, V. (2014). The path of anti-tuberculosis drugs: From blood to lesions to mycobacterial cells. Nat. Rev. Microbiol. 12, 159-167.

Davis, T.D., Gerry, C.J., and Tan, D.S. (2014). General platform for systematic quantitative evaluation of 
small-molecule permeability in bacteria. ACS Chem. Biol. 9, 2535-2544.

Dejesus, M.A., Gerrick, E.R., Xu, W., Park, S.W., Long, J.E., Boutte, C.C., Rubin, E.J., Schnappinger, D., Ehrt, S., Fortune, S.M., et al. (2017). Comprehensive essentiality analysis of the Mycobacterium tuberculosis genome via saturating transposon mutagenesis. MBio 8.

Dick, T., and Dartois, V. (2018). TB drug susceptibility is more than MIC. Nat. Microbiol. 3, 971-972.

Domenech, P., Kobayashi, H., Levier, K., Walker, G.C., and Barry, C.E. (2009). BacA, an ABC transporter involved in maintenance of chronic murine infections with mycobacterium tuberculosis. J. Bacteriol. 191, 477-485.

Duan, W., Li, X., Ge, Y., Yu, Z., Li, P., Li, J., Qin, L., and Xie, J. (2019). Mycobacterium tuberculosis Rv1473 is a novel macrolides ABC Efflux Pump regulated by WhiB7. Future Microbiol. 14, 47-59.

Faksri, K., Tan, J.H., Disratthakit, A., Xia, E., Prammananan, T., Suriyaphol, P., Khor, C.C., Teo, Y.Y., Ong, R.T.H., and Chaiprasert, A. (2016). Whole-genome sequencing analysis of serially isolated multi-drug and extensively drug resistant Mycobacterium tuberculosis from Thai patients. PLoS One 11, 1-16.

Gorla, P., Plocinska, R., Sarva, K., Satsangi, A.T., Pandeeti, E., Donnelly, R., Dziadek, J., Rajagopalan, M., and Madiraju, M. V. (2018). MtrA Response Regulator Controls Cell Division and Cell Wall Metabolism and Affects Susceptibility of Mycobacteria to the First Line Antituberculosis Drugs. Front. Microbiol. 9, 2839.

Hicks, N.D., Yang, J., Zhang, X., Zhao, B., Grad, Y.H., Liu, L., Ou, X., Chang, Z., Xia, H., Zhou, Y., et al. (2018). Clinically prevalent mutations in Mycobacterium tuberculosis alter propionate metabolism and mediate multidrug tolerance. Nat. Microbiol. 3, 1032-1042.

Hicks, N.D., Giffen, S.R., Culviner, P.H., Chao, M.C., Dulberger, C.L., Liu, Q., Stanley, S., Brown, J., Sixsmith, J., Wolf, I.D., et al. (2020). Mutations in dnaA and a cryptic interaction site increase drug resistance in Mycobacterium tuberculosis. PLoS Pathog. 16, 1-28.

Hugonnet, J.E., Tremblay, L.W., Boshoff, H.I., Barry, C.E., and Blanchard, J.S. (2009). Meropenemclavulanate is effective against extensively drug-resistant Mycobacterium tuberculosis. Science (80-. ). 323, 1215-1218.

Hunt, M., Bradley, P., Lapierre, S.G., Heys, S., Thomsit, M., Hall, M.B., Malone, K.M., Wintringer, P., Walker, T.M., Cirillo, D.M., et al. (2019). Antibiotic resistance prediction for Mycobacterium tuberculosis from genome sequence data with mykrobe [version 1; peer review: 2 approved, 1 approved with reservations]. Wellcome Open Res. 4.

Jankute, M., Cox, J.A.G., Harrison, J., and Besra, G.S. (2015). Assembly of the Mycobacterial Cell Wall. Annu. Rev. Microbiol. 69, 405-423.

Jarlier, V., and Nikaido, H. (1994). Mycobacterial cell wall: Structure and role in natural resistance to antibiotics. FEMS Microbiol. Lett. 123, 11-18.

Jenner, L., Starosta, A.L., Terry, D.S., Mikolajka, A., Filonava, L., Yusupov, M., Blanchard, S.C., Wilson, D.N., and Yusupova, G. (2013). Structural basis for potent inhibitory activity of the antibiotic tigecycline during protein synthesis. Proc. Natl. Acad. Sci. U. S. A. 110, 3812-3816.

Johnson, E.O., LaVerriere, E., Office, E., Stanley, M., Meyer, E., Kawate, T., Gomez, J.E., Audette, R.E., Bandyopadhyay, N., Betancourt, N., et al. (2019). Large-scale chemical-genetics yields new M. tuberculosis inhibitor classes. Nature 571, 72-78.

Kannan, K., Kanabar, P., Schryer, D., Florin, T., Oh, E., Bahroos, N., Tenson, T., Weissman, J.S., and Mankin, A.S. (2014). The general mode of translation inhibition by macrolide antibiotics. Proc. Natl. Acad. Sci. U. S. A. 111, 15958-15963.

Kaur, S., Rana, V., Singh, P., Trivedi, G., Anand, S., Kaur, A., Gupta, P., Jain, A., and Sharma, C. (2016). Novel mutations conferring resistance to kanamycin in Mycobacterium tuberculosis clinical isolates from Northern India. Tuberculosis 96, 96-101.

Knight, Z.A., and Shokat, K.M. (2007). Chemical Genetics: Where Genetics and Pharmacology Meet. Cell 128, 425-430. 
bioRxiv preprint doi: https://doi.org/10.1101/2021.11.27.469863; this version posted November 27, 2021. The copyright holder for this preprint (which was not certified by peer review) is the author/funder, who has granted bioRxiv a license to display the preprint in perpetuity. It is made available under aCC-BY-ND 4.0 International license.

Koh, E.-I., Ruecker, N., Proulx, M.K., Soni, V., Murphy, K.C., Papavinasasundaram, K.G., Reames, C.J., Trujillo, C., Zimmerman, M.D., Aslebagh, R., et al. (2021). Chemical-genetic interaction mapping links carbon metabolism and cell wall 1 structure to tuberculosis drug efficacy 2 3. BioRxiv 2021.04.08.439092.

Krause, K.M., Serio, A.W., Kane, T.R., and Connolly, L.E. (2016). Aminoglycosides: An overview. Cold Spring Harb. Perspect. Med. 6, 1-18.

Kumar, P., Capodagli, G.C., Awasthi, D., Shrestha, R., Maharaja, K., Sukheja, P., Li, S.G., Inoyama, D., Zimmerman, M., Liang, H.P.H., et al. (2018). Synergistic lethality of a binary inhibitor of mycobacterium tuberculosis kasA. MBio 9.

LaMarre, J.M., Howden, B.P., and Mankin, A.S. (2011). Inactivation of the indigenous methyltransferase $\mathrm{RImN}$ in Staphylococcus aureus increases linezolid resistance. Antimicrob. Agents Chemother. 55, 29892991.

Larrouy-Maumus, G., Marino, L.B., Madduri, A.V.R., Ragan, T.J., Hunt, D.M., Bassano, L., Gutierrez, M.G., Moody, D.B., Pavan, F.R., and De Carvalho, L.P.S. (2016). Cell-envelope remodeling as a determinant of phenotypic antibacterial tolerance in mycobacterium tuberculosis. ACS Infect. Dis. 2, 352-360.

Lawrence, M., Huber, W., Pagès, H., Aboyoun, P., Carlson, M., Gentleman, R., Morgan, M.T., and Carey, V.J. (2013). Software for Computing and Annotating Genomic Ranges. PLoS Comput. Biol. 9, 1-10.

Lee, R.E., Hurdle, J.G., Liu, J., Bruhn, D.F., Matt, T., Scherman, M.S., Vaddady, P.K., Zheng, Z., Qi, J., Akbergenov, R., et al. (2014). Spectinamides: A new class of semisynthetic antituberculosis agents that overcome native drug efflux. Nat. Med. 20,152-158.

Lenaerts, A., Barry, C.E., and Dartois, V. (2015). Heterogeneity in tuberculosis pathology, microenvironments and therapeutic responses. Immunol. Rev. 264, 288-307.

Li, W., Xu, H., Xiao, T., Cong, L., Love, M.I., Zhang, F., Irizarry, R.A., Liu, J.S., Brown, M., and Liu, X.S. (2014). MAGeCK enables robust identification of essential genes from genome-scale CRISPR/Cas9 knockout screens. Genome Biol. 15, 554.

Liao, Y., Smyth, G.K., and Shi, W. (2019). The R package Rsubread is easier, faster, cheaper and better for alignment and quantification of RNA sequencing reads. Nucleic Acids Res. 47.

Liu, J., Shi, W., Zhang, S., Hao, X., Maslov, D.A., Shur, K. V., Bekker, O.B., Danilenko, V.N., and Zhang, Y. (2019). Mutations in efflux pump Rv1258c (Tap) cause resistance to pyrazinamide, isoniazid, and streptomycin in M. tuberculosis. Front. Microbiol. 10, 1-7.

Love, M.I., Huber, W., and Anders, S. (2014). Moderated estimation of fold change and dispersion for RNAseq data with DESeq2. Genome Biol. 15, 1-21.

Luna-Herrera, J., Reddy, V.M., Daneluzzi, D., and Gangadharam, P.R. (1995). Antituberculosis activity of clarithromycin. Antimicrob. Agents Chemother. 39, 2692-2695.

Madsen, C.T., Jakobsen, L., Buriánková, K., Doucet-Populaire, F., Pernodet, J.L., and Douthwaite, S. (2005). Methyltransferase Erm(37) slips on rRNA to confer atypical resistance in Mycobacterium tuberculosis. J. Biol. Chem. 280, 38942-38947.

Maitra, A., Munshi, T., Healy, J., Martin, L.T., Vollmer, W., Keep, N.H., and Bhakta, S. (2019). Cell wall peptidoglycan in Mycobacterium tuberculosis: An Achilles' heel for the TB-causing pathogen. FEMS Microbiol. Rev. 43, 548-575.

Marín, A.V., Rastogi, N., Couvin, D., Mape, V., and Murcia, M.I. (2021). First approach to the population structure of Mycobacterium tuberculosis complex in the indigenous population in Puerto Nariño-Amazonas, Colombia. PLoS One 16.

Marks, J., Kannan, K., Roncase, E.J., Klepacki, D., Kefi, A., Orelle, C., Vázquez-Laslop, N., and Mankin, A.S. (2016). Context-specific inhibition of translation by ribosomal antibiotics targeting the peptidyl transferase center. Proc. Natl. Acad. Sci. U. S. A. 113, 12150-12155.

McNeil, M.B., Chettiar, S., Awasthi, D., and Parish, T. (2019). Cell wall inhibitors increase the accumulation of rifampicin in Mycobacterium tuberculosis. Access Microbiol. 1, e000006. 
bioRxiv preprint doi: https://doi.org/10.1101/2021.11.27.469863; this version posted November $27,2021$. The copyright holder for this preprint (which was not certified by peer review) is the author/funder, who has granted bioRxiv a license to display the preprint in perpetuity. It is made available under aCC-BY-ND 4.0 International license.

Merker, M., Kohl, T.A., Barilar, I., Andres, S., Fowler, P.W., Chryssanthou, E., Ängeby, K., Jureen, P., Moradigaravand, D., Parkhill, J., et al. (2020). Phylogenetically informative mutations in genes implicated in antibiotic resistance in Mycobacterium tuberculosis complex. Genome Med. 12, 1-8.

Morris, R.P., Nguyen, L., Gatfield, J., Visconti, K., Nguyen, K., Schnappinger, D., Ehrt, S., Liu, Y., Heifets, L., Pieters, J., et al. (2005). Ancestral antibiotic resistance in Mycobacterium tuberculosis. Proc. Natl. Acad. Sci. U. S. A. 102, 12200-12205.

Murphy, K.C., Papavinasasundaram, K., and Sassetti, C.M. (2015). Mycobacterial Recombineering. In Mycobacteria Protocols, T. Parish, and D.M. Roberts, eds. (New York, NY: Springer New York), pp. 177199.

Netikul, T., Palittapongarnpim, P., Thawornwattana, Y., and Plitphonganphim, S. (2021). Estimation of the global burden of Mycobacterium tuberculosis lineage 1. Infect. Genet. Evol. 104802.

Nguyen, H.T., Wolff, K.A., Cartabuke, R.H., Ogwang, S., and Nguyen, L. (2010). A lipoprotein modulates activity of the MtrAB two-component system to provide intrinsic multidrug resistance, cytokinetic control and cell wall homeostasis in Mycobacterium. Mol. Microbiol. 76, 348-364.

O'Neill, M.B., Shockey, A., Zarley, A., Aylward, W., Eldholm, V., Kitchen, A., and Pepperell, C.S. (2019). Lineage specific histories of Mycobacterium tuberculosis dispersal in Africa and Eurasia. Mol. Ecol. 28, 3241-3256.

Okonechnikov, K., Conesa, A., and García-Alcalde, F. (2016). Qualimap 2: Advanced multi-sample quality control for high-throughput sequencing data. Bioinformatics 32, 292-294.

Palittapongarnpim, P., Ajawatanawong, P., Viratyosin, W., Smittipat, N., Disratthakit, A., Mahasirimongkol, S., Yanai, H., Yamada, N., Nedsuwan, S., Imasanguan, W., et al. (2018). Evidence for Host-Bacterial Coevolution via Genome Sequence Analysis of 480 Thai Mycobacterium tuberculosis Lineage 1 Isolates. Sci. Rep. 8, 1-14.

Personne, Y., and Parish, T. (2014). Mycobacterium tuberculosis possesses an unusual tmRNA rescue system. Tuberculosis 94, 34-42.

Peterson, E.J., Brooks, A.N., Reiss, D.J., Kaur, A., Wu, W.-J., Srinivas, V., Turkarslan, S., Pan, M., Carter, W., Arrieta-Ortiz, M.L., et al. (2021). MtrA regulation of essential peptidoglycan cleavage in Mycobacterium tuberculosis during infection 1. BioRxiv 2021.02.25.432019.

Phelan, J.E., Lim, D.R., Mitarai, S., de Sessions, P.F., Tujan, M.A.A., Reyes, L.T., Medado, I.A.P., Palparan, A.G., Naim, A.N.M., Jie, S., et al. (2019). Mycobacterium tuberculosis whole genome sequencing provides insights into the Manila strain and drug-resistance mutations in the Philippines. Sci. Rep. 9, 1-6.

Pi, R., Liu, Q., Jiang, Q., and Gao, Q. (2019). Characterization of linezolid-resistance-associated mutations in Mycobacterium tuberculosis through WGS. J. Antimicrob. Chemother. 74, 1795-1798.

Piddock, L.J., Williams, K.J., and Ricci, V. (2000). Accumulation of rifampicin by Mycobacterium aurum, Mycobacterium smegmatis and Mycobacterium tuberculosis. J. Antimicrob. Chemother. 45, 159-165.

Price, M.N., Dehal, P.S., and Arkin, A.P. (2010). FastTree 2 - Approximately maximum-likelihood trees for large alignments. PLoS One 5.

Qi, L.S., Larson, M.H., Gilbert, L.A., Doudna, J.A., Weissman, J.S., Arkin, A.P., and Lim, W.A. (2013). Repurposing CRISPR as an RNA-yuided platform for sequence-specific control of gene expression. Cell 152, 1173-1183.

Rajagopal, M., Martin, M.J., Santiago, M., Lee, W., Kos, V.N., Meredith, T., Gilmore, M.S., and Walker, S. (2016). Multidrug intrinsic resistance factors in Staphylococcus aureus identified by profiling fitness within high-diversity transposon libraries. MBio 7.

Reeves, A.Z., Campbell, P.J., Sultana, R., Malik, S., Murray, M., Plikaytis, B.B., Shinnick, T.M., and Posey, J.E. (2013). Aminoglycoside Cross-Resistance in Mycobacterium tuberculosis Due to Mutations in the $5=$ Untranslated Region of whiB7.

Rempel, S., Gati, C., Nijland, M., Thangaratnarajah, C., Karyolaimos, A., de Gier, J.W., Guskov, A., and 
bioRxiv preprint doi: https://doi.org/10.1101/2021.11.27.469863; this version posted November 27, 2021. The copyright holder for this preprint (which was not certified by peer review) is the author/funder, who has granted bioRxiv a license to display the preprint in perpetuity. It is made available under aCC-BY-ND 4.0 International license.

Slotboom, D.J. (2020). A mycobacterial ABC transporter mediates the uptake of hydrophilic compounds. Nature 580, 409-412.

Rock, J.M., Hopkins, F.F., Chavez, A., Diallo, M., Chase, M.R., Gerrick, E.R., Pritchard, J.R., Church, G.M., Rubin, E.J., Sassetti, C.M., et al. (2017). Programmable transcriptional repression in mycobacteria using an orthogonal CRISPR interference platform. Nat. Microbiol. 2.

Rodvold, K.A. (1999). Clinical pharmacokinetics of clarithromycin. Clin. Pharmacokinet. 37, 385-398.

Safi, H., Gopal, P., Lingaraju, S., Ma, S., Levine, C., Dartois, V., Yee, M., Li, L., Blanc, L., Liang, H.P.H., et al. (2019). Phase variation in Mycobacterium tuberculosis glpK produces transiently heritable drug tolerance. Proc. Natl. Acad. Sci. U. S. A. 116, 19665-19674.

Sandgren, A., Strong, M., Muthukrishnan, P., Weiner, B.K., Church, G.M., and Murray, M.B. (2009). Tuberculosis drug resistance mutation database. PLoS Med. 6, 0132-0136.

Sassetti, C.M., Smith, C.M., Baker, R.E., and loerger, T.R. (2020). Antibiotics against Mycobacterium tuberculosis. 5, 1-18.

Schrader, S.M., Botella, H., Jansen, R., Ehrt, S., Rhee, K., Nathan, C., and Vaubourgeix, J. (2021). Multiform antimicrobial resistance from a metabolic mutation. Sci. Adv. 7, 1-18.

Seemann, T. et al. (2020). Snippy - Rapid haploid variant calling and core genome alignment.

Seung, K.J., Becerra, M.C., Atwood, S.S., Alcántara, F., Bonilla, C.A., and Mitnick, C.D. (2014). Salvage therapy for multidrug-resistant tuberculosis. Clin. Microbiol. Infect. 20, 441-446.

Sharkey, L.K.R., Edwards, T.A., and O’Neill, A.J. (2016). ABC-F proteins mediate antibiotic resistance through ribosomal protection. MBio 7.

Sharma, A.K., Chatterjee, A., Gupta, S., Banerjee, R., Mandal, S., Mukhopadhyay, J., Basu, J., and Kundu, M. (2015). MtrA, an essential response regulator of the MtrAB two-component system, regulates the transcription of resuscitation-promoting factor B of Mycobacterium tuberculosis. Microbiol. (United Kingdom) $161,1271-1281$.

Sheen, P., Couvin, D., Grandjean, L., Zimic, M., Dominguez, M., Luna, G., Gilman, R.H., Rastogi, N., and Moore, D.A.J. (2013). Genetic Diversity of Mycobacterium tuberculosis in Peru and Exploration of Phylogenetic Associations with Drug Resistance. PLoS One 8.

Shell, S.S., Wang, J., Lapierre, P., Mir, M., Chase, M.R., Pyle, M.M., Gawande, R., Ahmad, R., Sarracino, D.A., loerger, T.R., et al. (2015). Leaderless Transcripts and Small Proteins Are Common Features of the Mycobacterial Translational Landscape. PLoS Genet. 11, 1-31.

da Silva, P.E.A., von Groll, A., Martin, A., and Palomino, J.C. (2011). Efflux as a mechanism for drug resistance in Mycobacterium tuberculosis. FEMS Immunol. Med. Microbiol. 63, 1-9.

Thibault, D., Jensen, P.A., Wood, S., Qabar, C., Clark, S., Shainheit, M.G., Isberg, R.R., and van Opijnen, T. (2019). Droplet Tn-Seq combines microfluidics with Tn-Seq for identifying complex single-cell phenotypes. Nat. Commun. 10.

Trouplin, V., Boucherit, N., Gorvel, L., Conti, F., Mottola, G., and Ghigo, E. (2013). Bone marrow-derived macrophage production. J. Vis. Exp.

Truffot-Pernot, C., Lounis, N., Grosset, J.H., and Ji, B. (1995). Clarithromycin is inactive against Mycobacterium tuberculosis. Antimicrob. Agents Chemother. 39, 2827-2828.

Vargas, R., Freschi, L., Spitaleri, A., Tahseen, S., Barilar, I., Niemann, S., Miotto, P., Cirillo, D.M., Köser, C.U., and Farhat, M.R. (2021). The role of epistasis in amikacin, kanamycin, bedaquiline, and clofazimine resistance in Mycobacterium tuberculosis complex. BioRxiv 2021.05.07.443178.

Vilchèze, C., and Jacobs JR., W.R. (2014). Resistance to Isoniazid and Ethionamide in Mycobacterium tuberculosis: Genes, Mutations, and Causalities. Microbiol. Spectr. 2.

Walker, T.M., Kohl, T.A., Omar, S. V., Hedge, J., Del Ojo Elias, C., Bradley, P., lqbal, Z., Feuerriegel, S., Niehaus, K.E., Wilson, D.J., et al. (2015). Whole-genome sequencing for prediction of Mycobacterium 
bioRxiv preprint doi: https://doi.org/10.1101/2021.11.27.469863; this version posted November 27, 2021. The copyright holder for this preprint (which was not certified by peer review) is the author/funder, who has granted bioRxiv a license to display the preprint in perpetuity. It is made available under aCC-BY-ND 4.0 International license.

tuberculosis drug susceptibility and resistance: A retrospective cohort study. Lancet Infect. Dis. 15, 11931202.

Warit, et al. (2015). Genetic characterisation of a whiB7 mutant of a Mycobacterium tuberculosis clinical strain. J Glob Antimicrob Resist 3(4), 262-266.

Wasserman, S., Louw, G., Ramangoaela, L., Barber, G., Hayes, C., Omar, S.V., Maartens, G., Barry, C., Song, T., and Meintjes, G. (2019). Linezolid resistance in patients with drug-resistant TB and treatment failure in South Africa. J. Antimicrob. Chemother. 74, 2377-2384.

WHO (2021). Global Tuberculosis Report.

Wilson, D.N. (2014). Ribosome-targeting antibiotics and mechanisms of bacterial resistance. Nat. Rev. Microbiol. 12, 35-48.

Wong, S.Y., Lee, J.S., Kwak, H.K., Via, L.E., Boshoff, H.I.M., and Barry, C.E. (2011). Mutations in gidB confer low-level streptomycin resistance in Mycobacterium tuberculosis. Antimicrob. Agents Chemother. 55, 2515-2522.

Wong, S.Y., Javid, B., Addepalli, B., Piszczek, G., Strader, M.B., Limbach, P.A., and Barry, C.E. (2013). Functional role of methylation of G518 of the 16S rRNA 530 loop by GidB in Mycobacterium tuberculosis. Antimicrob. Agents Chemother. 57, 6311-6318.

Xia, E., Teo, Y.Y., and Ong, R.T.H. (2016). SpoTyping: Fast and accurate in silico Mycobacterium spoligotyping from sequence reads. Genome Med. 8, 19.

Xu, W., Dejesus, M.A., Rücker, N., Engelhart, C.A., Wright, M.G., Healy, C., Lin, K., Wang, R., Park, S.W., loerger, T.R., et al. (2017). Chemical Genetic Interaction Profiling Reveals Determinants of Intrinsic Antibiotic Resistance in Mycobacterium tuberculosis.

Yin, S., Daum, R.S., and Boyle-Vavra, S. (2006). VraSR two-component regulatory system and its role in induction of pbp2 and vraSR expression by cell wall antimicrobials in Staphylococcus aureus. Antimicrob. Agents Chemother. 50, 336-343.

Zahrt, T.C., and Deretic, V. (2000). An essential two-component signal transduction system in Mycobacterium tuberculosis. J. Bacteriol. 182, 3832-3838.

Zaunbrecher, M.A., Sikes, R.D., Metchock, B., Shinnick, T.M., and Posey, J.E. (2009). Overexpression of the chromosomally encoded aminoglycoside acetyltransferase eis confers kanamycin resistance in Mycobacterium tuberculosis. Proc. Natl. Acad. Sci. U. S. A. 106, 20004-20009.

Zhang, Y., Heym, B., Allen, B., Young, D., and Cole, S. (1992). The catalase - Peroxidase gene and isoniazid resistance of Mycobacterium tuberculosis. Nature 358, 591-593.

Zimmerman, M., Lestner, J., Prideaux, B., O’Brien, P., Dias-Freedman, I., Chen, C., Dietzold, J., Daudelin, I., Kaya, F., Blanc, L., et al. (2017). Ethambutol partitioning in tuberculous pulmonary lesions explains its clinical efficacy. Antimicrob. Agents Chemother. 61. 